\title{
Alpha2-adrenergic receptor agonists in myocardial ischemia
}

Citation for published version (APA):

Roekaerts, P. M. H. J. (1997). Alpha2-adrenergic receptor agonists in myocardial ischemia. [Doctoral Thesis, Maastricht University]. Universiteit Maastricht. https://doi.org/10.26481/dis.19970313pr

Document status and date:

Published: 01/01/1997

DOI:

10.26481/dis.19970313pr

Document Version:

Publisher's PDF, also known as Version of record

\section{Please check the document version of this publication:}

- A submitted manuscript is the version of the article upon submission and before peer-review. There can be important differences between the submitted version and the official published version of record.

People interested in the research are advised to contact the author for the final version of the publication, or visit the DOI to the publisher's website.

- The final author version and the galley proof are versions of the publication after peer review.

- The final published version features the final layout of the paper including the volume, issue and page numbers.

Link to publication

\footnotetext{
General rights rights.

- You may freely distribute the URL identifying the publication in the public portal. please follow below link for the End User Agreement:

www.umlib.nl/taverne-license

Take down policy

If you believe that this document breaches copyright please contact us at:

repository@maastrichtuniversity.nl

providing details and we will investigate your claim.
}

Copyright and moral rights for the publications made accessible in the public portal are retained by the authors and/or other copyright owners and it is a condition of accessing publications that users recognise and abide by the legal requirements associated with these

- Users may download and print one copy of any publication from the public portal for the purpose of private study or research.

- You may not further distribute the material or use it for any profit-making activity or commercial gain

If the publication is distributed under the terms of Article $25 \mathrm{fa}$ of the Dutch Copyright Act, indicated by the "Taverne" license above, 
Alpha ${ }_{2}$-adrenergic receptor agonists in myocardial ischemia 
(C) Paul Roekaerts, Maastricht 1997 ISBN 90-9010268-X

Vormgeving en druk: Datawyse | Universitaire Pers Maastricht

Omslag: Bull's eye opnames van het hart. Bovenste opname laat beduidend meer myocardischemie (zwarte gebied) zien dan onderste opname. (Met dank aan Simon Braat) 


\section{Alpha $_{2}$-adrenergic receptor agonists in myocardial ischemia}

\section{PROEFSCHRIFT}

ter verkrijging van de graad van doctor aan de Universiteit Maastricht, op gezag van de Rector Magnificus, Prof. mr. M.J. Cohen, volgens het besluit van het College van Decanen, in het openbaar te verdedigen in de Aula, op donderdag 13 maart 1997 om 16.00 uur

door

Paul M.H.J. Roekaerts 


\section{Promotor:}

Prof. dr. S. de Lange

\section{Co-promotor:}

Dr. F. W. Prinzen

\section{Beoordelingscommissie:}

Prof.dr. R. Reneman (voorzitter)

Prof.dr. J. Flacke (University of California, USA)

Prof.dr. P.J.E.H.M. Kitslaair

Prof.dr. H. Struyker Boudier

Prof.dr. H.J.J. Wellens

Financial support by the Netherlands Heart Foundation and by the Department of Anesthesiology of the University Hospital of Maastricht for the publication of this thesis is gratefully acknowledged. 
In memory of my father To my mother To Monika, Anouk, Esmée and Nona, with love 


\section{Contents}

CHAPTER 1 Introduction 9

CHAPTER 2 Review of the literature on perioperative myocardial ischemia 11

CHAPTER 3 Review of the literature on alpha 2 -adrenergic receptor agonists 21

CHAPTER 4 Alleviation of the peripheral hemodynamic effects of dexmedetomidine by the calcium channel blocker isradipine 33

CHAPTER 5 Reversal of the systemic and coronary vasoconstrictive effects of dexmedetomidine by the purinoceptor agonist ATP 47

CHAPTER 6 Coronary vascular effects of dexmedetomidine during reactive hyperemia in the anesthetized dog 63

CHAPTER 7 Beneficial effects of dexmedetomidine on ischaemic myocardium of anaesthetized dogs 81

CHAPTER 8 The effects of alpha ${ }_{2}$-adrenergic stimulation with mivazerol on myocardial blood flow and function during coronary artery stenosis in anesthetized dogs 87

CHAPTER 9 The effect of mivazerol on perioperative hemodynamic stability and myocardial ischemia 103

CHAPTER 10 Summary and conclusions 111

CHAPTER 11 Samenvatting en conclusies 115

Acknowledgements 179

List of Publications 121

Curriculum Vitae 125 


\section{CHAPTER 1}

\section{Introduction}

Despite continuing improvements in anesthetic and surgical techniques, it is expected that perioperative cardiac morbidity and mortality will continue to increase because of the rapid aging of the surgical population and greater prevalence of more advanced coronary artery disease. ${ }^{1}$ Solution of this problem requires identification of the predictors of adverse perioperative cardiac outcome, followed by therapeutic trials aimed at modifying these predictors in an effort to decrease morbidity and mortality. Perioperative outcome studies have identified preoperative, intraoperative and postoperative predictors of perioperative cardiac morbidity. ${ }^{1}$ The most important preoperative predictors of cardiac outcome are unstable coronary syndromes, decompensated congestive heart failure, significant arrhythmias and severe valvular disease. The classic intraoperative predictors include emergency surgery, vascular surgery, prolonged thoracic or upper abdominal surgery and hypotension and tachycardia. It was recently shown by Mangano and co-workers that the single most important predictor of adverse cardiac outcome was early postoperative myocardial ischemia. ${ }^{2,3}$ Such postoperative ischemia conferred a ninefold increase in the odds of experiencing cardiac death, a nonfatal myocardial infarction, or unstable angina.

These results suggest that prevention and therapy for perioperative - and especially postoperative -ischemia may hold the key to reducing perioperative cardiac morbidity. There are very few randomized trials of medical therapy before surgery to prevent perioperative myocardial ischemia, and they do not provide enough data from which to draw firm conclusions. ${ }^{4-12}$ Studies in non-surgical patients have suggested that the alpha $\mathrm{a}_{2}$-adrenergic receptor agonist clonidine has anti-anginal and ischemialimiting effects. ${ }^{13-14}$ Recently, several studies have evaluated the use of alpha ${ }_{2}$-adrenoreceptor agonists during the perioperative period. ${ }^{15}$ Most of these studies have concentrated on their sedative, sympatholytic and hemodynamic stabilizing effects. The present series of investigations was initiated in order to study possible mechanisms for the potential anti-ischemic effect of the new alpha ${ }_{2}$ agonists dexmedetomidine and mivazerol, and to gain information on the possible usefulness of these drugs as anesthesia adjuvants in high-risk cardiovascular patients at risk for coronary artery disease. 


\section{REFERENCES}

1. Mangano D: Perioperative cardiac morbidity. Anesthesiology 72: 153-184, 1990

2. Mangano DT, Browner WS, Hollenberg M, London MJ, Tubau JF, Tateo IM: Association of perioperative myocardial ischemia with cardiac morbidity and mortality in men undergoing noncardiac surgery. N Engl $\mathbb{M}$ Med 323: 1781-1788, 1990

3. Mangano DT, Browner WS, Hollenberg $M, L i J$, Tateo IM: Long-term cardiac prognosis following noncardiac siurgery. JAMA 268: 233-239, 1992

4. Stone JG, Foex P, Sear JW, Johnson LL, Khambatta HJ, Triner L. Myocardial ischemia in untreated hypertensive patients: effect of a single small oral dose of a beta-adrenergic blocking agent. Anesthesiology 68: 495-500, 1988

5. Pasternack PF, Imparato AM, Baumann FG, Laub G, Riles TS, Lamparello PJ, Grossi EA, Berguson $P$, Becker $G, B e a r G$ : The hemodynamics of beta-blockade in patients undergoing abdominal aortic aneurysm repair. Circulation 76 (supp| 3): $\|1-1-1\|-7,1987$

6. Pasternack PF, Grossi EA, Baumann FG, Riles TS, Lamparelia PJ, Giangola G, Primis LK, Mintzer

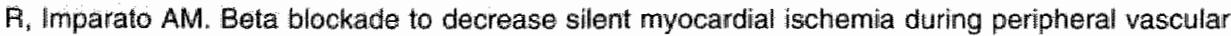
surgery. Am J Surg 158: 113-116, 1989

7. Slogoff S, Keats AS: Does chronic treatment with calcium entry blocking drugs reduce perioperative myocardial ischemia ? Anesthesiology 68: 676-680, 1988

8. Godet $G$, Corlat $P$, Baron JF, Bertrand $M$, Diquet $B$, Sebag $C$, Viars $P$ : Prevention of intraoperative myocarcial ischemia during noncardiac surgery with intravenous diltiazem: a randomized trial versus placebo. Anesthesiology 66: 241-245, 1987

9. Coriat $P$, Daloz M, Bousseau D, Fusciardi J, Echter E, Viars P: Prevention of intraoperative myocardial ischernia during noncardiac surgery with intravenous nitroglycerin. Anesthesiology $61: 193-196,1984$

10. Dodds TM, Stone JG, Coromilas J, Weinberger $M_{1}$ Levy DG: Prophylactic nitroglycerin infusion during noncardiac surgery does not reduce perioperative ischemia. Anesth Analg 76: 705-713, 1993

11. Gallagher JD, Moore RA, Jose $\mathrm{AB}$, Botros $\mathrm{SB}$, Clark DL: Prophylactic nitroglycerin infusions during coronary artery bypass surgery. Anesthesiology 64: 785-789, 1986

12. Thomson IR, Mutch WA, Culligan JD: Failure of intravenous mitroglycerin to prevent intraoperative myocardial ischemia during fentanyl-paancuronium anesthesia. Anesthesiology 61: 385-393, 1984

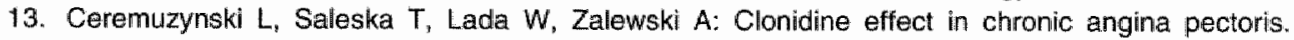
Double-blind crossover trial on 60 patients. Eur J Cardiol 10: 415-427, 1979

14. Thomas MG, Quiroz AC, Rice JC, Sander GE, Giles TD: Antianginal effects of clonidine. J Cardiovasc Pharmacol 8 (suppl3): S69-S75, 1986

15. Maze $M$. Tranquilli W: Alphaz-adrenoreceptor agonists: Defining the role in clinical anesthesia. Anesthesiology 74: 581-605, 1991 


\section{Review of the literature on perioperative myocardial ischemia}

\subsection{Myocardial ischemia}

In the heart, a complex relation exists between contraction and perfusion. While cardiac contraction generates the driving pressure required for perfusion of all organs including the heart, systolic contraction impedes myocardial perfusion. The exact mechanism of this impediment is not entirely understood, but it is undoubtly more pronounced in the endocardial than in the epicardial layers. As a consequence, the endocardial layers are perfused almost exclusivelly during diastole. Nevertheless, perfusion of the myocardium is matching demands under all physiological conditions, including the most severe physical exercise, and blood flow in the endocardial layers is equal to or slightly higher than the epicardial blood flow (endo-/epicardial blood flow ratios 1.0-1.1). To match supply with demand, the heart possesises a powerful autoregulation, which means that very small parts of the myocardial muscle regulate their own perfusion, presumably by feedback through arteriolar content of oxygen and metabolites like $\mathrm{CO}_{2}, \mathrm{H}^{+}$, and adenosine. ${ }^{1}$ So, as long as the heart functions within its autoregulatory range, cardiac work determines perfusion. The opposite is true when myocardial peifusion is impaired, for example by obstruction of a coronary artery. In that case, myocardial function rapidly deteriorates. Under these conditions, the endocardial layers are most at risk for underperfusion. During moderate stenosis, endocardial blood flow can decrease below $50 \%$ of normal while epicardial blood flow may still be normal or even higher. ${ }^{2,3}$ This is due partly to the limited time for perfusion of the endocardial layers, but is believed to be also partly due to "steal" of endocardial blood flow by the epicardial layers: if perfusion in a vascular bed is entirely pressure dependent, dilation in one part of the bed may decrease blood flow to another part of the same bed. 1,4 For these reasons, coronary stenosidues gradually leads to endocardial ischemia. When obstruction of the coronary vessel is complete, epicardial blood flow is severely compromized also and transmural ischemia occurs. Myocardial ischemia occurs because of a mismatch of oxygen supply and demand. Coronary obstruction due to atherosclerosis, emboli or thrombosis obvilously leads to reduced supply. In the presence of any obstruction, hypotension and tachycardia may reduce supply further. Tachycardia reduces supply because it decreases the diastolic time interval, available for coronary perfusion. Because tachycardia also increases myocardial oxygen demand considerably, it is ussually the highest risk factor for induction of ischemia, and is clinically used to provoke ischemia by pacing the patient"s heart at higher heart rate. 
Hypotension may decrease coronary perfusion because, in the presence of reduced perfusion pressure, the ischemic region and especially the endocardial layers are already maximally vasodilated, and any further drop in pressure will affect perfusion. For that reason, vasodilators may, through systemic or coronary vasodilation, worsen myocardial ischemia, especially in the endocardium. This phenomenon is known as "coronary steal" 5-7 Nathan and Feigl studied the effect of alpha-adrenergic vasoconstriction on the transmural distribution of myocardial blood flow. ${ }^{8}$ They showed that, during normal perfusion as well as during ischemia, alpha-adrenergic stimulation decreased epicardial blood flow and increased endocardial blood flow, thus producing a "reverse-steal" effect. To what extent this reverse-steal effect may improve myocardial ischemia in the clinical situation is, until now, incompletely understood.

\subsection{Perioperative autonomous reactions affecting myocardial ischemia}

The major body injury induced by surgery/anesthesia and by the recovery from surgery/anesthesia evokes a stress response. ${ }^{9-12}$ Perioperative factors like pain, anxiety, the presence of an endotracheal tube, and physiological derangements like hypoxia, hypercarbia, hypothermia, intravascular volume overload or depletion may all evoke these responses. They consist of stimulation of the hypothalamus-pituitaryadrenal axis, renin-angiotensin axis, and the sympathetic nervous system.

Levels of hormones like vasopressin, insulin, growth hormone, and aldosterone become elevated. Moreover, high levels of anti-insulin hormones like epinephrine, cortisol, and glucagon induce endogenous hepatic glucose production and reduced glucose uptake which results in hyperglycemia. Therefore, the major fuel of the body becomes fat, while proteins are catabolized also. Especially fatty acids are considered to be harmful for the ischemic heart, because they increase the oxygen cost of ATP production and may make the heart more suceptible to arrhythmias. ${ }^{13}$ An important aspect of the effect of surgical stress on myocardial ischemia are the changes in cardiovascular function. Infusions with cortisol, glucagon and epinephrine demonstrated a synergistic effect of the three hormones on the rate-pressure product. ${ }^{11}$ However, with respect to the ischemic heart, sympathetic stimulation is the most important factor in the stress response.

\subsection{Sympathetic stimulation}

Norepinephrine is the transmitter at most postganglionic sympathetic nerve endings and at several synapses in the central nervous system, especially in the hypothalamus. In the adrenal medulla, not only norepinephrine, but especially epinephrine is secreted. After their secretion, both adrenergic agents are transported through the blood to their target organ. Catecholamines stimulate alpha and beta receptors. Alpha-receptor stimulation causes vasoconstriction, beta-1 receptor stimulation causes increased cardiac chronotropy and inotropy and beta-2 receptor stimulation 
causes vasodilation. The serum levels of the catecholamines norepinephrine, epinephrine and dopamine have been observed to increase after a variety of stresses. Surgical stress increases the levels of these hormones, but the highest levels have been observed immediately after the end of surgery and anesthesia. ${ }^{14}$ Plasma epinephrine concentrations reflect adrenomedullary secretion, whereas plasma norepinephrine concentrations are used as an index of sympathetic nervous system activity. It is important to realize that most of the norepinephrine released at post-ganglionic neuro-effector sites is removed from the synapse by re-uptake into the nerve ending. The excess spills over into the circulation and can be measured.

Tachycardia and hypertension appear to be associated with increased levels of circulating norepinephrine ${ }^{10,11}$ and may result in increased myocardial oxygen demand and reduced supply at higher heart rates. These changes in catecholamines are associated with parallel increases in platelet aggregation and reduced fibrinolytic activity. ${ }^{15-17}$

\subsection{Anesthesia and perioperative myocardial ischemia}

There are three categories of potential etiologies for perioperative myocardial ischemia. A first category includes the factors associated with the myocardial oxygen demand-supply ratio. Decreased supply can be due to hypoperfusion, redistribution or spasm and increased demand is usually related to stress response phenomena. A second categorie includes factors associated with thrombosis, e.g. inflammatory response, leucocyte activation, plaque rupture/spasm, hypercoagulable state. And a third categorie includes coronary artery factors (shear stress/spasm, endothelial factors, embolism). ${ }^{18}$

Postoperatively, the incidence of ischemia is significantly higher than intraoperatively or preoperatively. It is also well documented that the termination of anesthesia and surgery, with emergence and transition into the postoperative period, is associated with continued activation of the sympathetic nervous system. Plasma catecholamine levels are usually higher in the immediate postoperative period than during surgery. Increased levels of circulating norepinephrine appear to be associated with tachycardia and hypertension and may result in increased myocardial oxygen demand and reduced supply at higher heart rates. ${ }^{10,11}$ In the presence of a compromized circulation, the imbalance between supply and demand could lead to myocardial ischemia and, possibly, serious adverse outcome. ${ }^{19-21}$ Elevated plasma catecholamines are also associated with accelerated coagulation and this hypercoagulable state may also increase the incidence of ischemia. These findings suggest that increased sympathetic nervous system activity is a key factor for the increased incidence of myocardial ischemia.

These factors contribute to the perceived need for greater control of the hyperadrenergic state and the postoperative stress response, which has implications for metabolism, the immune response, coagulation, and the cardiovascular system, and which may have an important impact on outcome. 


\subsection{Reducing perioperative myocardial ischemia}

There are a variety of options for reducing peri-operative cardiac morbidity:

\subsubsection{Increasing anesthetic depth}

Intra-operatively, the incidence of myocardial ischemia is not significantly different from the incidence of pre-operative ischemia, despite the many stresses affecting intra-operative myocardial demand for oxygen, as long as hemodynamics are well controlled. ${ }^{22}$ It appears that anesthetics or the anesthetic-like state may have protective effects against surgical stress. This protective effect of anesthesia during surgery however is not fully maintained during the emergence. Recent findings suggest that inhalation anesthetics, moderate levels of narcotics, or regional anesthesia by intrathecal or epidural anesthetics substantially decrease the intra-operative stress response, including the increased level of circulating catecholamines, $23-25$ Whether anesthetics prevent the increase of ischemia by controlling hemodynamic variability, preventing surges in catecholamines, antinociception, or through an unknown anti-ischemic effect, has not been determined. However, it is clear that the anesthetic state is able to protect the myocardium from stressful events which would otherwise lead to ischemia.

Opioids are known to decrease heart rate, wall tension, pain and circulating levels of plasma catecholamines without depression of ventricular function. It is therefore not surprising that extending anesthesia with opioids for 18-24 hours postoperatively blunts the stress response and reduces perioperative morbidity. 26,27

\subsubsection{Regional anesthetic techniques}

It is well documented that the combination of general anesthesia with epidural anesthesia and analgesia intraoperatively and postoperatively, can smooth the transition from surgery to postoperative recovery and in this way can reduce postoperative morbidity. The typical postoperative increase in heart rate is reduced threefold when epidural anesthesia and analgesia is used after aortic surgery. ${ }^{28}$ Reiz and co-workers showed that patients undergoing emergency vascular surgery in the face of recent myocardial infarctions had a lower incidence of ischemia and ventricular dysfunction and a lower reinfarction rate when they were randomized to receive epidural anesthesia and analgesia.29

Yeager and colleagues demonstrated that high-risk patients had far fewer cardiovascular, intectious, and overall complications when they received epidural anesthesia and analgesia compared with a general anesthetic technique. ${ }^{30}$ Tuman and co-workers studied the effect of epidural anesthesia and analgesia on coagulation and outcome after major vascular surgery. ${ }^{31}$ They found less thrombotic complications in the patient group receiving general anesthesia plus epidural anesthesia and analgesia versus the patient group receiving general anesthesla alone. The perioperative ischemia randomized anesthesia trial (PIRAT) study randomized 100 patients under- 
going lower extremity revascularization to receive epidural anesthesia and analgesia or general anesthesia. ${ }^{32}$ Regional anesthesla was associated with lower catecholamine levels and fewer vascular graft occlusions.

Blomberg and co-workers used Thoracic Epidural Anesthesia (TEA) in the treatment of myocardial ischemia in patients with severe angina pectoris unresponsive to multiple medical regimens and found that TEA achieved more than mere control of pain. ${ }^{33}$ TEA reduced myocardial oxygen demand by decreasing systolic arterial blood pressure, heart rate, and pulmonary capillary wedge pressure without significant changes in coronary perfusion pressure or cardiac output. Several possible mechanisms exist for these salutary effects of TEA. On a global basis, TEA decreases myocardial oxygen demand. $34,35-38$ Reduction in wall stress, heart rate, and inotropy have all been reported. Despite the potential for a coronary steal, improvements in perfusion to ischemic areas have been observed. ${ }^{35,} 39-42$ This effect may be on the basis of reduced left ventricular wall pressure with a redistribution of blood flow to the subendocardial layer. Conversely, TEA decreases cardiac autonomic tone and thus may favorably alter the endo/epicardial blood flow ratio. However, this mechanism is thought to be only a minor determinant of transmural coronary blood flow. $43-45$ TEA also alters myocardial metabolism and reduces the uptake of catecholamines. $36,37,43$ Sympathetic blockade may inhibit lipolysis within the ischemic area, thereby decreasing regional myocardial oxygen consumption and reducing the severity of the ischemic injury. Finally, the possible effect of sympathetic blockade on coronary vasoconstriction distal to coronary stenoses is apt to be involved. Heusch and colleagues have shown that sympathetic poststenotic vasoconstriction can be blocked by epidural anesthesia. 40-42 Poststenotic ischemia may activate further sympathetic discharge via spinal reflexes, and produce a positive feedback mechanism leading to a vicious cycle of progressive vasoconstriction and worsening of myocardial ischemia. The persistent therapeutic effect of TEA in alleviating ischemia may be due to blocking of this feedback mechanism.

\subsubsection{Control of hemodynamic instability}

Control of blood pressure, heart rate, cardiac output, and vascular resistance with a variety of interventions that attenuate the cardiovascular effects of perioperative sympathetic hyperactivity has been shown to impact positively on cardiovascular outcome.22

Berlauk and co-workers showed that intensive perioperative care facilitated by the use of prolonged invasive hemodynamic monitoring is associated with a markedly reduced rate of graft occlusion after peripheral vascular surgery. ${ }^{46}$

\subsubsection{Beta-blockers and calcium-antagonists}

Three limited studies have examined the use of perioperative beta-blockers. Stone et al gave oral beta-blockers 2 hours before surgery to a randomized group of patients with mild hypertension who had predominantly $(58 \%)$ vascular surgery. ${ }^{47}$ Controll 
subjects had a higher frequency $(28 \%)$ of ST-segment depression than treated patients ( $2 \%$ ). In a nonirandomized study, Pasternack gave oral metoprolol immediately before surgery and followed with intravenous drug during abdominal aortic aneurysm repair. ${ }^{48}$ Only $3 \%$ suffered an acute MI, compared with $18 \%$ for matched controls. In a later report, the same author reported less intraoperative ischemia in patients treated with oral metoprolo: before peripheral vascular surgery. ${ }^{49}$ Calcium entry blockers alone do nol appear to be effective in reducing the incidence of new perioperative myocardial ischemia. 50,51 This makes it unlikely that they have any direct impact on perioperative outcome.

No data yet exist to describe the impact on outcome of any strategy directed at detecting and systematically treating silent perioperative ischemia.

\subsubsection{Nitroglycerin}

Nitroglycerin has been shown to reverse myocardial ischemia intraoperatively. Prophylactic use of nitroglycerin in patients at high risk may have no effects, however, or may actually lead to cardiovascular decompensation through decreases in preload. Additionally, nitroglycerin paste or patch may have uneven absorption intraoperatively. Accordingly, nitroglycerin should usually be administered in the intravenous formulation, if required. Four controlled studies have evaluated the value of prophylactic nitroglycerin infusions for high-risk patients, including two studies in noncardiac surgery patients. $52-55$ Only one study, performed in patients with stable angina undergoing carotid endarterectomy, demonstrated a reduced incidence of intraoperative myocardial ischemia in the group receiving $1 \mu \mathrm{g} . \mathrm{kg}^{-1} . \mathrm{min}^{-1}$ of nitroglycerin. 52 Neither of the two small studies demonstrated any reduction in the incidence of $\mathrm{MI}$ or cardiac death.

\subsubsection{Improvement of the economy of myocardial axygen usage}

Inhibition of free fatty acid uptake in favour of carbohydrate metabolism should be advantageous during myocardial ischemia. 56

Glucose-insulin-potassium solutions 57 and compounds which induce a pharmacological shift of cardiac metabolism with reduction in FFA utilization may be of clinical value. 58

\subsubsection{Improwement of blood flow through poststenotic vascular bed}

Improvement in poststenotic blood supply by the administration of vasodilators is of limited value, since a greater degree of coronary steal might occur. Thromboxane A2 may be critically involved in the pathophysiology of myocardial ischemia by constricting blood vessels, inducing platelet aggregation and by increasing the permeability of cellular membranes. An attractive approach is to inhibit thromboxane synthesis selectively, thereby to redirect endoperoxide metabolism towards vasodilating prostacycline metabolites. 59 
Adenosine, adenosine regulating agents and nucleoside transport inhibitors are currently being investigated for their coronary vasodilatory and cardioprotective properties. 60

\subsubsection{Anticoagulation}

It is possible that anticoagulation alone might benefit cardiovascular oulcome in the high-risk surgical patient. In addition to reducing mortality rates after acute myocardial infarction, anticoagulation also lessens the rate of reinfarction. This finding in medical patients potentially has tremendous significance for surgical patients with a history of recent $\mathrm{MI}$, because the mortality of perioperative reinfarction remains near $30 \%$ to $50 \%$. Obviously, this needs to be examined rigorously before recommending even low-dose postoperative anticoagulation in high-risk patients. There is, however, at least one controlled randomized trial examining the effect of postoperative anticoagulation on outcome in high-risk cardiac patients undergoing lower extremity revascularization that has shown a lower incidence of vascular graft failure in anticoagulated patients as well as improved postoperative survival compared with controls. ${ }^{61}$

\subsubsection{Reducing central sympathetic outflow}

The above mentioned studies suggest that controlling the peri-operative stress response may attenuate peri-operative myocardial ischemia. Unfortunately, none of the interventions to blunt the stress-response is without complications. High levels of inhalation anesthetics will delay awakening. Narcotics also may delay awakening and cause post-operative respiratory depression, nausea and vomiting. Vasodilators which act directly on the vascular smooth muscle may induce reflex tachycardia and increased levels of circulating catecholamines. ${ }^{62,63}$ Although vasodilators modulate preload and afterload, the resulting tachycardia may decrease the ratio of oxygen supply to demand significantly. Blocking some of the adrenergic receptors to achieve hemodynamic control will leave the action of the unblocked receptors unopposed. Epidural or intrathecal nerve conduction block reduces the intraoperative stress response but is not appropriate postoperatively for all patients. The use of anesthetics or high-dose analgesics is not clinically feasible for most patients postoperatively, when the incidence of ischemia and adverse outcome is highest.

The development of an anesthetic-like drug that could blunt the adrenergic response to the stresses of major surgery, thereby promoting hemodlynamic stability, without causing respiratory depression would be ideal: alpha 2 -adrenergic receptor agonists appear to be promising candidates. 


\section{REFERENCES}

1. Feigl E0: Coronary Physiology. Physiol. Rev. 63: 1-205, 1983

2. Gallagher KP, Osakada G, Hess OM, Koziol JA, Kemper WS, Ross JR jr: Subepicardial segmental function during cororiany stenosis and the role of imyocardial fiber orientation. Circ Res 50: 352-359, 1982

3. Prinzen FW, Arts T, Van der Vusse GJ, Coumans WA, Reneman RS: Gradients in fiber shortening and metabolism across the ischemic left ventricular wall. Am J Physiol 250: H255-H264, 1986

4. Feigl EO: The paradox of adrenergic coronary vasoconstriction. Circulation $76: 737-7.45,1987$

5. Becker LC: Conditions for vasodilator-induced coronary steal in experimental myocardial ischemia. Circulation 57: 1103-1110, 1978

6. Schaper W, Flameng W, Winkler B, Wusten B, Turschmann W, Neugebauer $G$, Carl M: Quantification of collateral resistance in acute and chronic experimental coronary occlusion in the dog. Circ Res 39 : $371-377,1976$

7. Waltier DC, Gross GJ, Brooks HL: Coronary-steal induced increase in myocardial infarct size after pharmacologic coronary vasodilation. Am J Cardiol 46: 83-89, 1980

8. Nathan HJ, Feigl EO: Adrenergic vasoconstriction lessens transmural steal during coronary hypoperfusion. Am J Physiol 250: H645, 1986

9. Weissman $\mathrm{C}$ : The metabolic response to stress: An overview and update. Anesthesiology 73 : 308-327, 1990

10. Halter JB, Pflug $A E$, Porte $D$ : Mechanisms of plasma catecholamine increases during surgical stress in man. J Clin Endocrinol Metab 45: 936-944, 1977

11. Gil KM, Forse RA, Askanazi $J$, Weisman $C_{n}$ Kinney $J M$ : Energy metabolism in stress, substrate and energy metabolism. Ed. Garrow JS, Halliday D. London, John Libbey, 203-212, 1985

12. Udelsman R, Norton JA, delenich SE: Responses of the hypothalamic-pituitary-adrenal and reninangiotensin axes and the sympathetic system during contralled surgical and anesthetic stress. $J$ Clin Endocrinol Metab 64: 986-994, 1987

13. Oliver MF, Opie LH: Effects of glucose and fatty acids on myocardial ischaemia and arrhythmias. The Lancel 343: 155-148, 1994

14. Flacke JW, Bloor BC, Flacke WE, Wong D, Dazza S, Stead SW, Laks H: Reduced narcotic requirement by clonidline with improved hemodynamic and adrenergic stability in patients undergoing coronary bypass surgery. Anesthesiology $67: 11-19_{n} 1987$

15. Mansfield AO: Alteration infibrinolysis associated with surglery and venous thrombosis. Br J Surg 59: 814-820, 1972

16. Britton B, Hawkey C, Wood W, Peele M: Stress-A significant factor in venous thrombosis ? Br J Surg $61: 814 \times 820,1974$

17. Grabfield $G$ : Factors affecting the coagulation time of blood. IX. The effect of adrenaline on the factors of coagulation. Am J Physiol 42: 46-55, 1916

18. Mangano DT: Preoperative Risk Assessment: Many Studies. Few Solutions. Anesthesiology 83: 897-901, 1995

19. Roizen MF: Should we all have a sympathectomy at birth ? Or at least pre-operatively ? Anesthesiology $68: 482,484,1988$

20. Roizen MF, Lampe GH. Benefiel DJ: ls increased operative stress associated with worse outcome? Anesthesiology 67: A1, 1987

21. Slogoff $S$, Keats AS: Does perioperative myocardial ischemia lead to postoperative myocardial infarction? Anesthesiology 62: 107-114, 1985

22. Mangano DT, Hollenberg M, Fegert G, SP\| Research Group: Peri-operative myocardial ischemia in patients undergoing non-cardiac surgery. I: Incidence and severity during the 4 day peri-operative period. $\downarrow$ Am Coll Cardiol 7: 843-850, 1991 
23. Rutberg $\mathrm{H}$, Hakanson $\mathrm{E}$, Anderberg $\mathrm{B}$, Jorfeldt $\mathrm{L}$, Martensson J, Schildt B: Effects of the extradural administration of morphine, or bupivacaine, on the endocrine response to upper abdominal surgery. BrJ Anaesth 56: 233-238; 1984

24. Brown F III, Owens WD, Felts JA, Spitznagel EL, Cryer PE: Plasma epinephrine and norepinephritine levels during anesthesia: enflurane- $\mathrm{N}_{2} \mathrm{O}-\mathrm{O}_{2}$ compared with fentanyl- $\mathrm{N}_{2} \mathrm{O}-\mathrm{O}_{2}$. Anesth Analg 61:366370,1982

25. Monk TG, Ding $Y$, White PF: Total intravenous anesthesia: effects of opioid versus hyphotic supplementation on autonomic responses and recovery. Anesth Analg 75: 798-804 1992

26. Mangano DT, Siliciano D, Hollenberg $M$, Leung JM, Browner WS, Goehner P, Merrick S, Verrier $E$, SPI Research Group: Postoperative myocardial ischemia. Therapeutic trials using intensive analgesia following surgery. Anesthesiology 76: 342-353, 1992

27. Anand KJS, Hickey PR: Halothane-morphine compared with high-dose sufentanil for anesthesia and postoperative analgesia in neonatal cardiac surgery. N Engl J Med 326: 1-9, 1992

28. Diebel $L N$, Lange MP, Schneider F: Cardiopulmonary complications after major surgery: a role for epidural analgesia? Surgery 102: 660-666, 1987

29. Reiz $S$, Balfors $E$, Sorensen MB: Coronary hemodynamic effects of general anesthesia and surgery: modification by epidural analgesia in patients with ischemic heart disease. Reg Anesth 7:S8-S20, 1982

30. Yeager MP, Glass DD, Neff RK, Brinck-Johnson T: Epidural anesthesia and analgesia in high-risk surgical patients. Anesthesiology 66: 729-735, 1987

31. Tuman KJ, McCarthy RJ, March RJJ: Effects of epidural anesthesia and analigesia on coagulation and outcome after major vascular surgery. Anesth Analg 73: 696-704, 1991

32. Christopherson $\mathrm{A}$, Beattie C, Frank SM: Perioperative morbidity in patients randomized to epidural or general anesthesia for lower extremity vascular surgery. Anesthesiology 79: 422-434, 1993

33. Blomberg S, Emanuelsson H, Ricksten SE: Thoracic epidural anesthesia and central hemodynamics in patients with unstable angina pectoris. Anesth Analg 69: 558-562, 1989

34. Sivarajan $M$, Amory DW, Lindbloom LE: Systemic and regional blood flow during epidural anesthesia without epinephrine in the rhesus monkey. Anesthesiology 45:300-310, 1976

35. Davis RF, deBoer LWV, Maroko PR: Thoracic epidural anesthesia reduces myocardial infarct size after coronary artery occlusion in dogs. Anesth Analg 65: 711-717, 1986

36. Reiz S, Nath S, Rais O: Effects of tharacic epidural block and prenalterol on coronary vascular resistance and myocardial metabolism in patients with coronary artery disease. Acta Anaesthesiol Scand 24:11-16, 1980

37. Reiz $S$, Haggmark $S$, Rydvall $A_{n}$ Ostman M: Beta-blockers and thoracic epidural analgesia. Cardioprotective and synergistic effects. Acte. Anaesthesiol Scand 76 (Suppl):54-61, 1982

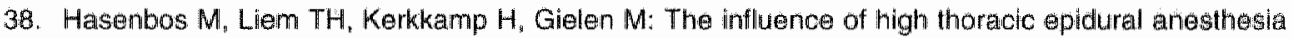
on the cardiovascular system. Acta Anaesthesiol Belg 39: 49-54, 1988

39. Klassen GA, Bramwell RS, Bromage PR, Zborowska-Sluis DT: Effect of acute sympathectomy by epidural anesthesia on the canine coronary circulation. Anesthesiology 52:8.15, 1980

40. Heusch $G$, Deussen $A$, Thamer $V$ : Cardiac sympathetic nerve activity and progressive vasoconstriction distal to coronary stenoses: feed-back aggravation of myocardial ischemia. J Auton Nerv Syst $13: 316-326,1985$

41. Heusch $G$, Schipke J, Thamer V: Sympatheic mechanism in poststenotic myocardial ischemia. J Cardiovasc Pharmacol 8 (Suppl 3): S33-S40, 1986

42. Heusch $G$. Deussen $A$ : The effects of cardiac sympathetic nerve stimulation on perfusion of stenotic coronary arteries in the dog. Circ Res 53: 8-15, 1983

43. Vik-mo $H_{i}$ Ottesen $S$, Renck $\mathrm{H}$ : Cardiac effects of thoracic epidural analgesia before and during acute coronary artery occlusion in open $\cdots$ chest dogs. Scand I Clin Lab Invest 38: 737-746, 1978

44. Merin A: Clinical implications of effects of thoracic epidural blockade on endocardial/epicardial blood flow distribution ratio are not justified. Anesthesiology 53: 349.351, 1980 
45. Sohwartz PJ, Sione HL: Tonic influence of the sympathetic nervous system on myocardial reactive hyperemia and on coronary blood flow distribution in dogs. Circ Res $41: 51-58,1977$

46. Berlauk $J$, Abrams $\mathrm{JH}_{\text {s }}$ Gilmour IJ: Preoperative aptimization of cardiovascular hemodynamics improves outcome in peripheral wascular surgery. Ann Surg 214: 289-297, 1991

47. Stone JG, Foex P, Sear JW, Johnsan LL, Khambatta HJ, Triner L: Myocardial ischemia in untreated hypertensive patients: effect of a single small oral dose of a beta-adrenergic blocking agent. Anesthesiology 68: 495-500, 1988

48. Pasternack PF, Imparato AM, Baumann FG, Laub G, Riles TS, Lamparello PJ, Grossi EA, Berguson $P$, Becker $G$, Bear $G$ : The hemodynamics of beta-blockade in patients undergoing abdominal aortic aneurysm repair. Circulation 76 (supp| 3): \|\|$-1-1 \| 1-7,1987$

49. Pasternack PF, Grossi EA, Baumann FG, Riles TS, Lamparello $\mathrm{PJ}_{\mathrm{J}}$, Giangola $\mathrm{G}_{n}$ Primis $L K_{\text {, }}$ Mintzer $\mathrm{A}$. Imparato $A M$. Beta blockade to decrease silent myocardial ischemia during peripheral vascular surgery. Am J Surg 158: 113-116, 1989

50. Slogoff $S$, Keats AS: Does chronic treatment with calcium entry blocking drugs reduce perioperative myocardial ischemia? Anesthesiology 68: 676-680, 1988

51. Godet $G$, Coriat $P$, Baron JF, Bertrand $M_{0}$ Diquet $B$, Sebag $C$, Viars $P$ : Prevention of intraoperative myocardial ischemia during noncardiac surgery with intravenous diltiazem: a randomized trial versus placebo. Anesthesiology 66: 241-245, 1987

52. Coriat $P$, Daloz M, Bousseau $D$, Fusciardi J, Echter $E$, Viars $P$ : Prevention of intraoperative myocardial ischemia during noncardiac surgery with intravenous nitroglycerin. Anesthesiology $61: 193-196,1984$

53. Dodds TM, Stone JG, Coromilas J, Weinberger M, Levy DG: Prophylactic nitroglycerin infusion during noncardiac surgery does not reduce perioperative ischemia. Anesth Analg 76: 705-713, 1993

54. Gallagher JD, Moore RA, Jose $\mathrm{AB}$, Botros $\mathrm{SB}$, Clark DL: Prophylactic nitroglycerin infusions during coronary artery bypass surgery. Anesthesiology 64: 785-789, 1986

55. Thomson IR, Mutch WA, Culligan JiD: Failure of "ntrawenous nitroglycerin to prevent intraoperative myocardial ischemia during fentanyl-pancuronium anesthesia. Anesthesiology 61: 385-393, 1984

56. Ople LH. The glucose hypothesis: Relation to acute myocardial ischemia. I Molecul Cellul Cardiol 1: $107-115,1970$

57. Sodi-Pallares D, Testelli MR, Fishleder BL: Effects of an intravenous infusion of a potassium-glucoseinsulin solution on the electrocardiographic signs of myocardial infarction. Am J Physiol 9: 166-181, 1962

58. Korb $H$, Hoeft A, Hunneman DH, Schraeder $R$, Wolpers HG, Wober W, Hellige G: Changes in myocardial substrate utilisation and protection of ischemic stressed myocardium by oxfenicine [(5)-4-hydroxyphenyl-glycine]. Naunyn-Schmiedeberg's. Archives of Pharmacology 327:70-74, 1984

59. Hoeft $A_{n}$ Korb B, Bock J, Woipers HG, Wober W. Hellige G: Preservatoion of myocardium by the thromboxane synthetase inhibitor UK 38485. Fesearch in experimental Medicine 186:35-46, 1986

60. Demeyere F: Myocardial protection during ischaemia and reperfusion. Current Opinion in Anesthesilogy $7: 65-72,1994$

61. Kretschmer $\mathrm{G}$. Schemper $\mathrm{M}$, Ehringer $\mathrm{H}$, et al: linfluence of postoperative anticoagulant treatment on patient survival after femoropopliteal vein bypass surgery. Lancet 1:797-799, 1988

62. Knight PR, Lane GA, Hensinger RN, Bolles AS, Bjoraker DG: Catecholamine and renin-angiotensin response during hypotensive anesthesia induced by sodium-nitroprusside or trimethaphan camsylate. Anesthesiology 59: 248-253, 1983

63. Bernard JM, Pinaud M, Francoirs T, Babin M, Macquin-Mavier I, Letenneur J: Deliberate hypotension with nicardipine or nitroprusside during total hip arthroplasty. Anesth Analg 73: 341-345, 1991 


\section{Review of the literature on alpha ${ }_{2}$-adrenergic receptor agonists}

This review will focus mainly on the potential benefits and risks of the perioperative use of alphan-adrenergic agonists, especially in patients with serious cardiovascular disease.

\subsection{Alpha 2 -adrenergic receptors}

The original classification of adrenergic receptors into alpha and beta, based on their graded responses to a series of agonists, was made by Ahlquist in $1948{ }^{1}$ The subclassification of alpha-adrenergic receptors was initially based on the presumed synaptic anatomical localization: presynaptic alpha 2 receptors and postsynaptic alpha $_{1}$ receptors. 2,3 This anatomic classification of alpha-adrenoreceptors was not supported for long because alphan-adrenoreceptors were also found postsynaptically, or even extrasynaptically. ${ }^{4}$ Currently, the classification of alpha-receptors is based on their pharmacological characteristics, for instance, at the alpha, -receptor, $^{-}$ the antagonist prazosin is more potent than yohimbine, whereas at the alpha ${ }_{2}$-receptors the reverse is true. ${ }^{5}$ Different alpha 2 -isoreceptors have recently been described in mammalian tissues. A pharmacological subdivision of alpha2-adrenoreceptors into at least three alpha 2 -isoreceptors (alpha $2 A$, alpha ${ }_{2 B}$, alpha 2 ) has been suggested based on the affinities of different alpha $a_{2}$ adrenoreceptor agonists and antagonists. ${ }^{6}$ The existence of another class of receptors or binding sites resembling the alpha2* adrenoreceptors has been indicated by both functional and radioligand binding studies. These sites bind selectively alpha 2 -ligands that are either imidazolines $\left(e . g_{1}\right.$ clonidine or idazoxan) or oxazolines (e.g. rilmenidine), but have very low affinity for agonists or antagonists without the imidazoline or oxazoline stucture, such as adrenaline and yohimbine, 7,8 Molecular biology has recently made it possible to obtain structural information on the alphaa -adrenoreceptors. 9.10

Beginning with the platelet-type alpha 2 -adrenoreceptor, 11 three distinct human alpha $2^{-a d r e n o r e c e p t o r ~ s u b t y p e ~ g e n e s ~ o r ~ c D N A s ~ h a v e ~ b e e n ~ c l o n e d ~ t o ~ d a t e, ~ d e s i g n a t e d ~}$ alpha ${ }_{2}-\mathrm{C} 10,{ }^{11}$ alpha $a_{2}-\mathrm{C}^{12}$ and alpha $-\mathrm{C} 2,{ }^{13}$ according to the location of these genes on human chromosomes 10,4 and 2 . The alphaz-adrenoreceptor is a member of the G-protein (guanine nucleotide binding proteins) coupled family of membrane receptors. ${ }^{14} \mathrm{G}$ proteins are needed to transfer the initial external stimulus from alpha $2_{2}$-adrenoreceptors into a cellular response. Activated $G$ proteins can either modulate the synthesis or availability of intracellular second messenger, or can directly alter the activity of transmembrane ion channels. ${ }^{15}$ 


\subsection{Location and physiological functions of alpha $a_{2}$ adrenoreceptors}

Alphap-adrenorecptors exist in several tissues and organs of the body, and the functions mediated by these vary depending on the type of the adrenoreceptor and the tissue. Inhibition of neurotransmitter release from peripheral nerve endings is one of the most prominent actions ascribed to alpha 2 -adrenoreceptors; ${ }^{2}$ certainly the CNS actions are at least equally important. Most, if not all, of the central alpha 2 -receptors are postsynaptic. In the human brain, the highest density of alpha 2 -agonist binding sites have been observed in the medullary dorsal motor complex, which may be the site of bradycardic and hypotensive effects of alphaz-adrenoreceptor activa-

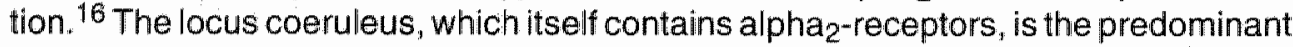
noradrenergic nucleus in the brain and is an important modulator of vigilance. ${ }^{17} \mathrm{High}$ densities of alpha $a_{2}$-agonist binding sites have also been demonstrated in the intermediolateral cell column, the substantia gelatinosa and the motor nuclei of the ventral horn of the human spinal cord. 16,18 Peripheral tissues contain both presynaptic alpha $_{2}$-adrenoreceptors on sympathetic nerve endings and postsynaptic alpha ${ }_{2}$-adrenoreceptors on target cells, where they have distinct physiological functions. ${ }^{19}$ For example, in arterial and venous smooth muscle, they mediate vasoconstriction. ${ }^{20-22}$

\subsection{Pharmacology of alphar agonists}

Clonidine is the prototypical alphaz-adrenoreceptor agonist to which all other alpha agonists are compared. ${ }^{23-25}$ Its actions are mediated mainly by central pre-and

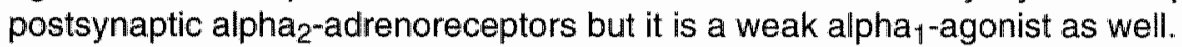

In humans, clonidine has been used for the treatment of mild or moderate hypertension for more than a decade. ${ }^{26}$ It has also been investigated extensively as an adjunct to anesthesia. 27,28 Clonidine is an imidazoline derivative with a distribution half life (iv) of approximately $10 \mathrm{~min}$ and an elimination half life (iv) of approximately 8.5 hours. 24

Mivazerol ${ }^{29}$ and dexmedetomidine $e^{30-32}$ are novel alpha 2 agonists with high affinity to alpha $a_{2}$-adrenoreceptors. These new drugs have a considerably higher alpha $a_{2} / a_{1 p h a_{1}-}$ selectivity ratilo than clonidine and are more potent as alpha 2 agonists. Dexmedetomidine has a distribution half life (iv) of approximately 5 min and an elimination half life (iv) of approximately 2.3 hours. 33

\subsection{Physiologic responses mediated by alpha ${ }_{2}$-adrenoreceptors}

The predominant effect of alpha, agonists, such as clonidine, is on receptors within the CNS which bring about a baroreceptor-mediated decrease in sympathetic tone and a concomitant increase in parasympathetic vagal outflow, 23,25 This results in reduction in blood pressure and heart rate, as well as a decline in plasma catechola- 
mine concentrations. These agents act within the medullary system to increase the gain and decrease the set-point of the baroreceptor reflex, thus maintaining blood pressure at a lower level. At the same time, stimulation of peripheral postiunctional alpha 2 -receptors on vascular smooth muscle causes vasoconstriction, tending to raise blood pressure. 20-22 Higher blood levels of the drugs are required for this peripheral action than for the central effects. This mode of action is in marked contrast to the blood-pressure lowering actions of peripherally acting direct vasodilators, such as nitroprusside. ${ }^{34,35}$ it is also different from the effects of other types of drugs acting on peripheral structures of the autonomic nerwous system: ganglionic blocking agents (trimethaphan), drugs depressing the postganglionic adrenergic neurons (reserpine, guanethidine), cardiac beta-blocking drugs, which may lower blood pressure by decreasing heart rate, contractility, and cardiac output, or by drugs that prevent vasoconstriction by blocking alpha ${ }_{1}$-adrenergic receptors on vascular smooth muscle (prazosin). in all these cases, the central homeostatic cardiovascular control system can be expected to oppose the actions of these drugs that directly inhibit effector systems. ${ }^{34-37}$ The resultant increased activity of the nonblocked portions of the system (eg, reflex tachycardia) may result in increased rather than decreased metabolic activity and myocardial oxygen demand. In contrast, the alpha 2 agonists regulate autonomic activity by acting on the control mechanisms themselves, and thus achieve a more physiologic, coordinated or balanced blood pressure control.

In addition to these antiadrenergic and hemodynamic effects, these drugs are sedatives, anxiolytics and powerful analgesics, with antisialagogue and antiemetic properties. Clonidine's actions in decreasing anesthetic requirements seem related to its attenuating effect on central noradrenergic transmission. For a complete discussion of the possible mechanisms by which anesthesia is produced by stimulation of central alphai2-receptors, see the review by Maze and Tranquilly.38 The mechanisms of the analgesic actions of alpha. agonists have not been fully elucidated. ${ }^{39}$

This combination of actions makes it clear why these drugs are of interest in anesthesia today. If appropriately used, these compounds may produce an ideal pharmacodynamic profile for an adjunctive agent for clinical anesthesia ${ }^{38}$ While clinicall experience with the modern, specific alpha 2 agonists is limited, clonidine has been used extensively.

\subsection{Benefits of clonidine during the perioperative period}

\subsubsection{Decreased doses of anesthetic and analgesic drugs}

There are many sedative and hypnotic drugs that potentiate general anesthetics, including the barbiturates, benzodiazepines, and opioids. Opioids are effective analgesics and also smooth out hemodynamics and decrease the stress response to some extent. However, almost all of the other anesthetic-sparing and analgesic drugs produce these effects at the cost of prolonged awakening. In the case of the opioids, postoperative respiratory depression may necessitate artificial ventilation. Clonidine 
and the other alpha 2 agonists have not been reported to be respiratory depressants, except occasionally in cases of massive, accidental overdose. The lack of respiratory depression from alpha 2 agonists, as well as their lack of potentiation of narcotic-induced respiratory depression, is supported by the fact that patients treated with clonidine in a CABG study were extubated significantly sooner as compared to patients in the control group. 40

\subsubsection{Improved hemodynamic stability}

In several clinical studies in patients undergoing cardiac or major vascular surgery, it was shown that clonidine could decrease episodes of high blood pressure and tachycardia, $40-42$

We've been using in our department clonidine for more than 10 years for hemodynamic stabilization in the immediate postoperative period after cardiac surgery. The next table shows the hemodynamic effects of $150 \mu \mathrm{g}$ of clonidine, given slowly iv over 10 min in 24 cardiac surgical patients with postoperative hypertension (unpublished data, Van Vliet $J$ and Roekaerts $P, 1995)$.

\begin{tabular}{lcc}
\hline Clonidine $150 \mu \mathrm{Hg}$ iv & before intusion & 10 min after end of infusion \\
\hline mean arterial pressure $(\mathrm{mmHg})$ & $101 \pm 12$ & $78 \pm 15^{*}$ \\
heart rate (beats. $\left.\mathrm{min}^{-1}\right)$ & $107 \pm 16$ & $99 \pm 14$ \\
cardiac index $\left(\mathrm{L} \cdot \mathrm{Kg}^{-1} \cdot \mathrm{mir}^{-1}\right)$ & $3.9 \pm 1.1$ & $3.3 \pm 0.6^{*}$ \\
LV stroke work index $\left(\mathrm{gm} \cdot \mathrm{m}^{-2}\right)$ & $48 \pm 11$ & $37 \pm 10^{*}$ \\
Pulmonary capillary wedge pressure $(\mathrm{mmHg})$ & $9 \pm 5$ & $7 \pm 3$ \\
Systemic vascular resistance (Ds.cm & $1106 \pm 356$ & $891 \pm 276^{*}$ \\
\hline
\end{tabular}

These data indicate that, in these patients, clonidine can significantly decrease blood pressure, cardiac index, LV stroke work index and systemic vascular resistance, with a moderate decrease in heart rate.

The primary aim of careful control of blood pressure and heart rate during and after anesthesia and surgery in patients with cardiovascular disease is prevention of myocardial ischemia. The effect of premedication with clonidine on the incidence of ischemic ST-segment changes in the pre-bypass period was reported by Kent et al ${ }^{43}$ and by Dorman et $\left.a\right|^{44}$ Both groups reported less ischemia in clonidine-treated patients than in a control group. In a non-surgical population, it had been shown previously that clonidine could improve the myocardial oxygen supply/demand ratio in ischemic heart disease and reduce attacks of angina pectoris. ${ }^{45,46}$

Clonidine appears to affect both myocardial oxygen supply and demand beneficially by reducing sympathetic outtlow to the systemic vascular bed and to the heart. Moreover, in the heart it reduces beta-adrenergic and alpha-adrenergic (both alpha, and $a_{1 p h}$ ) effector systems. By acting on central control systems, clonidine does this in a well-coordinated fashion. Whereas beta-adrenergic blocking drugs deal only 
with heart rate and contractility, the alphaz agonists also reduce adrenergically mediated vasaconstriction, including coronary vasoconstriction, which may have in fact been exacerbated by the use of a beta-blocker alone.

\subsubsection{Sympatholysis}

In patients undergoing coronary artery bypass grafting surgery, it has been demonstrated that pre- and intraoperative clonidine therapy maintained significantly lower plasma catecholamine levels during episodes of major noxious stimuli when compared to control patients. $40,47,48$

In the clonidine-treated patients in one CABG study the lower levels of norepinephrine and epinephrine (compared with the control group) continued into the immediate postoperative period, 40 which is the time when these patients are the most likely to suffer from hyperdynamic and ischemic episodes. In aortic surgery, Quintin et al found similar results, with plasma levels of both catecholamines significantly lower in clonidine-treated patients before, during, and after cross-clamping. ${ }^{42,49}$ This decreased adrenergic response in aortic surgery has been confirmed by others. ${ }^{41}$

\subsubsection{Decreased postoperative shivering}

Shivering is common in patients after major surgery. In order to supply the increased oxygen required by the shivering tissues, the respiratory and circulatory systems are severely taxed. Oxygen consumption and carbon dioxide production have been found to increase by up to $500 \%$ above basal levels. $50-52$ If cardiac output cannot increase sufficiently, or if hypoxemia and/or anemia are also present, oxygen transport may not keep pace with metabolic demand. Thus, disproportional tissue oxygen extraction may occur, causing mixed venous and sometimes arterial desaturation and lactic acidosis. ${ }^{50-54}$ It is well known that central adrenergic systems influence temperature regulation, ${ }^{55-56}$ and there are laboratory reports of suppression of shivering by clonidine ${ }^{57}$ In the study by Flacke and colleagues of patients undergoing CABG surgery, it was observed that the incidence of shivering in the immediate postoperative period was significantly reduced by clonidine. Since then, several more formal investigations have pointed out the efficacy of clonidine in suppressing postanesthetic shivering, as well as in decreasing total body oxygen consumption in the immediate postoperative period. ${ }^{58-62}$ This decreased postoperative oxygen consumption together with the increased cardiovascular and sympathoadrenal stability may be of clinical importance in certain high-risk patients with compromised oxygen supply-anddemand balance.

\subsection{Potential side effects}

Potential side-effects of alphaz-adrenoreceptor agonists in the high-risk patient population are bradycardia, hypertension and hypotension. ${ }^{63}$ Bradycardia is usually beneficial in these patients, but, should it require treatment, responds easity to the 
administration of atropine iv. Hypertension occurs mainly when the alphaz-adrenoreceptor agonists are administered as a large, rapid intravenous bolus. This effect can be avoided by using a slower infusion. The hypotension associated with the alphazadrenoreceptor agonists usually is limited to a $20 \%$ decrease in blood pressure in healthy patients, but can decrease further in chronically hypertensive patients with high basal sympathetic tone. Alpha ${ }_{2}$-adrenoreceptor agonist-induced hypertension is mainly peripherally-mediated, hypotension is centrally-mediated. Because these cardiovascular effects of alphas agonists might be overcome phamacologically by peripheral-acting vasoactive drugs, ${ }^{64}$ the benefits of low sympathetic activity and circulating catecholamines associated with the use of alpha 2 agonists are retained (see also chapters 4 and 5). Sedation is considered a side-effect in ambulatory patients. The sedative effect is desirable in patients who will remain hospitalized post-operatively, but not in patients who will be discharged from the hospital on the day of surgery. However, specific alpha 2 -adrenoreceptor antagonists are availlable 65 which also antagonize the central effects of the alpha $a_{2}$ agonists (see chapters 5 and 6).

\subsection{Limitations of clonidine therapy in patients with ischemic heart disease}

Previous reports, although limited, have suggested that the non-specific alpha. agonist clonidine, because it can produce perioperative hemodynamic and adrenergic stability and also because it can reduce attacks of angina pectoris in patients with coronary artery disease, could be especially beneficial as a perianesthetic adjuvant in patients with ischemic heart disease.

On the other hand, alphaz-adrenoreceptor stimulation also causes coronary vasoconstriction. Studies on the effects of alpha $a_{2}$-adrenoreceptor activation during experimental myocardial ischemia have yielded conflicting results. Heusch reported that alpha $a_{2}$ excitation by sympathetic nerve stimulation and exercise could induce myocardial ischemia. ${ }^{66}$ This regional myocardial ischemia further activated cardiac sympathetic nerves, thus inducing alpha 2 -adrenoreceptor vasoconstriction of the poststenotic vascular bed and further aggravation of myocardial ischemia. However, systemic administration of clonidine prevented the sympathetic initiation and aggravation of post-stenotic myocardial ischemia by a central nervous system action. This may be why clonidine is effective in exertional angina. Two other potential mechanisms by which alpha 2 -adrenoreceptor activation can prevent myocardial ischemia have been described. Nathan \& Feigl reported that alpha-adrenergic coronary vasoconstriction exerts a favourable effect on ischemic myocardium by preventing a transmural redistribution of blood flow away from the ischemic endocardium, a so-called anti-steal phenomenon. 67 In addition, Kitakaze demonstrated that intracoronary clonidine enhanced the wasodilatory effects of adenosine released from ischemic myocardium, thereby attenuating myocardial ischemia. 68

Clonidine has been studied for management of peri-operative ischemia. Kent and co-workers ${ }^{43}$ premedicated 23 cardiac surgery patients with $200 \mu \mathrm{g}$ of clonidine or 
placebo po. Ischemia was monitored from the time of premedication to cardiopulmonary bypass using leads $\mid I$ and V5. Patients receiving clonidine had decreased incidence and duration of ischemia compared with the placebo group. Quintin and colleagues reported the results of a study of 26 cardiac surgery patients who were premedicated with $2.5 \mathrm{\mu g} \mathrm{kg}{ }^{-1}$ clonidine or placebo po. ${ }^{69}$ Ischemia was monitored from the time of premedication to bypass using leads II and V5. The cumulative duration of ST changes was decreased in the clonidine group. Recently, Dorman and co-workers evaluated the effect of clonidine on 43 patients undergoing coronary artery bypass surgery. ${ }^{44}$ Oral clonidine $\left(5 \mu \mathrm{g} \cdot \mathrm{kg}^{-1}\right)$ or placebo was administered pre-operatively and immediately prior to cardiopulmonary bypass. ST segments were analyzed continuously in leads 11 and V5. From stemotomy to aortic cross-clamping, the placebo group had a significantly increased incidence of ST depression when compared to the clonidine group. It was also shown that small, oral dose of clonidine reduces the incidence of myocardial ischemia in patients having vascular surgery. ${ }^{70}$

\subsection{Aims of the study}

New, more specific and selective alphaz-adrenergic receptor agonists have recently been introduced for perioperative use to reduce anesthetic requirements and to provide hemodynamic stability in low-risk (ASA I-II) surgical patients.

The present series of investigations was initiated in order to gain information on the possible usefulness of the new alpha 2 agonists dexmedetomidine and mivazerol as anesthesia adjuvants in the perioperative period in patients with cardiovascular disease at risk for coronary artery lesions (chapter 9). Because information on the effects of dexmedetomidine and mivazerol on myocardial ischemia was limited, we initiated 5 laboratory investigations in dogs which were among the first to study the effects of dexmedetomidine and mivazerol on the coronary circulation and on the ischemic myocardium. We wanted to gain more information about possible mechanisms for the potential anti-ischemic effects of these new alphaz agonists.

More specifically, these investigations were designed:

- to assess the central sympatholytic effect and the peripheral vasoconstrictive effect of dexmedetomidine and to assess whether the systemic and coronary vasoconstriction of dexmedetomidine can be overcome by a calcium-channel blocker (chapter 4).

- to investigate whether this peripheral vasoconstrictive effect of dexmedetomidine can be reversed by the purinoceptor agonist ATP and to investigate whether the effects of dexmedetomidine on cardiac function are secondary to the peripheral effects (chapter 5 ).

- to study the balance between exogenous alpha $a_{2}$-adrenergic and endogenous metabolic vasoregulation in normal myocardium and during reactive hyperemia, a situation when high endogenous purinergic substances like adenosine are present (chapter 6). 
- to gain inore information on the effect of dexmedetomidine and mivazerol on blood flow, metabolism and function of normal and ischemic myocardium, with special emphasis on the transmural distribution of myocardial blood flow (chapters 7 and 8 ). 


\section{REFERENCES}

1. Ahlquist RP: A study of the adrenotropic receptors. Am J Physiol 153: 586-600, 1948

2. Langer SZ: Presynaptic regulation of catecholamine release. Biochem Pharmacol 23: 1793-1800, 1974

3. Langer $S Z$; Presynaptic regulation of the release of catecholamines. Pharmacol Pev 32:337-362, 1981

4. Wikberg JES: Synthesis of $3 \mathrm{H}$-acetylcholine in the rabbit lacrimal gland and its release by electrical field stimulation. Acta Physiol Scand 468 (Suppl1):189, 1979

5. Bylund DB: Subtypes of alphaz-adrenoreceptors: Pharmacological and molecular biological evidence converge. Trends Pharmacol Sci 9: 356-361, 1988

6. Bylund $\mathrm{DB}$, Ray-Prenger $\mathrm{C}$, Murphy $\mathrm{TJ}$ : Alpha2A and $\mathrm{A}_{2} \mathrm{~B}$-Adrenergic subtypes: antagonist binding in tissues and cell lines containing only one subtype. J Pharmacol Exp Ther 245; 600-607, 1988

7. Ernsberger P, Meeley MP, Mann Jل, Reis DJ: Clonidine binds to imidazoline binding sites as well as alpha2-adrenoreceptors in the ventrolateral medulla. Eur J Pharmacol 134: 1-13, 1987

8. Kamisaki $Y$, Ishikawa $T$. Takao $Y$, Omodani $H_{3}$ Kuno $N$, ltoh $T$ : Binding of [ ${ }^{3} \mathrm{H}$ ]p-aminoclonidine to two sites, alpha2-adrenoreceptors and imidazoline binding sites in rat brain. Brain Res 514: 15-21, 1990

9. Harrison JK, Pearson WR, Lynch K: Molecular characterization of alpha 1 -and alpha2-adrenoreceptors. Trends Pharmacol Sol 12: 62-67, 1991

10. Lomasney JW, Cotecchia $S$, Lefkowitz RJ, Caron MG: Molecular biology of alpha-adrenergic receptors: implications for receptor classification and for structure-function relationships. Biochem Biophys Acta 1095: 127-139, 1991

11. Kobilka BK, Matsui $H$, Kobilka TS: Cloning, sequencing, and expression of the gene coding for the human platelet, alpha2-adrenergic receptor. Science 238; 650-656, 1987

12. Regan JW, Kobilka TS, Yang-Feng TL, Caron MG, Lefkowitz RJ, Kobilka BK: Cloning and expression of a human kidney cDNA for an alpha2-adrenergic receptor subtype. Proc Natl Acad Sci USA 85: $6301-6305_{n} 1988$

13. Lomasney JW, Lorenz W. Allen LF: Expansion of the alpha2-adrenergic receptor family: cloning and characterization of a human alphag-adrenergic receptor subtype, the gene for which is lacated on chromosome 2. Proc Natl Acad Sci USA 87: 5094-5098, 1990

14. Gillman AG: G proteins: Trainsducers of receptor-generated signals. Annu Rev Biochem 56:615-649, 1987

15. Birnbaumer $\mathrm{L}$, Abramowitz. J Brown AM: Receptor-effector coupling by G proteins. Biochem Biophys Acta 1031: 163-224, 1990

16. Unnerstall JR, Kopajtic TA, Kuhar MJ: Distribution of alpha $2^{-a g o n i s t ~ b i n d i n g ~ s i t e s ~ i n ~ t h e ~ r a t ~ a n d ~ h u m a n ~}$ central nervous system: Analysis of some functional ${ }_{*}$ anatomic correlates of the pharmacologic effects of clonidine and related adrenergic agents. Brain Res Rev 77: 69-101, 1984

17. Aston-Jones G, Ennis M. Pieribone VA, Nickell WT, Shipley MT: The brain nucleus locus coeruleus: Restricted afferent control of a broad efferent network. Science 234: 734-737, 1986

18. Probst $A$, Cortes $R$, Pallacios JM: Distribution of alphaz-adrenergic receptors in the human brain stem: an autoradiographic study using [ ${ }^{3} \mathrm{H}$ ]p-aminoclonidine. Eur J Pharmacol 106: 477.488, 1985

19. MCGrath JC: Evidence for more than one type of postjunctional alpha-adrenoreceptor. Blochem Pharmacol 31: 467-484, 1982

20. Langer SZ, Hicks PE: Alpha-adrenoreceptor subtypes in blood vessels: physiology and pharmacolagy. J Cardiovasc Pharmacol 6 (suppl): S547-S558, 1984

21. Nielsen H, Mortensen FV, Mulvany MJ: Responses to moradrenaline in human subcutaneous resistance arteries are mediated by both alpha ${ }_{1}$ - and alphaz-adrenoreceptors. $\mathrm{Br} J$ Pharmacol 99 : $31-34,1990$ 
22. Nielsen H, Thom SM, Hughes AD, Martin GM, Mulvany MJ, Sever PS: Postjunctional alphazadrenoreceptors mediate vasoconstriction in human subcutaneous resistance vessels. Bi J Pharmacol 97: $829.834,1989$

23. Van Zwieten PA: Drugs interacting with alpha adrenoreceptors. Cardiovasc Drugs Ther 3: 121-133, 1989

24. Feid $\mathrm{JL}$ : The clinical pharmacology of clonidine and related central antihypertensive agents. $\mathrm{Br} J \mathrm{Clin}$ Pharmacol 12: 295-302, 1981

25. Iseac L: Clonidine in the central nervous system: site and mechanism of hypotensive action. $J$ Cardiovasc Pharmacol 2 (suppl1): \$5-\$19, 1980

26. Wing LMH, Reid JL, Davies DS, Neill EAM, Tippett P, Dollery CT: Pharmacokinetics and concentration-effect relationship of clonidine in essential hypertension. Eur J Clin Pharmacol 12; 463-469, 1977

27. Bloor BC, Flacke WE: Reduction in halothane anesthetic requirement by clonidine, an alpha 2 -adrenergic agonist. Anesth Analg 61: 741-745, 1982

28. Ghignone $M$, Quintin L, Duke PC. Kehler $\mathrm{CH}$, Cavillo $\mathrm{O}$ : Effects of clonidine on narcotic requirements and hemodynamic responses during induction of fentanyl anesthesia and endotacheal intubation. Anesthesiology $64: 36-42,1986$

29. Noyer M, De Laveleye F, Vauquelin G: Mivazerol, a novel compound with high specificity for alpha2 adrenergic receptors: binding studies on different human and rat membrane preparations. Neurochem int 1994; 24: 221-229

30. Savola JM. Ruskoaho H, Puurunen $\Downarrow$, Saloner JS, Karki NT: Evidence for medetomidine as a selective and potent agonist at alphaz-adrenoreceptors. J Auton Pharmacol 5: 275-284, 1986

31. Scheinin $M$, Kallio $A$, Koulu $M$, Viikari $\downarrow$, Scheinin $H$ : Sedative and cardiovascular effects of medetomodine, a novel selective alphaz-adrenoreceptor agonist in healthy volunteers. $\mathrm{Br}\rfloor \mathrm{Clin}$ Pharmacol 24: 443-451, 1987

32. Kallio A, Scheinin M, Koulu M, Ponkilainen $R$, Ruskoaho H, Vinamoki $O$, Scheinin H: Effects of dexmedelomidine, a selective alphaz-adrenoreceptor agonist, on hemodynamic controll mechanisms. Clinical Pharmacol Ther 46: 33-42, 1989

33. Virtanen $R_{i}$ Savola. $\mathrm{JM}$, Saano V, Nyman L: Characterization of the selectivity, specificity and potency of medetomidine as an alphaz-adrenoreceptor agonist. Eur J Pharmacol 150: 9-14, 1988

34. Flacke JW. Flacke WE, Cant JW: Reflex responses to sodium nitroprusside and their controll by cryptenamine. Anesth Analg 59: 909-916, 1980

35. Bloor BC, Finander LS, Flacke WE: Effect of clonidine on sympathoadrenal response during sodium nitroprusside hypotension. Anesth Analg 65: 468-474, 1986

36. Feigl EO: Carotid sinus reflex control of coronary blood flow. Circ Res 23: 223-237, 1968

37. Mitchell HC, Pettinger WA: The hypernoradrenergic state in vasodilator drug-treated hypertensive patients: effect of clonidine. J Cardiovasc Pharmacol 2: 1-7, 1980

38. Maze $M$, Tranquilli $W$ : Alphaz-adrenoreceptor agonists: Defining the role in clinical anesthesia. Anesthesiol 74: 581-605, 1991

39. Wang YC, SU CA, Lin MT: The site and the mode of analgesic actions exerted by clonidine in monkeys. Exp Neurol 90: 479-488, 1985

40. Flacke JW, Bloor BC, Flacke WE, Wong D, Dazza S, Stead SW, Laks $H$ : Reduced narcotic requirement by clonidine with improved hemodynamic and adrenergic stability in patients undergoing coronary bypass surgery. Anesthesiology $67: 11-19,1987$

41. Engelman E, Lipszyc M, Gilbart E: Effects of clonidine on anesthetic drug requirements and hemodynamo response during aortic surgery. Anesthesiology 71: 178-187, 1989

42. Quintin I. Bonnet F, Macquin I, Szekely B, Becquemin JP, Ghignone M: Aortic surgery: effect of clonidine on intraoperative catecholaminergic and circulatory stability. Acta Anaesthesiol Scand 34: 132137,1990

43. Kent $M$, Thomsen $B$, Cicala $R$ : Clonidine decreases ischemic events during coronary artery surgery. Anesthesiology 73: A129, 1990 
44. Dormain BH, Zucker JR, Verrier ED, Gartman DM, Slachman FN: Clonidine improves perioperative myocardial ischemia, reduces anesthetic requirement, and alters themodynamic parameters in patients undergoing coronary artery bypass surgery. J Cardiothorac Vasc Anesth 7(4):386-395, 1993

45. Ceremuzynski $L$, Saleska $T$, Lada $W$, Zalewski $A$ : Clonidine effect in chionio angina pectoris. Double-blind crossover trial on 60 patients. Eur $J$ Cardiol 10: 415-427, 1979

46. Thomas MG, Quiroz AC, Rice JC, Sander GE, Giles TD: Antianginal eftects of clonidine. $J$ CardiovasC Pharmacol 8 (suppl3): S69-S75, 1986

47. Helbo-Hansen S, Fletcher $R$, Lundberg D: Clonidine and the sympathicoadrenal response to coronary artery bypass surgery. Acta Amaesth Scand 30: 235-242, 1986

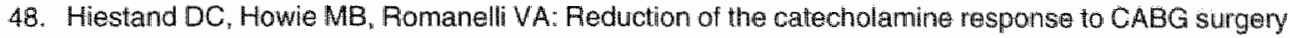
by clonidine. Anesthesiology 75:A 153, 1991

49. Quintin $L$. Rioudot F, Roux $C$ : Effect of clonidine on the circulation and vasoactive hormones after aortic surgery. Br J Anaesth 66: 108-115, 1991

50. Bay J, Nunn JG, Prys-Roberts $\mathrm{C}$ : Factors influencing arterial $\mathrm{PO}_{2}$ during recovery from anesthesia. BrJ Anaesth 40: 398-406, 1968

51. Kaplan JA, Guffin AV: Shivering and changes in mixed venous oxygen saturation after cardiac surgery. Anesth Analg 64: 185-304, 1985

52. Macintyre PE: Pavlin EG. Dwersteg JF: Effect of meperidine on oxygen consumption, carbon dioxide production, and respiratory gas exchange in postanesthesia shivering. Anesth Analg 66: 751-755. 1987

53. Flacke JW, Flacke WE: Inadvertent hypothermia: frequent, insidious, and often serious. Semin Anesth 3: $186-195,1982$

54. Guffin A, Girard D, Kaplan JA: Shivering following cardiac surgery: Hemodynamic changes and reversal. J Cardiothorac Anesth 1: 24-28, 1987

55. Delaunay L, Bonnet F, Liu N, Beydon L, Catoire P, Sessier Dil: Clonidine comparably decreases the thermoregulatory thresholds for vasoconstriction and shivering in humans. Anesthesiology 79 : $470-474,1993$

56. Delaunay L, Bonnet F, Liu $\mathbb{N}$, Beydon L, Sessler Dl: Effect of clonidime on thermo-regulation. Anesthesiology 77 (suppl): A 387, 1992

57. Mora F Lee TF, Myers RD: Involvement of alpha- and beta-adrenoreceptors in the central action of norepinephrine on temperature, metabolism, heart and respiratory rates of the conscious primate. Brain Res Bull 11: 613-616, 1983

58. Goldfarb $G, A n g E T$, Debaene $B$ : Effect of clonidine on postoperative shivering in man: A double blind study. Anesthesiology 71: A650, 1989

59. Banache $M$, Joris $d_{\text {, Lamy }} M$ : Comparative effects of clonidine and ketanserin on postoperative shivering. Anesthesiology 75: A51, 1991

60. Goldfarb $\mathrm{G}$, Ang $\mathrm{ET}$, Debaene B: Effect of clonidine on postoperative oxygen consumption in humans: A double-blind study. Anesthesiology 73: A317, 1990

61. Quintin L, Viale JP, Annat G: Oxygen uptake after major abdominal surgery: Effect of clonidine. Anesthesiology $74: 236-241,1991$

62. Delaunay $\mathrm{L}$, Bonnet $\mathrm{F}$, Liu $\mathrm{N}$ : Clonidine prevents postoperative increase in $\mathrm{VO}_{2}$. Anesthesiology 75 : A981, 1991

63. Thormann $J$, Neuss $H$, Schlepper $M$, Mitrovic $V$ : Clonidine on sinus function in man. Chest 80 : $201-206,1981$

64. Bloor BC, Frankland M, Alper G, Raybould D, Weitz J, Shurtliff M: Hemodynamic and sedative elfects of dexmedetomidine in dog. J Pharmacoll Exp Ther 1992: 263: 690-697

65. Virtanen R: Pharmacological profiles of medetomidine and its antagonist, atiparnezole. Acta Veterinaria Scandinavica $85: 29-37,1989$

66. Heusch $G$. Deussen $A$ : The effects of cardiac sympathetic nerve stimulation on perfusion of stenotic coronary arteries in the dog. Circ Res 53: 8-15, 1983 
67. Nathan H. Feigl EO: Adrenergic wasoconstriction lessens transmural steal during coronary hypoperfusion. Am J Physiol 250: H645, 1986

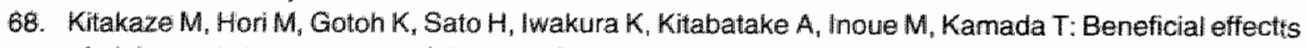
of alphar-adrenoreceptor activity on ischemic myocardium during coronary hypoperfusion in dogss. Circ Res 65: 1632-1645, 1989

69. Quintin L, Cicala $\mathrm{F}_{*}$ Kent $M$, Thomsen $B$ : Effect of clonidine on myocardial ischaemia: a double-bling pilot trial. Can J Anaesthesiol 40: 85-86, 1993 (Letter)

70. Stühmeier KD, Mainzer B, Cierpka $J_{s}$ Sandmann W; Tamow J: Small, oral dose of clonidine reducess the incidence of intraoperative myocardial ischemia in patients having vascular surgery. Anesthesiiology $85: 706-712,1996$ 
CHAPTER 4

\title{
Alleviation of the peripheral hemodynamic effects of dexmedetomidine by the calcium channel blocker isradipine
}

\author{
P.M.H.J. Roekaerts \\ C.J. Lawrence \\ F.W. Prinzen \\ S. de Lange
}




\title{
Alleviation of the peripheral hemodynamic effects of dexmedetomidine by the calcium channel blocker isradipine
}

\begin{abstract}
Background: Alpha $a_{2}$-adrenergic agonists have peripheral vasoconstrictive effects and central sympatholytic and sedative effects. Whereas the latter are the basis of their use in anesthesia, the former could limit their clinical application.

Methods: To study whether a vasodilator could alleviate the systemic and coronary vasoconstrictor effects of dexmedetomidine without influencing the central sympathoIytic effects, the calcium-channel blocker isradipine was infused after a high dose of dexmedetomidine in anesthetized dogs.
\end{abstract}

Results: Dexmedetomidine $10 \mu \mathrm{g} \cdot \mathrm{kg}^{-1}$ decreased plasma concentrations of norepinephrine and epinephrine by more than $90 \%$, heart rate by $39 \%$, cardiac output by $64 \%$, dp/dt max by $29 \%$ and increased mean arterial pressure by $55 \%$ and the left ventricular end-diastolic pressure 4-fold as compared to baseline. In addition, coronary blood flow decreased by $52 \%$ and coronary venous oxygen saturation by $51 \%$. Isradipine could completely antagonize all the coronary and systemic hemodynamic changes induced by dexmedetomidine, but only partially the increase in LVEDP. Isradipine caused no changes in plasma catecholamine levels.

Conclusion: Isradipine could alleviate the peripheral hemodynamic actions of dexmedetomidine while having no effect on it's central sympatholytic properties.

Key words: alpha 2 -adrenergic agonists -dexmedetomidine - calcium channel blockers - isradipine - cardiac function

\section{INTRODUCTION}

Alpha $a_{2}$-adrenergic receptor agonists, as novel anesthetic agents, have been shown to have multiple beneficial effects in the perioperative period. These include improved hemodynamic stability, sedation, and a reduction in the anesthetic and analgesic requirements. "These effects are related to activation of pre-synaptic alpha 2 -adrenergic receptors in the central nervous system with a reduction in norepinephrine release from adrenergic neurons. Drugs that activate these central alphar-receptors also demonstrate useful antihypertensive effects. ${ }^{2}$ Paradoxically, although alpha adrenergic agonists are centrally acting anti-hypertensive agents, activation of peripheral post-synaptic alpha 2 -adrenergic receptors may include intense vasoconstriction, 3 especially after rapid intravenous bolus administration. This pressor effect could 
cause coronary vasoconstriction and thus seriously limil the utillity of these drugs. Therefore, if peripheral vasoconstriction would occur after the administration of alpha. agonists, a drug that could rapidly antagonize this vasoconstriction whille preserving the central actions of alpha 2 agonists could be useful. Calcium channel blockers, widely used as antihypertensives and antiarrhythmics in cardiovasular therapy, could perhaps be administered for this purpose. The action of these drugs is attributed to a selective inhibition of the calcilum influx into the cardiac and smooth muscle cells, which results in vascular smooth muscle relaxation and vasodilation, inhibition of cardiac automaticity and conduction and a reduction of myocardial contractility. ${ }^{4}$ it has previously been shown that alpha $a_{2}$-adrenoreceptor-mediated vasoconstriction could be antagonized by calcium channel blockers and is therefore primarily attributed to the facilitated influx of extracellular calcium ions. 5,6

However, few studies have been published on the hemodynamic interactions of calcium-channel blockers and alpha 2 agonists. 7,8 Bloor and colleagues studied the effect of nifedipine infusion after dexmedetomidine $20 \mu \mathrm{g} \mathrm{kg}^{-1}$ in isoflurane-anesthetized dogs. ${ }^{8}$ However, these investigators did not study the effects of dexmedetomidine and nifedipine on the coronary blood flow.

The present investigation was designed to study whether isradipine, a calcium channel blocker with low lipid solubility and little negative inotropic effect, ${ }^{9-11}$ is effective in alleviating the systemic and coronary hemodynamic effects of dexmedetomidine in halothane-anesthetized dogs.

\section{METHODS}

\section{Anesthesia and Instrumentation}

The studies were approved by the Local Animal Care Committee.

Eight mongrel dogs of either sex, weighing $29.7 \pm 1.7 \mathrm{~kg}$ (range $23-34 \mathrm{~kg}$; mean \pm SEM) were premedicated with $10 \mu \mathrm{g} \cdot \mathrm{kg}^{-1}$ fentanyl IM. Anesthesia was induced 30 minutes later with thiopental. The dose of thiopental required to produce unconsciousness was $18.4 \pm 1.7 \mathrm{mg} \cdot \mathrm{kg}^{-1}$ (mean \pm SEM). The dogs were intubated and mechanically ventilated to normocapnia with halothane and $67 \%$ nitrous oxide in oxygen. ECG electrodes were placed, and catheters for fluid administration and injection/infusion of drugs were inserted into the femoral vein, and into the superior vena cava through the right external jugular vein. Two $7 F$ Millar microtransducertipped catheters were placed via a femoral artery, one in the central aorta and one in the left ventricle. A Swan-Ganz oximetric catheter (Edwards Oximetry TD Catheter $93 \mathrm{~A} / 731 \mathrm{H})$ was floated into the pulmonary artery via the right external jugular vein. The chest was entered through a left thoracotomy incision; the heart was exposed, and an electromagnetic 2 or $2.5 \mathrm{~mm}$ blood flow sensor (Skalar transflow 601 system, Module MDL 400) was placed around the left anterior descending coronary artery. A small catheter for blood sampling was placed in the accompanying coronary vein. After instrumentation was completed, halothane was discontinued, and nitrous oxide 
was supplemented as needed by additional fentanyl. The animals were allowed to stabilize for at least 30 minutes. No muscle relaxants were used, and no additional fentanyl had to be given after beginning the experimental protocol.

\section{Measurements}

ECG, heart rate (HA), phasic and mean arterial blood pressure (MAP), left ventricular pressure (LVP) and fits first derivative ( $\mathrm{dP} / \mathrm{dt}_{\text {max }}$ ), left ventricular end-diastolic pressure (LVEDP), phasic and mean flow in the left anterior descending coronary artery $(\mathrm{CBF})$, and oxygen saturation in the puimonary artery $\left(\mathrm{S}_{\mathrm{W}} \mathrm{O}_{2}\right)$ were measured continuously. Pressures were transduced and amplified with Philips amplifiers PR9330; $\mathrm{S}_{\mathrm{V}} \mathrm{O}_{2}$ was determined and recorded continuously with an Edwards SAT 1 combined cardiac output and $\mathrm{O}_{2}$ saturation computer and recorder. MAP, LVP, dP/dt, LVEDP, $C B F$, and ECG were recorded continuously on a Schwarzer 10 channel RE 412 recorder. Cardiac output (CO) was determined in triplicate at the various measuring points by thermodilution, and arterial, mixed venous, and coronary venous blood samples were drawn at the same times for immediate determination of blood gases (ABL 3 Radiometer), oxygen saturation, and hemoglobin (OSM 2 Radiometer, calibrated for dog blood). Blood samples taken at baseline (BL), after 1 and $10 \mu \mathrm{g}$. $\mathrm{kg}^{-1}$ dexmedetomidine and after isradipine were also prepared for later determination of plasma catecholamines (arterial blood only) by HPLC. ${ }^{12}$ Systemic vascular resistance (SVR), coronary vascular resistance (CVR) [calculated as (MAP. LVEDP)/CBF], arterial, mixed venous, and coronary venous oxygen contents, systemic and regional myocardial oxygen extraction ((arterial minus mixed venous) and (arterial minus coronary venous) oxygen contents, respectively], were calculated.

\section{Experimental protocol}

After BL measurements were taken, dexmedetomidine was given intravenously in increasing cumulative doses of $0.1,0.3,1.0,3.0$, and $10 \mu \mathrm{g} \cdot \mathrm{kg}^{-1}$. Each dose was given over one minute. After the last dose of dexmedetomidine, isradipine was infused for approximately 15 minutes at a rate sufficient to restore and maintain MAP at $B L$ levels. Hernodynamic measurements and blood samples (as described below) were taken as follows: at $\mathrm{BL}$; at the peak MAP response after each dose of dexmed; at equilibrium during the infusion of isradipine, and 30 and 60 minutes after discontinuation of isradipine.

\section{Statistical Analysis}

All data are expressed as mean \pm SEM. The entire series of sampling points for all hemodynamic variables was analyzed by means of General Linear Model Analysis of Variance, and differences between individual points were identified by the Fisher's Least Squares Deviation test. As the catecholamine data were not normally distrib- 
uted, the non-parametric Friedman test was used, with individual point di detected by the Wilcoxon signed rank test. $P<0.05$ was considered signifi

\section{RESULTS}

The peak increase in MAP occurred within one minute of the dexmedt administration. Times between the different doses of dexmedetomidine rar 6 to 11 minutes, due to minor variations in time necessary to take the hem measurements and the blood samples. Isradipine was started $6.5 \pm 0.6$ min the last dose of dexmedetomidine. The dose of isradipine required to retur BL values was $0.86 \pm 0.18 \mu \mathrm{g} \cdot \mathrm{kg}^{-1} \cdot \mathrm{min}^{-1}$. Isradipine measurements were $\mathbb{F}$ at $8 \pm 1.5$ minutes after the start of the infusion.

\section{Hemadynamic Effects}

There was no significant change from $\mathrm{BL}$ levels in any variable after the $\left(0.1 \mu \mathrm{g} \cdot \mathrm{kg}^{-1}\right)$ of dexmedetomidine. The effects of subsequent doses are

Table. Hemodynamic effects of dexmedetomidine and isradipine

\begin{tabular}{|c|c|c|c|c|c|c|c|}
\hline & $\mathrm{BL}$ & $\begin{array}{l}D M \\
0.3\end{array}$ & $\begin{array}{c}\text { DM } \\
1\end{array}$ & $\begin{array}{c}\text { DM } \\
3\end{array}$ & $\begin{array}{c}\text { DM } \\
10\end{array}$ & $\begin{array}{l}\text { ISAA } \\
\text { INF }\end{array}$ & $\begin{array}{c}\text { ISRA } \\
\text { OFF } 30^{\circ}\end{array}$ \\
\hline$H R$ & $140 \pm 11$ & $123 \pm 10$ & $99 \pm 6+$ & $92 \pm 10^{\circ}$ & $86 \pm 11^{\prime \prime}$ & $120+7 t$ & $102 \pm 7^{*}$ \\
\hline MAP & $109 \div 7$ & $133 \pm 7^{i x}$ & $150 \pm 7^{*}$ & $157 \pm 6^{8}$ & $169 \pm 10^{*}$ & $98 \pm 6+$ & $1018 \pm 4$ \\
\hline $\mathrm{CO}$ & $4.9 \pm 0.5$ & $4.4 \pm 0.5$ & $3.1 \pm 0.3^{*}$ & $2.4 \pm 0.3^{*}$ & $1.8 \pm 0.2^{2}$ & $4.9 \pm 0.5$ & $3.1 \pm 0.5^{*}$ \\
\hline SVR & $1916 \pm 228$ & $2566 \pm 244$ & $4128 \pm 191^{* 2}$ & $5549 \pm 381^{*}$ & $7727 \pm 435^{+}$ & $1769=257^{4}$ & $3112 \pm 439^{*}$ \\
\hline LWEDP & $5.1 \pm 0.9$ & $9.2 \pm 2.1^{\prime \prime}$ & $13.3 \pm 0.8^{64}$ & $16.7 \pm 1.8^{2+t}$ & $21.6 \pm 22^{x+4}$ & $10.1 \pm 1.0^{n+}$ & $0.1+1.0$ \\
\hline dPidtmax & $1093: 140$ & $1929 \pm 154$ & $1807 \pm 149$ & $1593+152$ & $11414 \pm 100^{\circ}$ & $1657 \pm 116$ & $1600 * 114$ \\
\hline $\mathrm{CBF}$ & $40 \pm 5$ & $33 \pm 7$ & $26 \pm 7^{*}$ & $23 \pm 8^{n}$ & $19 \pm 9^{*}$ & $44: 8^{4}$ & $36 \pm 7$ \\
\hline CVR & $3.2 \pm 0.7$ & $5.5 \pm 1.4$ & $10.9 \pm 3.6^{*}$ & $13.4 \pm 5.3^{\circ}$ & $23.5 \pm 7.5^{5+}$ & $2.7 \pm 0.6^{+}$ & $3.7: 0.9$ \\
\hline ( $\mathrm{A} \cdot \mathrm{V}$ ) O2Cont & $5.0 \pm 0.7$ & $6.3 \pm 0.8$ & $7.3 \pm 0.7^{\circ}$ & $9.2 \pm 0.8^{* 4}$ & $11,6 \pm 1.0^{4}$ & $4.1 \pm 0.8^{*}$ & $6.8 \pm 0.8^{\prime \prime}$ \\
\hline Ven O2 Sal & $75 \div 3$ & $72 \pm 3$ & $70 \pm 3^{*}$ & $63 \pm 2^{x+t}$ & $56+3^{2+\frac{4}{4}}$ & $82: 2^{t+}$ & $72 \pm 3^{4}$ \\
\hline (A.CW) O2Cont & $1.4 .9 \pm 1.3$ & $17.3 \pm 1.5^{\circ}$ & $20.1 \pm 0.9^{4+}$ & $20.2 \pm 1.4^{*}$ & $22.2 \pm 0.8^{* t}$ & $11.4 \pm 1^{*}$ & $15.5=1.3^{+}$ \\
\hline Cor O2 siat & 31.4 & $25 \pm 4$ & $20 \pm 3$ & $19 \pm 4^{*}$ & $16 \pm 44^{*}$ & $563^{4}$ & $39 \pm 5^{34 t}$ \\
\hline
\end{tabular}

" = significantly different from baseline value; ${ }^{+}=$significantly different from preceding valu Abbrewations: $\mathrm{BL}=$ baseline; $\mathrm{DM}=$ dexmedetamidine in $\mu \mathrm{g} \cdot \mathrm{kg}^{*}$. isra = isradipine; inf $=$ inf heart rate in beats. $\mathrm{min}^{-1} ; M A P=$ mean arterial pressure in $\mathrm{mmHg} ; \mathrm{CO}=$ cardiac output in $\mathrm{L} \cdot \mathrm{f}$ systemic vascular resistance in dyne. $s \cdot \mathrm{cm}^{-5}$; LVEDP = left ventricular end-diastolic pressu $\mathrm{dP} / \mathrm{dtmax}=$ first derivative of $\mathrm{LV}$ pressure in $\mathrm{mmHg} \cdot \mathrm{s}^{-1} ; \mathrm{CBF}=$ caronary blood flow in $\mathrm{ml} \cdot \mathrm{n}$ coronary vascular resistance in $\mathrm{mmHg} \cdot \mathrm{ml}^{1-1} \mathrm{~min}^{-1},(\mathrm{~A}-\mathrm{V}) \mathrm{O}_{2} \mathrm{Cont}=$ arterial - mixed venous ox $)$ in $\mathrm{ml}^{-\mathrm{dl}^{-}}$; Ven $\mathrm{O}_{2}$ sat $=$ mixed venous oxygen saturation in $\%$; (A-CV) $\mathrm{O}_{2} \mathrm{Cont}=$ arterial -coro oxygen content in ml all ${ }_{i}^{-1}$ Cor $\mathrm{O}_{2}$ sat: regional coronary venous oxygen saturation in $\%$ isra min after discontinuation of isradipine; Isra off $60^{\circ}=60$ min after discontinuation of isradipin 


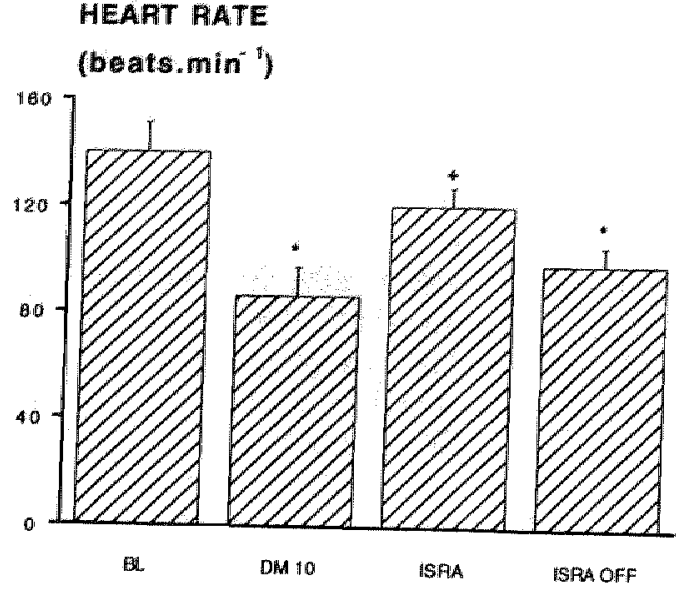

MEAN ARTERIAL PRESSUIRE $(\mathrm{mmHg})$

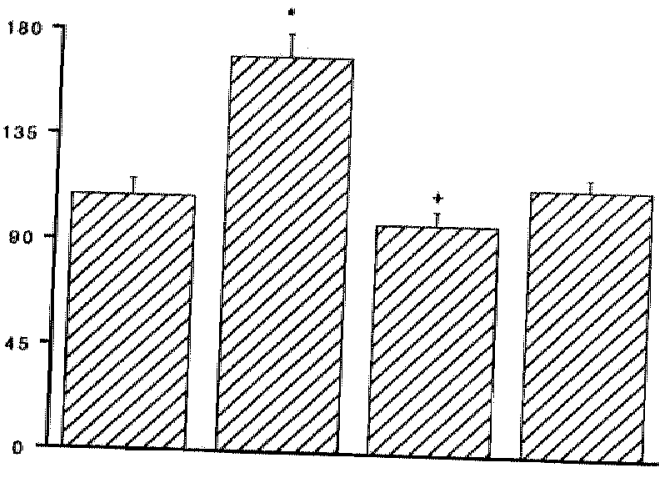

B.

DM 10
Figure 1. Heart rate mean arterial pressune and cardiac output

mean \pm sem data; $\mathrm{n}=8$; ; significantly different from $\mathrm{BL}$ value $(\mathrm{P}<0.05)$; + significantly different from preceding value $P<$ $0.05)$; Abbreviations: $\mathrm{BL}=$ balselline; $\mathrm{DM} 10=$ dexmedetomidine $10 \mu \mathrm{g} \cdot \mathrm{kg}^{-1}$, ISAA = isradipine $0.86 \pm 0.18 \mu \mathrm{gkg}^{-1} \cdot \mathrm{min}^{-1} ;$ ISRA OFF $=60$ min after discontinuation of isradipine infusion:

\section{CARDIAC OUTPUT}

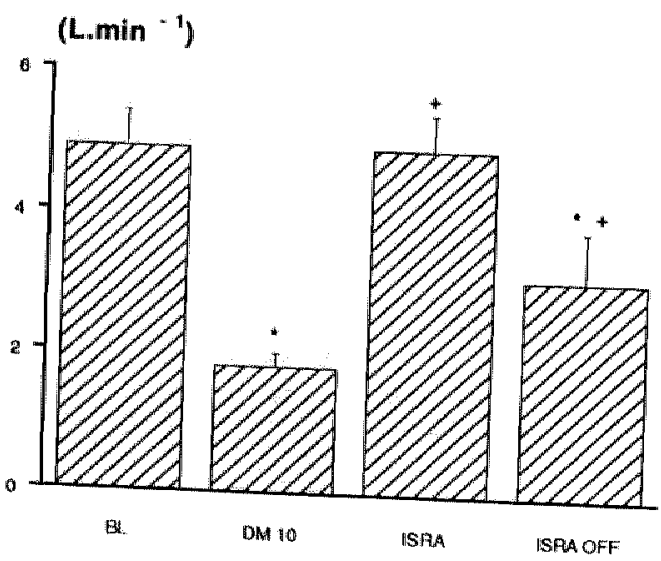



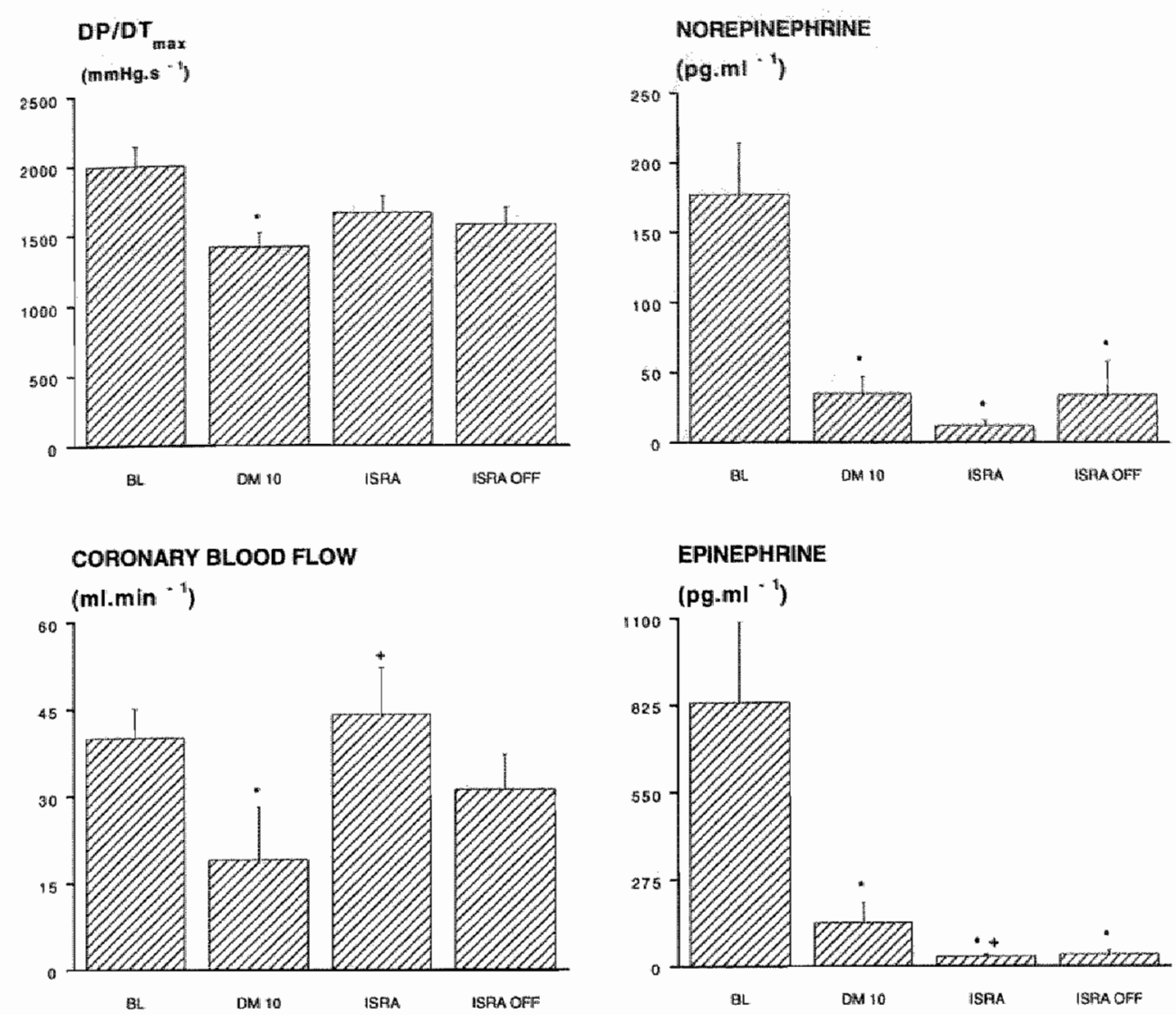

Figure 2. DP/dTmax and coronary blood flow mean \pm sem data; $n=8 ;{ }^{*}=$ significantly different from $B L$ value $(P<0.05) ;+=$ significantly different from preceding value $(\mathrm{P}<0.05)$; Abbreviations: $\mathrm{BL}$ = baseline: $\mathrm{DM} 10=$ dexmedetomidine $10 \mu \mathrm{g} \mathrm{kg}^{-1}$; ISRA $=$ isradipine $0.86 \pm 0.18 \mu \mathrm{g} \cdot \mathrm{kg}^{-1} \cdot \mathrm{min}^{-1} ;$ ISRA $\mathrm{OFF}=60 \mathrm{~min}$ after discontinuation of isradipine infusion

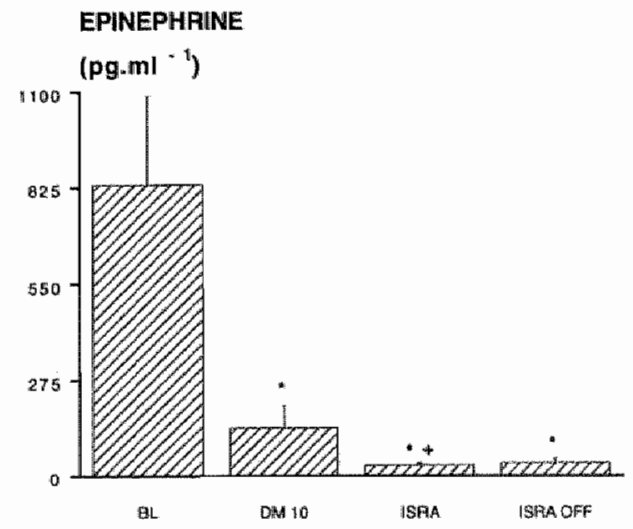

Figure 3. Plasma levels of norepinephrine and epinephrine

mean \pm sem data; $n=8 ; *$ significantly different from $B L$ value $(P<0.05) ;+=$ significantly different from preceding value $(\mathrm{P}<0.05)$; Abbreviations: $\mathrm{BL}=$ baseline; $D M 10=$ dexmedetomidine $10 \mu \mathrm{gg}-1$; ISRA $=$ isradipine $0.86 \pm 0.18 \mu \mathrm{g} \cdot \mathrm{kg}-1 \cdot \mathrm{min}=1 ;$ ISRA OFF $=60 \mathrm{~min}$ after discontinuation of isradipine infusion

the Table and in Figure 1,2 \& 3. All hemodymamic factors were changed significantly by the $1 \mu \mathrm{g} \cdot \mathrm{kg}^{-1}$ and higher doses of dexmedetomidine.

Systemic circulation. There was a progressive, dose-related decrease in HR and increase in MAP from BL levels; after the last dose of dexmedetomidine these were $61 \%$ and $155 \%$ of $B L$ respectively. Cardiac output decreased progressively to $36 \%$ of $\mathrm{BL}$ after last dose, and LVEDP increased concurrently to $424 \%$ of BL. SVR rose

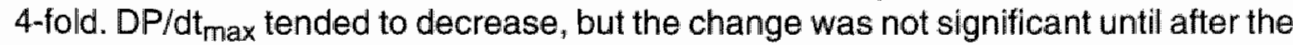


last dose (10 $\left.\mathrm{\mu g} \cdot \mathrm{kg}^{-1}\right)$ of dexmedetomidine. As CO fell, a compensatory doubling of systemic oxygen extraction occurred, resulting in a $30 \%$ decrease in mixed venous oxygen saturation. Within minutes after the start of the isradipine infusion, all systemic hemodynamic variables returned to $B L$ levels, except LVEDP, which remained elevated compared to BL. Systemic oxygen extraction decreased to BL concomitantly.

After discontinuation of the 15 min infusion of isradipine, most of the dexmedetomidine-mediated actions on the systemic circulation were no longer present: MAP, LVEDP and $\mathrm{dP} / \mathrm{dt}$ max were similar to $\mathrm{BL}$, the SVR was more than halved and the $\mathrm{CO}$ almost doubied as compared to the same values after DM $10 \mu \mathrm{g} \cdot \mathrm{kg}^{-1}$.

Coronary Circulation. After increasing doses of dexmedetomidine, CBF declined and CVR rose progressively. After the highest dose these were $48 \%$ and $734 \%$ of $\mathrm{BL}$, respectively. Myocardial oxygen extraction [( $\mathrm{A}-\mathrm{CV}) \mathrm{O}_{2 \mathrm{Cont}}$ increased from 14.9 $\mathrm{ml} \pm 1.3 \mathrm{ml} \cdot \mathrm{dl}^{-1}$ at BL to $22.2 \pm 0.8 \mathrm{ml} \cdot \mathrm{dl}^{-1}$ after the $10 \mu \mathrm{g} \cdot \mathrm{kg}^{-1}$ dose. Within minutes after the start of the isradipine infusion, all coronary hemodynamic variables returned to $\mathrm{BL}$ levels. Regional myocardial oxygen extraction even declined to less than $\mathrm{BL}$ values.

After discontinuation of isradipine, most of the coronary vascular effects of dexmedetomidine were no longer apparent.

\section{Changes in plasma catecholamines}

BL levels of plasma norepinephrine and epinephrine were $177 \pm 37$ and $833 \pm 256$ $\mathrm{pg} \cdot \mathrm{ml}^{-1}$, respectively. Dexmedetomidine decreased plasma concentrations of both catecholamines gradually and significantly. Isradipine did not change plasma catecholamine levels (figure 3 ).

\section{DISCUSSION}

The present study demonstrates that isradipine can reverse all the systemic and coronary hemodynamic effects of dexmedetomidine "except the effect on the LVEDP, without affecting dexmedetomidine's sympatholytic effect.

\section{Hemodynamic effects of dexmedetomidine}

The results on the systemic and coronary hemodynamic effects of dexmedetomidine in the present study were consistent with previous studies. ${ }^{13-16}$ Dexmedetomidine decreased heart rate, cardiac output, $\mathrm{dP} / \mathrm{dt}_{\text {max }}$, coronary blood flow, and the circulating level of plasma catecholamines and increased mean arterial pressure, LVEDP and the systemic and coronary vascular resistance.

These results can be explained by activation of central alpha $a_{2}$-adrenoreceptors, causing a reduction in sympathetic drive, ${ }^{17-18}$ a presynaptically induced decrease in 
norepinephrine release at the sympathetic neuron terminals, and activation of postsynaptic alpha $a_{2}$-adrenergic receptors on vascular smooth muscle cells. ${ }^{3}$

Reduction of cardiac output has been reported for most alphaz-adrenergic agonists. 19-22 There are several possible reasons for the decrease in cardiac output, including a reduction in heart rate, an increase in afterload, ${ }^{19}$ coronary vasoconstriction with reduction of oxygen delivery ${ }^{13}$ as well as a decrease in sympathetic tone. No direct negative inotropic effects from dexmetomidine have been observed in isolated canine hearts ${ }^{23}$ or in ferret papillary muscle. ${ }^{24}$

In the present study, sequential doses of dexmedetomidine were administered to the same animals. A potential limitation of this experimental design is that we were not able to study drug-related effects versus time-related effects. Nevertheless, previous studies have already shown that, in dogs, most of the peripheral vasoconstrictive effects of lower doses of dexmedetomidine $\left(0.5-1 \mu \mathrm{g} \cdot \mathrm{kg}^{-1}\right)$ disappear quickly within minutes after its administration, while the central sympatholytic effects remain much longer. ${ }^{13,25}$ Higher doses of dexmedetomidine $\left(5 \mu \mathrm{g} \cdot \mathrm{kg}^{-1}\right)$ cause prolonged vasoconstriction for several hours. ${ }^{8}$

Peripheral vasoconstrictive effects may thus dominate the central effects under such circumstances as high dosage, initially following a rapidly given intravenous bolus and when the pre-existing sympathetic tone is low and not much room is available for the central sympatholytic effects of these drugs. ${ }^{19,25,26}$ Because we wanted to study the vasodilatory effects of isradipine, we created such a vasoconstrictive condition in the present study: a high dose of $10 \mu \mathrm{g} \cdot \mathrm{kg}^{-11}$ dexmedetomidine was rapidly administered in anesthetized dogs, a model known to exert powerful alpha-adrenergic vasoconstriction. ${ }^{3,20}$

\section{Isradipine-induced vasodilation}

The calcium channel blocker isradipine has been used for treatment of hypertension. 27 The decrease in blood pressure after the administration of calcium channel blockers is probably due to relaxation of the vascular smooth muscle, secondary to decreased entry of calcium into the cell via voltage-dependent channels, ${ }^{28,29}$ the same channel which is involved in transmission of the vasoconstrictive signal from alpha2 adrenergic receptor activation. ${ }^{5,6}$ In the present experiment, isradipine could completely antagonize the vasoconstrictive effects of dexmedetomidine. This indicates that calcium influx plays a major role in dexmedetomidine's mediated vasoconstriction, as was previously shown for other alpha 2 agonists. ${ }^{30}$ In the present experiment, the reduction in cardiac output after dexmedetomidine could be restored by isradipine. Because isradipine is a powerful systemic as well as coronary vasodilator, and also because isradipine, probably by baroreceptor activation, increased heart rate, our experiments do not permit a firm conclusion as to the cause of the restoration of cardiac output. Although isradipine decreased cardiac afterload and increased coronary perfusion, there was still a reduction in cardiac function after the administration of isradipine, as expressed by the increased LVEDP. The decrease in central sympathetic outflow from the central nervous system therefore appears to be 
also an important mechanism for the decrease in cardiac function after dexmedetomidine.

When discussing interactions between alphar-adrenergic agonists and calcium channel blockers, it should be acknowledged that the hypnotic-anesthetic action of alpha agonists is influenced by the activation/gating of central calcium channels. 31 Calcium channel blockers therefore seem to facilitate the hypnotic-anesthetic effect of dexmedetomidine. 31

\section{Extrapolation to humans}

There is strong evidence to suggest a species-dependent heterogeneity of alpha ${ }^{*}$ adrenoreceptors. 8,32 There also appear to be species differences in the cardiovascular effects of alpha $\mathrm{2}_{2}$ adrenorececeptor agonists. Alpha ${ }_{2}$-adrenoreceptor agonists in dogs have been shown to result in an increase in blood pressure which is not followed by a decrease as occurs in humans. This would suggest that stimulation of the canine and human vascular alpha 2 -adrenoreceptor does not produce the same result. That is, in dogs a lengthy period of vasoconstriction occurs such that the centrally-mediated reduction in sympathetic tone does not result in reduced blood pressure. ${ }^{8}, 19,25$ The overall effect in humans is a centrally mediated lowering of the blood pressure with a decrease in heart rate. 20 However, the administration of dexmedetomidine in human volunteers caused a biphasic hemodynamic response: the rapid ( $2 \mathrm{~min}$ ) intravenous administration of dexmedetomidine 1 and $2 \mu \mathrm{g} \cdot \mathrm{kg}^{-1}$ produced a transient increase in MAP, having a peak effect at $3 \mathrm{~min}$ and lasting approximately $11 \mathrm{~min}$, whereas the systemic vascular resistance doubled. Thereafter, MAP remained below baseline levels for at least 5 hours. ${ }^{20}$ Presently, it is generally accepted that a continuous infusion of alpha $_{2}$ agonists might prevent this initial pressor phase and is perhaps the more appropriate way for administering these drugs to humans. ${ }^{33,34}$ Nevertheless, the present investigation not only showed that isradipine was able to reverse the peripheral hemodynamic effects of dexmedetomidine, but also that, after stopping the 15 min infusion of this short-acting calcium channel blocker, most of the initial hemodynamic side-effects of dexmedetomidine had already dissipated. Alphaz_adrenoreceptor agonists, as anesthetic adjuvants, appear to be especially beneficial in the high-risk cardiovascular population, because of their central sympatholytic and hemodynamic stabilizing properties. ${ }^{34}$ If peripheral, potentially undesirable, vasoconstrictive effects of alpha 2 agonists would occur initially after their administration, the present study indicates that the short-lasting administration of a short-acting calcium antagonist like isradipine could probably be used to rapidly antagonize these vasoconstrictive effects, while having no effect on the central sympatholytic and anesthetic qualities of the alpha 2 agonist. ${ }^{31}$ More investigations in humans are necessary to further study these interactions between alpha 2 agonists and calcium channel blockers.

The authors conclude that isradipine could alleviate the peripheral, potentially undesirable, hemodynamic actions of dexmedetomidine while having no effect on it's central sympatholytic properties. 


\section{Acknowledgements}

This work was supported in part by Orion Corporation, Farmos, Turku, Finland. We thank Ruud Kruger, Theo Van Der Nagel and Jo Habets for expert technical assistance. 


\section{REFERENCES}

1. Maze $M$. Tranquili $W$. Alpha 2 Adrenoreceptor agonists: defining the role in clinical anesthesia, Anesthesiology 1991: 74:581-605

2. Kobinger W. Central alpha-adrenergic systems as targets for hypotensive drugs. Rev Physiol Biochem Pharmacol 1978: 81: $39-100$

3. Heusch $G$, Deussen $A$, Schipke HO. Thamer $V$. Alphal and alphaz-adrenoreceptor mediated vasoconstriction of large and small canine arteries in vivo. J Cardiovasc Pharmacol 1984: 6: 961-968

4. Fleckenstein-Grum $G$, Frey $M_{n}$ Fleckenstein $A$. Calcium antagonists: mechanisms and therapeutic USes. TIPS 1984: 5: 283-287

5. Van Meel JCA. De Jonge A, Kalkman HO, Wilfert B, Timmermans PBMWM, Van Zwieten PA. Vascular smooth muscle contraction initiated by postsynaptic alphaz-adrenoreceptor activation is induced by an influx of extracellular calcium. Eur J Pharmacol 1981: 69: 205-208

6. Timmermans PBMMM, ChiL AT, Thoolen MJMC. Calcium handling in vasoconstriction to stimulation of alpha1-and alpha2-adrenoreceptors. Can J Physiol Pharmacol 1986: 65:1649-1657

7. Bari $F$. Horvath $G$. Benedek $G$. Dexmedetomidine-induced decrease in cerebral blood flow is attenuated by verapamil in rats: a laser Doppler study. Can J Anaesth 1993: 40(8): 747-754

8. Bloor $\mathrm{BC}$. Frankland $\mathrm{M}$, Alper $\mathrm{G}$, Raybould D, Weitz J, Shurtiff M. Hemodynamic and sedative effects of dexmedetomidine in dog. A Pharmacol Exp Ther 1992: 263: 690-697

9. Egerton K, Van den Berg EK, Dehmer GJ. Acute hemodynamic effects of intravenous isradipine. Am J Cardiol 1988: 61: 1102-1105

10. Mauser $M$, Voelker $W$, Karsch $K$, Seipel $L$. PN 200-110, a calcium antagonist with less negative inotropic properties compared to nifedipine. Eur Heart $\Perp 1987: 8$ (suppl 2): 170

11. Hoppeler $H H$, Hess $O M$. Hug $R_{r}$ Turina J Krayenbuhl HP: Effect of isradipine on left ventricular relaxation and diastolic tilling. J Cardiovasc Pharmacol 1990: 15 (suppt 1): $\$ 79$-S83

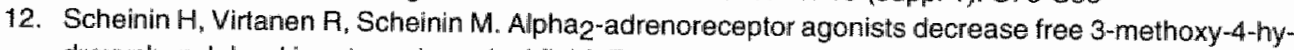
droxyphenylglycol in rat cerebrospinal fluid. Eur J Pharmacol 1986: 123:115-121

13. Flacke WE , Flacke JW" Bloor BC, Mclntee DF, Sagan M. Effects of dexmedetomidine on systemic and coronary hemodynamics in the anesthetized dog. J Cardiothorac Vasc Anesth 1993: 7: 41-49

14. Vickery RG, Sheridan BC, Segall IS, Maze M. Anesthetic and hemodynamic effects of the stereoisomers of medetomidine, an alpha2-adrenergic agonist, in halotane-anesthetized dogs. Anesth Analg 1988: $67: 611-615$

15. Roekaerts PMHJ, Prinzen FW, De Lange S. Coronary vascular effects of dexmedetomidine during reactive hyperemia in the anesthetized dog. J Cardiothorac Vasc Anesth 1996: 10 (5): 619-626

16. Roekaerts PMHJ, Prinzen FW, de Lange S. Beneficial effects of dexmedetomidine on ischaemic myocardium of anaesthetized dogs. Br J Anaesth 1996: 77:427-429

17. Unnerstall JR, Kopajtic TA, Kuhar MJ. Distribution of alpha 2 agonist binding sites in the rat and human central nervous system: analysis of some functional, anatomic correlates of the pharmacologic effects of clonidine and related adrenergic agents. Brain Res Rev 1984: 7:69-101

18. Isaac $\mathrm{L}$. Clonidine in the central nervous system: site and mechanism of hypotensive action. I Cardiovasc Pharmacol 1980: 2: S5-S19

19. Algeo S, Appleton CP, Martin GV. Effects of alphaz-adrenergic stimulation with UK 14,304-18 an the heart and peripheral circulation of intact dogs. $J$ Cardiovase. Pharmacol 1985: 7: 1055-1064

20. Bloor BC, Ward DS, Belleville JP, Maze M. Effects of intravenous dexmedetomidine in humans. Anesthesiology 1992: 77: 1134-1142

21. Flacke JW, Flacke WE, Bloor BC, Mclntee DF. Hemodynamic effects of dexmedetomidine, an alpha 2 -adrenergic agonist ${ }_{\text {in }}$ autonomically denervated dogs. J Cardiovasc Pharmacol 1990: 16: 
22. Roekaerts PMHId, Prinzen FW, Wiligers HMM, de Lange S. The effects of alphaz-adrenergic stimulation with mivazerol on myocardial blood flow and function during coronary artery stenosis in anesthetized dogs. Anesth Analg 1996: 82: 702-711

23. Flacke WE, Flacke JW, Blow KD, Mclitee DF, Bloor BC. Effect of dexmedetomidine, an alphaz-adrenergic agonist, in the isolated heart. $\rfloor$ Cardiothorac Vasc Amesth 1992: 6: $418-423$

24. Housmans PR. Effect of dexmedetomidine on contractility, relaxation, and intracellular calcium transients in isolated myocardium. Anesthesiology 1990: 73: 919-922

25. Schmeling WT, Kampine JP, Roerig DL, Wartier DC. The effects of the stereoisomers of the alpha2-adrenergic agonist medetomidine on systemic and coronary hemodynamics in conscious dogs. Anesthesiology 1991: 75: 499-511

26. Proctor LT, Schmeling WT, Roerig D, Kampine JP, Warttier DC. Oral dexmedelomidine attenuates hemodynamic responses during emergence from general anesthesia in chronically instrumented dogs. Anesthesiology 1991: 74: 108-114

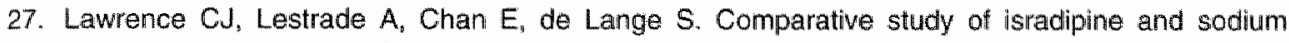
nitroprusside in the control of hypertension in patients foilowing coronary artery-bypass surgery. Acta Anaesthesiol Scand 1993: 37 (S 99): 48-52

28. Braunwald E. Mechanism of action of calcium channel blocking agents. N Engl J Med 1982: 307 : $1618-1627$

29. Vaghy PL, Willaims JS, Schwartz A. Receptor pharmacology of calcium entry blocking drugs. Am J Cardial 1987: 59: 9A-17A

30. Tirmmermans PBMWM, Thoolen MJMC, De Jonge A, Wilffert B, Van Zwieten PA. Calcium entry and alpha-adrenoreceptor-induced wasoconstriction in vivo and in vitro. In Alpha-adrenoreceptor blockers in cardiovascular diseases. Edited by H. Refsum and O.D. Mjos. Churchill Livingstone, London and New York, 1985: 30-50

31. Horvath $G$, Szikszay M, Benedek $G$. Calcium channels are involved in the hypnotic-anesthetic action of dexmedetomidine in rats. Anesth Analg 1992: 74: 884-888

32. Jalonen $J$, Halkola $L$, Kuttila K, Perttila d, Rajalin A, Savunen $T$ et al. Effects of dexmedetomidine on coronary hemodynamics and myocardial oxygen balance. J Cardiothorac Vasc Anesth 1995: 9(5): 519-524

33. Dyck JB, Maze $M$, Haack $C$, Vuorilehto $L$, Shafer $S L$. The pharmacokinetics and hemodynamic effects of intravenous and intramuscular dexmedetomidine hydrochloride in adult human volunteers. Anesthesiology 1993: 78: 813-820

34. Takke P, Li J, Jain U, Leung J, Drasner K, Hollenberg Met all. Effects of perioperative dexmedetomidine infusion in patients undergoing vascular surgery. Anesthesiology 1995: 82:620-633 
$\therefore$ 
CHAPTER 5

Reversal of the systemic and coronary vasoconstrictive effects of dexmedetomidine by the purinoceptor agonist ATP

\author{
P.M.H.J. Roekaerts \\ C.J. Lawrence \\ F.W. Prinzen \\ S. de Lange
}




\section{Reversal of the systemic and coronary vasoconstrictive effects of dexmedetomidine by the purinoceptor agonist ATP}

\section{ABSTRACT}

The specific alpha $a_{2}$-adrenoreceptor agonist dexmedetomidine has central sympatholytic and peripheral vasoconstrictive effects. Dexmedetomidine can cause coronary vasoconstriction and can reduce cardiac function. We investigated whether these two effects can be blocked or reversed by the purinoceptor agonist ATP and by the alpha ${ }_{2}$-adrenoreceptor antagonist atipamezole.

In halothane-anesthetized dogs, two sequential doses of $2 \mu \mathrm{g} \cdot \mathrm{kg}^{-1}$ dexmedetomidine decreased heart rate, cardiac output, and $\mathrm{dP} / \mathrm{dt}_{\text {max }}$ and increased mean arterial pressure, left ventricular end-diastolic pressure (LVEDP) and the systemic and coronary vascular resistance. After the first dexmedetomidine dose, coronary blood flow decreased by $54 \%$ and myocardial oxygen extraction increased by $28 \%$. Cardiac function, expressed as the ratio of left ventricular stroke work (LVSW) and LVEDP, decreased by approximately $50 \%$ while the plasma concentration of norepinephrine decreased as well. ATP infusion $\left(0.74\right.$ and $2.20 \mathrm{mg} \cdot \mathrm{kg}^{-1} \cdot \mathrm{min}^{-1}$ after the first and the second dose of dexmedetomidine, respectively) restored LVEDP, systemic vascular resistance and systemic oxygen extraction to baseline values and increased coronary blood flow by $170 \%$ compared to baseline, which resulted in a $60 \%$ drop in myocardial oxygen extraction. The LVSWILVEDP ratio however recovered onily partially while plasma catecholamine levels remained below baseline values. Atipamezole reversed systemic and coronary hemodymamic variables as well as plasma catecholamines to baseline values.

Since the administration of ATP only partially reversed the reduction in cardiac function induced by dexmedetomidine, the authors conclude that the reduction in cardiac function is mainly due to dexmedetomidine's sympathetic inhibitory effect rather than to it's peripheral vasoconstrictive effect.

Key words: Alphaz-adrenergic agonists, dexmedetomidine, ATP, atipamezole, cardiac function

\section{INTRODUCTION}

Previous studies have demonstrated the ability of alpha $a_{2}$-adrenergic agonists to alter systemic hemodynamics by activation of alpha 2 -adrenergic receptors in the brain. 
This results in diminished sympathetic tone and a decrease in arterial blood pressure and heart rate. ${ }^{31}$ Stimulation of these receptors in the central nervous system also produces a sedative-hypnotic effect and reduces the requirements for anesthetics and analgesics during general anesthesia. Therefore, these agents possess usefull properties as adjuncts for general anesthesia. ${ }^{18}$

However, a potential probiem might be the concomitant peripheral vasoconstriction by postsynaptic alphaz-adrenoreceptor stimulation. Activation of these peripheral alpha ${ }_{2}$-adrenergic receptors may result in significant alterations in systemic and coronary hemodynamics. $4,12,13,24$ Studies on the effects of dexmedetomidine, a highly selective alpha, -adrenoreceptor agonist, $6,27,32$ on coronary blood flow yielded conflicting results. Savola et al found no effect of dexmedetomidine on coronary blood flow using positron emission tomography in enflurane-anesthetized dogs.25 Schmeling and coworkers also reported no change in coronary blood flow after dexmedetomidine in awake dogs. ${ }^{28}$ In contrast, Flacke and colleagues reported a transient reduction of approximately $20 \%$ in coronary blood flow in enflurane-anesthetized dogs. ${ }^{10}$ Studies in halothane-anesthetized dogs in our laboratory also showed a significant reduction of myocardial blood flow. ${ }^{20}$

Dexmedetomidine, like other alpha 2 agonists, causes diminished cardiac function. ${ }^{1,3,7,21}$ It was shown that dexmedetomidine had no direct myocardial depressant effect, either in isolated papillary muscles ${ }^{15}$ or in the isolated canine heart. ${ }^{9}$ Two possible explanations for the diminished cardiac function after alpha $a_{2}$ agonists have been raised, none of which are fully supported by previous studies. The sympatholytic action of alpha 2 agonists could induce a reduction in cardiac function, but this does not explain why a diminished cardiac function was observed in autonomically blocked dogs. ${ }^{8}$ Flacke and coworkers suggested that limited myocardial oxygen supply due to coronary vasoconstriction could lead to decreased cardiac function. ${ }^{8} \| f \mathrm{so}$, it is not clear why no reduction in cardiac function was found in isolated, blood perfused, dog hearts. ${ }^{9}$ Therefore, these theories require further investigation.

The present experiments were designed to evaluate whether the systemic and coronary vasoconstriction of dexmedetomidine could be corrected by the purinoceptor agonist ATP, a potent vasodilator, ${ }^{11,23,30}$ and whether the observed changes in cardiac function, could be explained by changes in myocardial oxygen extraction and/or plasma catecholamine levels.

\section{MATERIAL AND METHODS}

\section{General Preparation}

The studies were approved by the local animal care committee.

Eight mongrel dogs of either sex, weighing $29.4 \pm 1.3 \mathrm{~kg}$ (range 24-36) (mean \pm SEM) were premedicated with fentanyl $10 \mu \mathrm{g} \cdot \mathrm{kg}^{-1} \mathrm{IM}$. Anesthesia was induced 40 min later with thiopental. The dose required for unconsciousness was $16 \pm 1.4$ $\mathrm{mg} \cdot \mathrm{kg}^{-1}$ (mean $\pm \mathrm{SEM}$ ). The dogs were intubated and mechanically ventilated to 
normocapnia with halothane and $67 \%$ nitrous oxide in oxygen. During the subsequent surgical preparation, supplemental fentanyl and/or thiopental were given as needed to maintain surgical anesthesia. Total supplemental doses were $4.1 \pm 2.4 \mu \mathrm{g} \cdot \mathrm{kg}^{-1}$ and $4.3 \pm 2.0 \mathrm{mg} \cdot \mathrm{kg}^{-1}$, respectively (mean \pm SEM). ECG electrodes were placed, and catheters for fluid administration and injection/infusion of drugs were inserted into the femoral vein, and into the superior vena cava via the right internal jugular vein. Two 7F Millar microtransducer-tipped catheters were placed via a femoral artery, one in the central aorta and one in the left ventricle. A Swan-Ganz oximetric catheter (Edwards Oximetry TD Catheter $93 \mathrm{~A} / 731 \mathrm{H}$ ) was floated into the pulmonary artery through the right internal jugular vein. The chest was entered through a left thoracotomy incision; the heart was exposed, and an electromagnetic 2 or $2.5 \mathrm{~mm}$ blood flow sensor (Skalar transflow 601 system, Module MDL 400) was placed around the left anterior descending coronary artery. A small catheter for blood sampling was introduced into the great cardiac vein and advanced retrogradely until it was positioned in the region to become ischemic. After instrumentation was discontinued, halothane administration was stopped, nitrous oxide was continued, and the animals were allowed to stabilize. No muscle relaxants were used. The experimental protocol was begun approximately 30 minutes later $(131 \pm 6$ min after induction; mean $\pm S E M)$.

\section{Measurements}

$E C G$, heart rate, phasic and mean arterial blood pressure, left ventricular pressure and its maximal rate of rise ( $\left.\mathrm{LVdP} / \mathrm{dt} t_{\max }\right)$, left ventricular end-diastolic pressure (LVEDP), phasic and mean flow in the left anterior descending coronary artery, and oxygen saturation in the pulmonary artery $\left(\mathrm{S}_{\mathrm{V}} \mathrm{O}_{2}\right)$ were measured continuously. Pressures were transduced and amplified with Philips amplifiers $P R 9330$ and $\mathrm{S}_{\mathrm{v}} \mathrm{O}_{2}$ was determined and recorded continuously with an Edwards Sat 1 combined cardiac output and $\mathrm{O}_{2}$ saturation computer and recorder. Mean arterial pressure, left ventricular pressure, LVdP/dt $\max$, LVEDP, coronary blood flow, and ECG were recorded continuously on a Schwarzer 10 channel RE 412 recorder. At each sampling point, cardiac output was determined by thermodilution in triplicate, and arterial, mixed venous and coronary venous blood samples were drawn at the same times (see experimental protocol). Blood gases ( $\mathrm{ABL} 3$ Radiometer), oxygen saturation and hemoglobin (OSM 2 Radiometer, calibrated for dog blood) were measured immediately in blood from all three sites. Plasma catecholamines were determined later by HPLC on arterial blood. ${ }^{26}$ Systemic vascular resistance, coronary vascular resistance [(mean arterial pressure -LVEDP) - coronary blood flow $\left.{ }^{-1}\right]$, arterial, mixed venous, and coronary venous oxygen contents $\left[(\mathrm{Hb} \cdot 1.39 \cdot\right.$ saturation $\left.)+\left(\mathrm{PO}_{2} \cdot .003\right)\right]$, systemic and myocardial oxygen extraction [(arterial - mixed venous) and (arterialcoronary venous) oxygen contents, respectively], and myocardial regional oxygen uptake (coronary blood flow - myocardial oxygen extraction) were calculated. The ratio of left ventricular stroke work (=systolic left ventricular pressure-stroke volume) and LVEDP was utilized as an index of cardiac function. Stroke volume was calculated
as cardiac index/heart rate. 
After baseline 1 measurements were taken, ATP was infused at a rate of $0.28 \pm 0.05$ $\mathrm{mg} \cdot \mathrm{kg}^{-1} \cdot \mathrm{min}^{-1}$ for $5 \mathrm{~min}$. After the measurements were performed, the infusion was stopped and 15 min was allowed for hemodynamic stabilization to a second baseline. Subsequently dexmedetomidine $2 \mu \mathrm{g} \cdot \mathrm{kg}^{-1}$, dissolved in $20 \mathrm{ml}$ saline, was administered slowly iv over $5 \mathrm{~min}$. Measurements were repeated $15 \mathrm{~min}$ after the end of the administration. Thereafter, an infusion of ATP was given at a rate necessary to return cardiac output and LVEDP to baseline levels. When conditions were steady at this level, measurements were repeated, representing the effect of the combination of dexmedetomidine $2 \mu \mathrm{g} \cdot \mathrm{kg}^{-1}$ plus ATP. One hour after the first dose of dexmedetomidine $2 \mu \mathrm{g} \cdot \mathrm{kg}-1$, a second dose of $2 \mu \mathrm{g} \cdot \mathrm{kg}-1$ dexmedetomidine was added slowly iv over 5 min while the ATP infusion was continued. To maintain cardiac output at baseline level, the rate of ATP infusion had to be adjusted. After measuring the effects of the combined dose of dexmedetomidine plus high dose ATP, the ATP infusion was discontinued and, $15 \mathrm{~min}$ after the end of the second dexmedetomidine administration, measurements were repeated, representing the effect of the two sequential doses of dexmedetomidine in the absence of ATP.

Finally, atipamezole, a specific pharmacological alpha $a_{2}$ antagonist, was given in a bolus dosis of $0.15 \mathrm{mg} \mathrm{kg}^{-1}$, and final measurements were taken at the time of peak blood pressure change. Since atipamezole antagonized also the central anestheticpotentiating effect of dexmedetomidine, the level of anesthesia became noticeably lighter and some dogs began to move. In these cases, thiopental was given IV promptly prior to the post-atipamezole measurements.

\section{Statistical analysis}

The entire series of sampling points was analysed by means of GLM ANOVA, or by the non-parametric Friedman test if the data were not normally distributed. Differences between individual points were identified by the Fisher least significant difference (LSD) test. All data are expressed as mean \pm SEM. $P<0.05$ was considered significant.

\section{RESULTS}

\section{Effect of ATP}

ATP infusion increased heart rate, cardiac output, $\mathrm{dP} / \mathrm{dt}_{\text {max, }}$ LVSW/LVEDP and decreased systemic vascular resistance and mean arterial pressure (table and figure 1 \& 2). ATP also increased coronary blood flow and decreased myocardial oxygen extraction (figure 3). Fifteen minutes after the discontinuation of the ATP infusion, all measured parameters had returned to the first baseline values apart from the mean 
Table. Hemodynamic effects of ATP, dexmedetomidine, dexmedetomidine + ATP and dexmedetomidine + alipamezole

\begin{tabular}{|c|c|c|c|c|c|c|c|c|}
\hline & BL(1) & ATP 0.28 & BL (2) & DWI & $\begin{array}{c}\text { DHI } 2 * \\
\text { ATP } 074\end{array}$ & $\begin{array}{c}\text { DM } 4+ \\
\text { ATP } 220\end{array}$ & DN 4 & ATIPAM \\
\hline $\mathrm{HF}$ & $131 \pm 9$ & $170 \pm 8^{2+}$ & $141 \pm 9^{+}$ & $94 \pm 8^{i+}$ & $112 \pm 7^{*}$ & $104 \pm 9^{\circ}$ & $90 \pm 10^{\circ}$ & $171 \pm 10^{4+4}$ \\
\hline MAP & 1093 & $86 \pm 6^{i 4}$ & $116 \pm 8^{84}$ & $120 \pm 66^{i \prime}$ & $92 \pm 5^{4 *}$ & $91 \pm 5^{2}$ & $115 \pm 7^{* 4}$ & $133 \pm 11^{+}$ \\
\hline LVEDP & $5.8 \pm 0.7$ & $3.4=0.8$ & $5.3 \pm 0.6$ & $101 \pm 23^{*}$ & $5 \pm 0.8^{*}$ & $8.5 \pm 1.4$ & $11 \pm 22^{*}$ & $7.6 \pm 1.9^{4}$ \\
\hline$d P / d t_{\text {fand }}$ & $1963 \pm 89$ & $2018 \pm 113^{*+}$ & $1969 \pm 116$ & $1443 \pm 62^{x+4}$ & $1600 \pm 68^{*}$ & $1588 \pm 79^{x}$ & $1375 \pm 80^{\circ}$ & $2025 \pm 126^{+}$ \\
\hline SVR & $2240+339$ & $1325 \pm 122^{4+4}$ & $2622 \pm 374^{+}$ & $4855 \pm 533^{n+2}$ & $2262 \pm 255^{+}$ & $2460 \div 309^{17}$ & $5234 \pm 466^{* 4}$ & $3237 \pm 519^{27}$ \\
\hline CVA & $2.9 \pm 0.6$ & $1.2 \pm 0.2$ & $3.3 \pm 0.7$ & $12 \pm 3.9^{r 4}$ & $1.4 \pm 0.3^{4}$ & $1.1 \pm 02^{14}$ & $116 \pm 4^{4 *}$ & $3.40 .7^{+}$ \\
\hline $\mathrm{VO}_{2}$ & $4.6 \pm 0.4$ & $6.1 \pm 0.6^{\circ}$ & $4.9 \pm 0.5$ & $2.4 \pm 0.6^{* 3}$ & $4.9 \pm 0 . t^{*}$ & $4.4 \pm 0.7^{7 t}$ & $2.4 \pm 0.7^{* *}$ & $5.6 \pm 1.3^{*}$ \\
\hline NEPI & $150 \pm 33$ & $211 \pm 47$ & $150 \pm 41$ & $31 \pm 7^{*+1}$ & $47 \pm 17^{*}$ & $24 \pm 7^{*}$ & $16 \pm 3^{\circ}$ & $207 \pm 64^{*}$ \\
\hline EF & $333 \pm 110$ & $344 \pm 115$ & $392 \pm 167$ & $87 \pm 40$ & $99 \pm 54$ & $56 \pm 24^{4}$ & $38 \pm 15^{\circ}$ & $582 \pm 381^{+}$ \\
\hline
\end{tabular}

* = significantly different from baseline (1) value; $+=$ significantly different from preceding value; significantly different from DM alone; mean \pm sem data; $n=8 ; P<0.05 ; A T P$ in $\mathrm{mg} \cdot \mathrm{kg}^{-1} \cdot \mathrm{min}^{-1} ;$; $\mathrm{DM}$ in $\mu \mathrm{gg} \cdot \mathrm{kg}^{-1}$; $D M 4=D M 2+2$ abbreviations: $B L=$ baseline; $D M=$ dexmedetomidine; atipam = atipamezole; $H R=$ heart rate in beats $m i n-1 ; M A P=$ mean arterial pressure in $m \mathrm{mHg}_{*} \mathrm{LVEDP}=$ left ventricular end-diastolic pressure in $\mathrm{mmHg}$; $\mathrm{dP} / \mathrm{dt} \mathrm{t}_{\max }=$ first derivative of $\mathrm{LV}$ pressure in $\mathrm{mmHg}^{-1}$; $\mathrm{SVH}=$ systemic vascular resistance in dyne $\cdot \mathrm{s} \cdot \mathrm{cm}^{-5}$; $\mathrm{CVR}=$ coronary vascular resistance in $\mathrm{mmHg}^{-1} \mathrm{ml}^{-1} \cdot \mathrm{min}^{-1} ; \mathrm{VO}_{2}=$ myocardial regional oxygen uptake in $\mathrm{ml} \cdot \mathrm{min}^{-1} ; \mathrm{NEPI}=$ norepinephrine in $\mathrm{pg} \cdot \mathrm{ml}^{-1} ; \mathrm{EPI}=$ epinephrine in $\mathrm{pg} \cdot \mathrm{ml}^{-1}$.

arterial pressure. Mean arterial pressure at baseline 2 was slightly, but significantly, higher than at baseline 1 .

\section{Effect of the first dose of DM}

Administration of $2 \mu \mathrm{g} \cdot \mathrm{kg}^{-1}$ dexmedetomidine decreased heart rate, cardiac output, and $\mathrm{dP} / \mathrm{dt}_{\max }$ and increased mean arterial pressure, LVEDP and the systemic and coronary vascular resistance (table and figure $1 \& 2$ ). Coronary blood flow decreased by $54 \%$ and myocardial oxygen extraction increased by $28 \%$ (figure 3 ). Cardiac function, expressed as the LVSW/LVEDP ratio decreased by approximately $50 \%$ while the plasma concentration of norepinephrine decreased as well.

\section{Effect of the first dose of DM in combination with ATP}

After these measurements had been performed, a second ATP infusion was begun and titrated to attain hemodynamic conditions close to the pre-dexmedetomidine baseline. These were in fact realized for cardiac output, LVEDP, systemic vascular resistance and systemic oxygen extraction. LVSW/LVEDP was fully restored as was mixed venous oxygen saturation. The infusion rate of ATP required was $0.74 \pm 0.1$ $\mathrm{mg} \cdot \mathrm{kg}^{-1} \cdot \mathrm{min}^{-1}$. Changes in heart rate, $\mathrm{dP} / \mathrm{dt}_{\max }$, and plasma catecholamines were not significant. Coronary blood flow increased five fold compared to the pre-ATP timepoint, and there was an increase of $123 \%$ compared to baseline. Myocardial
oxygen extraction was decreased accordingly. 


\section{Cardilac output}

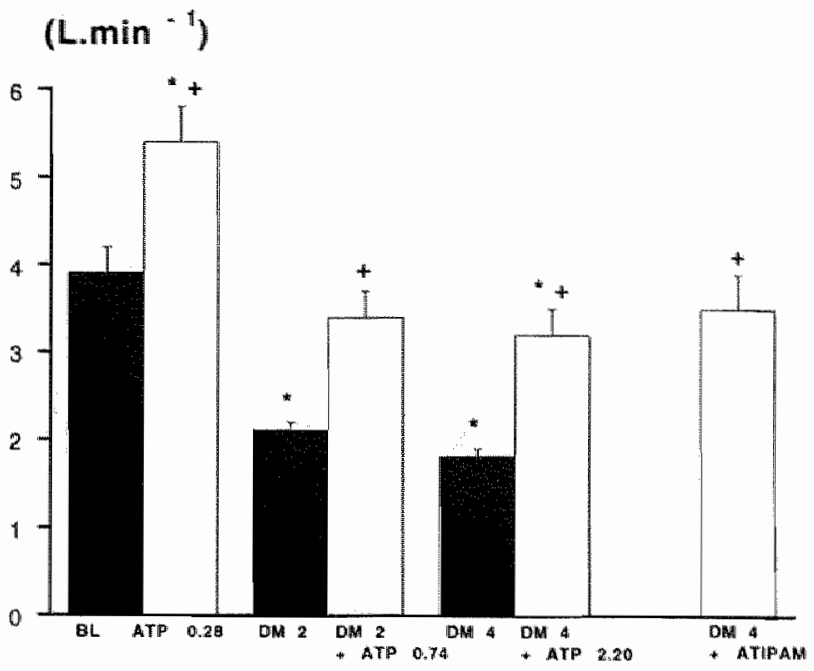

\section{Arterial - mixed venous oxygen content $\left(\mathrm{ml}^{\mathrm{d}} \mathrm{ll}^{-1}\right)$}

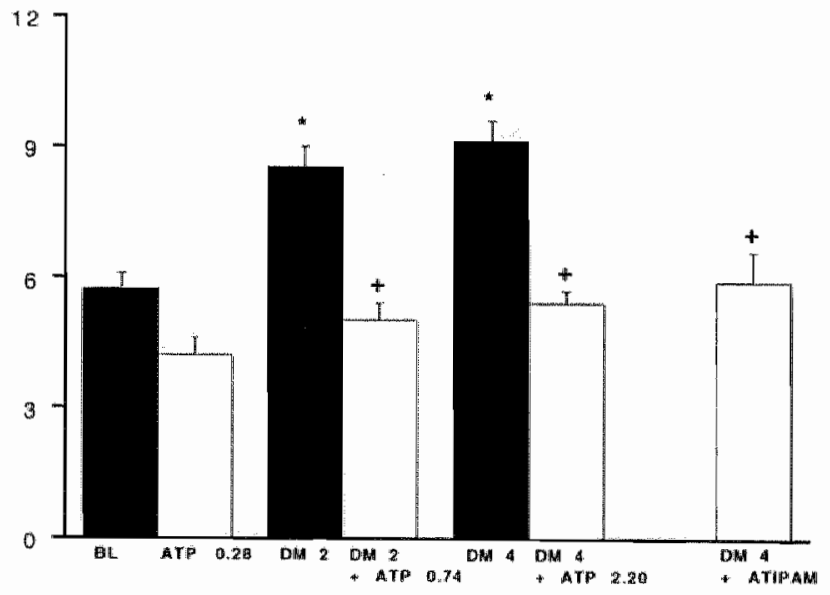

Figure 1. Cardiac output (upper) and arterial -mixed venous oxygen content (lower)

mean \pm sem data; $n=8 ;{ }^{*}=$ significantly different from $B L$ value $(P<$ $0.05)_{*}+=$ significantly different from preceding $B L$ or $D M$ value $(P<$ $0.05)$; abbreviations: $B L=$ baseline; $A T P=$ adenasine triphosphate; $\mathrm{DM}=$ dexmedetomidine; ATIPAM = atipamezole; $\mathrm{DM}$ in $\mu \mathrm{g} \cdot \mathrm{kg}^{-1} ;$ ATP

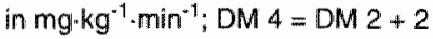



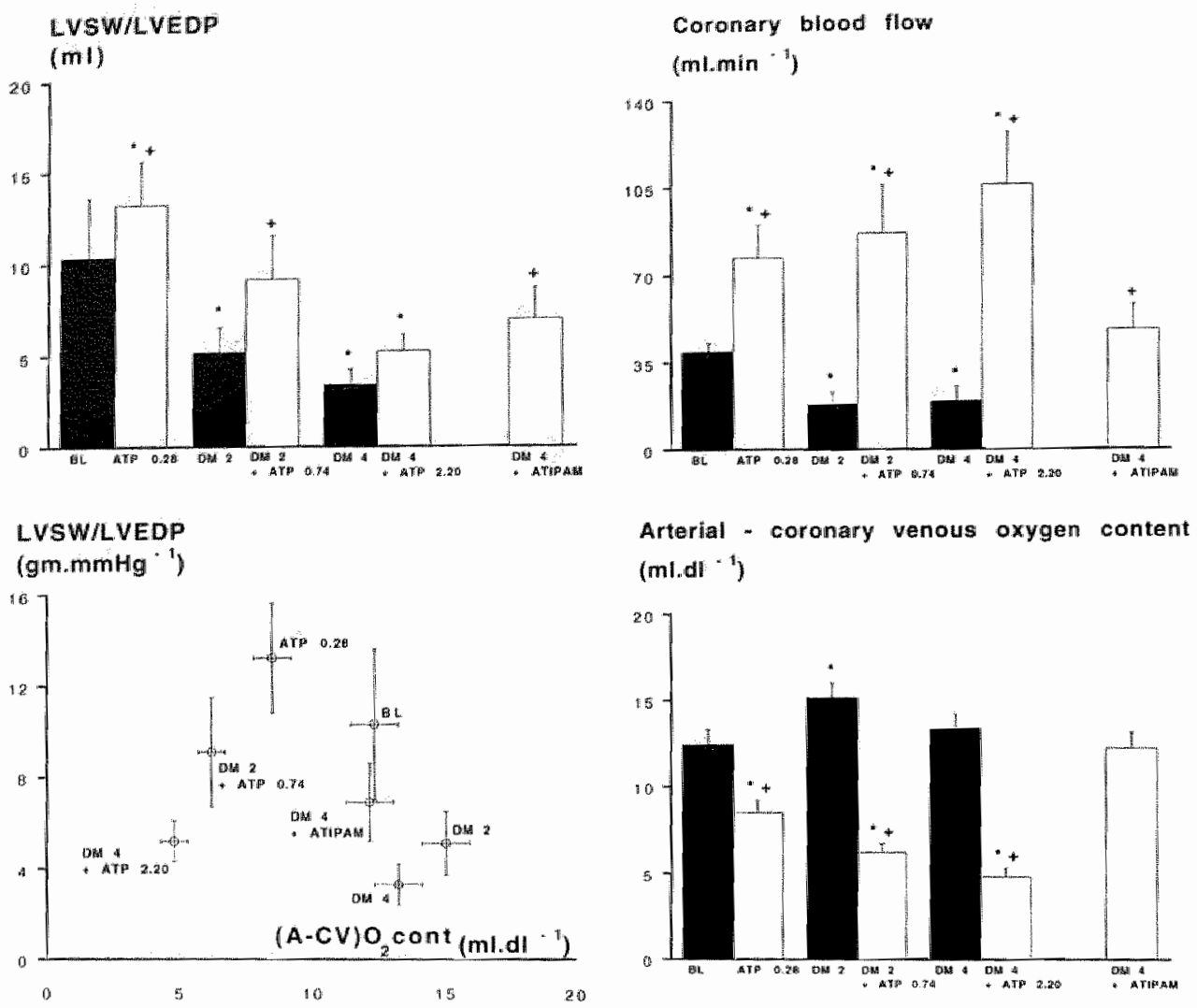

Figure 2. Left ventricular stroke work / left ventricular end-diastolic pressure ratio (upper) and LVSW/LVEDP ratio plotted against the arterial cononary wenous oxygen content (lower)

mean tsem data; $n=8 ;{ }^{*}=$ significantly different from $\mathrm{BL}$. vaiue $\left(\mathrm{P}^{\prime}<0.05\right) ;+=$ significantly different from preceding $B L$ or DM value $(P<0.05)$; Abbreviations: $B L=$ baseline: $A T P=$ adenosine triphosphate: $\mathrm{DM}=$ dexmedetomidine; ATIPAM $=$ atipamezole; DM in $\mu \mathrm{gg} \cdot \mathrm{kg}-1$; ATP in $\mathrm{mg} \cdot \mathrm{kg}-1 \cdot \mathrm{min}-1$;

Figure 3. Coronary blood flow (upper) and arterialcoronary venous oxygen content (lower)

mean \pm sem data; $n=8 ;{ }^{*}=$ significantly different from $B L$ value $(P<0.05) ;+=$ significantly different from preceding $B L$ or $D M$ value $(P<0.05)$; Abbreviations: $B L=$ baseline; $A T P=$ adenosine triphosphate; $\mathrm{DM}=$ dexmedetomidine; ATIPAM = atipamezolle; DM in $\mu \mathrm{g} \cdot \mathrm{kg}-1$; ATPin $\mathrm{mg} \cdot \mathrm{kg}-1 \cdot \mathrm{min}-1$; $\mathrm{DM} 4=\mathrm{DM} 2+2$

DM $4=$ DM $2+2$ 
When a second dose of $2 \mu \mathrm{g} \cdot \mathrm{kg}^{-1}$ dexmedetomidine was given over $5 \mathrm{~min}$, the ATP infusion rate had to be increased to $2.2 \pm 0.3 \mathrm{mg} \cdot \mathrm{kg}^{-1} \cdot \mathrm{min}^{-1}$ in order to maintain near baseline conditions. This was achieved for LVEDP, systemic vasular resistance and systemic oxygen extraction. Heart rate, cardiac output and $\mathrm{dP} / \mathrm{dt}_{\max }$ were between baseline levels and the values seen during the first infusion of dexmedetomidine. Plasma epinephrine level was decreased and the plasma norepinephrine level tended to decrease even further. Regional coronary blood flow, however, increased still by another $21 \%$ compared to ATP alone and by $170 \%$ compared to baseline. This resulted in an even greater drop in myocardial oxygen extraction. At this time, regional myocardial oxygen consumption had returned to the baseline value. The LVSW/LVEDP ratio however remained significantly below baseline value, as did arterial catecholamine levels.

\section{Effect of the first and second dose of DM}

After discontinuation of the ATP infusion, the hemodynamic effects of dexmedetomidine reappeared. Heart rate, cardiac output, LVSW/LVEDP and $\mathrm{dP} / \mathrm{dtmax}$ were slightly lower than after the first dose of dexmedetomidine, while systemic vascular resistance was slightly higher. Catecholamine levels decreased further to very low levels.

\section{Effect of Atipamezole}

The administration of the pharmacological antagonist atipamezole precipitated reversal to baseline levels of hemodynamic variables (cardiac output, LVEDP, $\mathrm{dP} / \mathrm{dt}_{\text {max }}$, LVSW/LVEDP, coronary blood flow, coronary vascular resistance, [Art-Ven] $\mathrm{O}_{2}$, [Art-CorVen] $\mathrm{O}_{2}$, regional myocardial $\mathrm{VO}_{2}$ ) and plasma catecholamines. Heart rate and mean arterial pressure even increased above baseline values.

To illustrate a possible relationship between myocardial oxygen extraction and cardiac function, LVSW/LVEDP was plotted as a function of (A-CV) $\mathrm{O}_{2}$ content differences (figure 2, lower pannel). Compared to the baseline situation, ATP caused a left upward shift and dexmedetomidine a right downward shift of the LVSW/LVEDP... $(A-C V) \mathrm{O}_{2}$ content difference relation. Infusion of ATP after dexmedetomidine 2 $\mu \mathrm{g} / \mathrm{kg}^{-1}$ recovered LVSW/LVEDP to baseline levels, but at (A-CV) $\mathrm{O}_{2}$ contents considerably below baseline. ATP infusion after the second dexmedetomidine dose did not recover LVSW/LVEDP even though $(A-C V) \mathrm{O}_{2}$ content differences were even lower.

\section{DISCUSSION}

The results of the present investigation demonstrated that the potent vasodilator ATP could reverse the systemic and coronary vasoconstrictive effects of dexmedetomid- 
ine, but could only partially restore parameters of reduced cardiac function to baseline values. On the other hand, atipamezole, which did not increase coronary blood flow but restored catecholamine plasma levels, improved parameters of cardiac function to baselline values.

\section{Experimental set-up}

In the present experiment, we wanted to make an attempt to determine whether the reduction in cardiac function after dexmedetomidine was secondary to it's periphera! vasoconstrictive effect. Therefore, we wanted to use a vasodilator lacking negative inotropic effects. To enable repetitive measurements with and without the vasodilator, a short-acting vasodilator was needed.

We recently observed that the vasoconstrictive effect of dexmedetomidine was abolished during reactive hyperemia, a condition mainly attributed to the vasodilatory effect of adenosine. Therefore, ATP, a short acting vasodilator lacking negative inotropic effects (table, figure 1 and figure 2) was chosen to reverse the vasoconstrictive effect of dexmedetomidine. ATP is an unspecific agonist on purinoceptors and may evoke vasorelaxation due to its own action on purinoreceptors or by triggering the release of nitric oxide. ${ }^{16}$ As ATP is degraded via ADP and AMP to adenosisne via ecto- $5^{3}$-nucleotidases with each step of degradation another powerful vasodilator is formed.

The overall cardiovascular effect of alpha 2 agonists is determined by the relative preponderance of central versus peripheral effects. It was shown that the clinical dose of Dexmedetomidine $1 \mu \mathrm{g} \cdot \mathrm{kg}^{-1}$ decreased the plasma catecholamine levels and decreased heart rate, but had no effect on cardiac output or mean arterial pressure in anesthetized dogs. ${ }^{20}$ Dexmedetomidine $3 \mu \mathrm{g} \cdot \mathrm{kg}^{-1}$ also decreased cardiac output by $30 \pm 6 \%$, increased mean arterial pressure by $23 \pm 10 \%$ and increased the systemic vascular resistance by $60 \pm 9 \%, 22$ After the high dose of dexmedetomidine $10 \mu \mathrm{g} \cdot \mathrm{kg}-1$, the vasoconstrictive effects of dexmedetomidine predominated: mean arterial pressure increased by $52 \pm 7 \%$, cardiac output decreased by $60 \pm 8 \%$ and systemic vascular resistance increased by $256 \pm 10 \% .20$

For the study of the interaction between the vasodilatory effects of ATP and the vasoconstrictive effects of dexmedetomidine, we used a dose of dexmedetomidine $2 \mu \mathrm{g} \cdot \mathrm{kg}^{-1}$. As mentioned above, in this dose rangle, alpha 2 -adrenergic vasoconstriction was not maximal "but was associated with a significant increase in systemic vascular resistance and decrease in cardiac function and plasma catecholamines. The second infusion of dexmedetomidine, one hour after the first dose, was given to study the effects of ATP at even lower levels of circulating plasma catecholamines. Previous studies have shown that, in dogs, most of the peripheral vasoconstrictive effects of dexmedetomidine have disappeared one hour after its infusion, while the central sympatholytic effects remain for several hours. 2, 10,28

Atipamezole is a potent, selective and specific antagonist of both centrally and peripherally located alphaz-adrenoreceptors, with an alphaz/alpha 1 selectivity of $8526 .{ }^{33,34}$ In previous studies, $600 \mu \mathrm{g} \cdot \mathrm{kg}^{-1}$ atipamezole completely reversed the 
hemodynamic effects of $10 \mu \mathrm{g} \cdot \mathrm{kg}-1$ dexmedetomidine, 20 while $150 \mu \mathrm{g} \cdot \mathrm{kg}^{-1}$ atipamezole reversed the hemodynamic effects of $3 \mu \mathrm{g} \cdot \mathrm{kg}-1$ dexmedetomidine. ${ }^{22}$ Therefore, we chose a dose of $150 \mu \mathrm{g} \cdot \mathrm{kg}^{-1}$ of atipamezole to reverse hemodynamic parameters to baseline values after the second dose of dexmedetomidine.

Analysis of changes in cardiac function of the various combinations of these drugs is hampered by changes in preload and afterload, which are known to influence cardiac output and LV dP/dtmax. We used LVSW/LVEDP as an index of cardiac function, because it takes into account changes in various hemodynamic variables, such as stroke volume, blood pressure and LVEDP.

\section{Purinoreceptor-induced vasodilation}

In the present experimental preparation, ATP alone caused a fall in blood pressure with associated reflex baroreceptor activation. ATP increased heart rate, cardiac output, $\mathrm{dP} / \mathrm{dt}_{\max }$ and the LVSW/LVEDP ratio. While ATP restored systemic vascular resistance after dexmedetomidine to baseline values, it increased coronary blood flow significantly above baseline values. This indicates that the vasodilator effects of ATP are more pronounced in the coronary vessels than in the systemic vascular bed. While ATP restored systemic vascular resistance after dexmedetomidine to baseline values, it is possible that the distribution of cardiac output between the various organs was not the same as during baseline. Studies in our laboratory have shown that alpha 2 -adrenergic vasoconstriction occurs non uniformly in various tissues, ${ }^{19}$ whereas ATP-induced vasodilation is probably more uniformly distributed to all vascular beds.

While the intravenous administration of ATP is probably not readily applicable in the clinical situation, this study showed in any case that purinoreceptor-induced vasodilation can overcome the vasoconstrictive effects of alpha ${ }_{2}$-adrenoreceptor activation. This finding is in agreement with previous studies on the effects of adenosine and reactive hyperemia on alphar-adrenoreceptor-mediated vasoconstriction. ${ }^{14,20}$ Kitakaze and coworkers showed that alpha 2 -adrenoreceptor activation by clonidine could enhance the vasodilatory effects of adenosine released from ischemic myocardium. ${ }^{17}$ We previously reported that dexmedetomidine did not decrease blood flow in the endocardial and midmyocardial layers of the myocardium during reactive hyperemia. ${ }^{20} \mathrm{~A}$ similar mechanism of overruling of adrenergic vasoconstriction by metabolic vasodilation could also be responsible for the absence of vasoconstriction in the inner layers of ischemic myocardium after the administration of dexmedetomidine or mivazerol. 21,22

\section{Effects of dexmedetomidine on cardiac function}

Reduction of cardiac function has been reported for most alpha 2 -adrenergic agonists, both in animals and in humans. $1,3,7,21$

The central sympatholytic action of alpha 2 agonists with a reduction in inotropic support might be an important contributive factor to the reduction in cardiac function. 
This could be evidenced by the findings that dexmedetomidine had no direct myocardial depressant effect in isolated papillary muscles or in the isolated canine heart. ${ }^{9,15}$ Flacke and coworkers suggested that limited myocardial oxygen supply due to coronary vasoconstriction could induce a decrease in cardiac function. ${ }^{8}$

in the present experiment, ATP infusion after dexmedetomidine $2 \mu \mathrm{g} \cdot \mathrm{kg}^{-1}$ administration could restore LVSW/LVEDP to baseline values, with a coronary blood flow significantly higher and an oxygen extraction significantly lower than at baseline. However, under baseline conditions with normal resting coronary blood flow, ATP also increased LVSW/LVEDP to a similar extent as seen after dexmedetomidine 2 $\mu \mathrm{g} \cdot \mathrm{kg}^{-1}$. This indicates that it is not likely that the improvement in cardiac function after ATP is secondary to improved oxygen supply to the heart. Moreover, after the second dose of dexmedetomidine, ATP infusion increased coronary blood flow to very high values while the LVSW/LVEDP remained below the baseline value. So, despite potent vasodilation by ATP, cardiac function recovered only partially. Restoration of cardiac function to baseline was obtained with atipamezole, which did not increase coronary blood flow but which restored plasma catecholamine levels. Therefore, the decrease in sympathetic outflow from the central nervous system appears to be a more important mechanism for the decrease in cardiac function after dexmedetomidine than the limitation of oxygen supply.

The possibility of an ischemia-reducing effect of the ATP treatment in the present experiment is not likely. We have shown that doses of dexmedetomidine up to 10 $\mu \mathrm{g} \cdot \mathrm{kg}^{-1}$ decrease coronary blood flow without a change in oxygen or lactate extraction, indicating adequate adaptation of myocardial blood flow to metabolic requirements. 20

\section{Extrapolation to man}

Because of their central sympatholyic and hemodynamic-stabilizing properties, alpha $_{2}$ agonists appear to be especially useful as anesthetic adjuvants in the high-risk cardiovascular patients undergoing major surgery. 5,7 Recent evidence suggests that dexmedetomidine, when administered perioperatively, may result in decreased risk for adverse cardiac events including myocardial ischemia. ${ }^{29}$

There is evidence to suggest that in dog the peripheral vasoconstrictive effects of alpha-adrenergic stimulation are more predominant as compared to humans. ${ }^{2} \mathrm{Nev}-$ ertheless, it is important to be able to reverse any possible peripheral vasoconstriction of alpha 2 agonists. The goal of the utilization of alpha 2 agonists in anesthesiology is to preserve the-desired-central actions of the drugs without incurring their peripheral-potentially undesirable- effects. The "antagonism" must be restricted to the periphery. It was previously shown that calcium-channel antagonists are effective in blocking alpha-adrenoreceptor induced vasoconstriction. ${ }^{2}$ In the present experiment, we showed that a vasodilator like ATP could functionally reverse the systemic and coronary vasoconstrictor effects of dexmedetomidine. 


\section{Conclusions}

The authors conclude that the potent vasodilator ATP can completely reverse the coronary vasoconstrictor effect of dexmedetomidine but only partially the reduction of cardiac function. The pharmacological antagonist atipamezole reversed the central as well as the peripheral effects of dexmedetomidine so that cardiac function and catecholamine levels returned to baseline. The reduction of cardiac function after dexmedetomidine therefore may be primarily attributed to the sympathetic inhibition and reduced plasma catecholamine levels and to some extent to peripheral effects.

\section{Acknowledgements}

This work was supported in part by Orion Corporation, Farmos, Turku, Finland. We thank Ruud Kruger, Theo Van Der Nagel and Jo Habets for expert technical assistance. 


\section{REFERENCES}

1. Algeo S, Appleton CP, Martin GV (1985) Effects of alphaz-adrenergic stimulation with UK 14,304-18 on the heart and peripheral circulation of intact dogs. Journal of Cardiovascular Pharmacology 7 : 1055-1064

2. Bloor BC, Frankland M. Alper G. Raybould D. Weitz J, Shurtiff M (1992) Hernodymamic and sedative effects of dexmedetomidine in dog. The Journal of Pharmacology and Experimental Therapeutics. 263: $690-697$

3. Bloor $\mathrm{BC}$, Ward DS, Belleville JP, Maze $\mathrm{M}$ (1992) Effects of intravenous dexmedetomidine in humans. Anesthesiolcgy $77: 1134-1142$

4. Chen $G$, Dai XZ, Zimmerman BG, Bache RI (1988) Postsynaptic alpha, and alphaz-mechanisms in coronary vasoconstriction. Journal of Cardiovascular Phamacology 11:61-67

5. Dorman $\mathrm{BH}$, Zucker JR, Verrier ED, Gartman DM, Slachman FN (1993) Clonidine improves perioperative myocardial ischemia, reduces anesthetic requirements, and alters hemodynamic parameters in patients undergoing coronary artery bypass surgery. Joumal of Cardiothoracic and Vascular Anesthesia 7: $386-395$

6. Dyck JB, Maze M, Haack C, Vuarilehto L, Shafer SL (1993) The pharmacokinetics and hemodynamic effects of intravenous and intramuscular dexmedetomidine hydrochloride in adult human volunteers. Anesthesiology $78: 813-820$

7. Flacke JW, Bloor BC, Flacke WE, Wong D, Dazza S, Stead SW, Laks H (1987) Reduced narcotic requirements by clonidine with improved hemodynamic and adrenergic stability in patients undergoing coronary bypass surgery. Anesthesiology 67: 11-19

8. Flacke JW, Flacke WE, Bloor BC, Mclntee DF (1990) Hemodynamic effects of dexmedetomidine, an alphap-adrenergic agonist, in autonomically denervated dogs. Journal of Cardiovascular Pharmacology 16: 616-623

9. Flacke WE, Flacke JW, Blow KD, Mclntee DF, Bloor BC (1992) Effect of dexmedetomidine, an alphaz-adrenergic agonist, in the isolated heart. Journal of Carciothoracic and Vascular Anesthesia 6: $418-423$

10. Flacke WE, Flacke JW, Bloor BC, Mclntee DF, Sagan M (1993) Effects of dexmedetomidine on systemic and coronary hemodynamics in the anesthetized dog. Journal of Cardiothoracic and Vascular Anesthesia 7: 41-49

11. Gordon Jh (1986) Extracellular ATP: effects, sources and fate. Biocinemical Journal 233: 309-319

12. Heusch G, Deussen A, Schipke HO, Thamer V (1984) Alpha 1 and alphar-adrenoreceptor mediated vasoconstriction of large and small canine arteries in vivo. Journal of Cardiovascular Pharmacology 6: $961-968$

13. Holtz J, Saeed $M$, Sommer $O$, Bassenge $E(1982)$ Norepinephrine constricts the canine coronary bed vla post-synaptic alphazmadrenoreceptors. European Journal of Pharmacology 82:199-202

14. Hori $M_{n}$, Kitakaze M, Tamai J, Iwakura K, Kitabatake $A_{s}$ Inove $M_{*}$ Kamada $T$ (1989) Alphaz-adrenoreceptor stimulation can augment coronary vasodilation maximally induced by adlenosine in dogs. American Journal of Physiology 257 (Heart Circulation Physiology 26): $\mathrm{H} 132-\mathrm{H} 140$.

15. Housmans PR (1990) Effect of dexmedetomidine on contractility, relaxation, and intracellular calcium transients in isolated myocardium. Anesthesiology 73: 919-922

16. Kelm M and Schrader $J$ (1990) Control of coronary vascular tone by nitric oxide. Circulation Research 66: $1561-1575$

17. Kitakaze M, Hori M, Gotoh K, Sato H, Iwakura K, Kitabatake A, Inoue M, Kamada T (1989) Beneficial effects of alpha2-adrenorecplor activity on ischemic myocardium during coronary hypoperfusion in dogs. Circulation Research 65: 1632-1645.

18. Maza M, Tranquilli W (1991) Alphaz-Adrenoreceptor agonists: defining the role in clinical anesthesia. Anesthesiology 74:581-605 
19. Prinzen FW, Lawrence CJ, Van Leeuwen CJ, De Lange S (1994) Effect of the alpha2-adrenergic receptor agonist dexmedetomidine on nutrient blood flow to various organs in anaesthetised dogis. Joumal of Cardiothoracic and Vascular Anesthesila 8 ( 3 (suppl 2)): 82

20. Roekaents PMHJ, Prinzen FW, De Lange S (1996) Coronary vascular effects of dexmedetomidine during reactive hyperemia in the anesthetized dog. Journal of Cardiothoracic and Vascular Anesthesia $10(5): 619-626$

21. Roekaerts PMHJ, Prinzen FW, Willigers $\mathrm{HMM}_{4}$ de Lange S (1996) The effects of alphaz-adrenergic stimulation with mivazerol on myocardial blood flow and function during coronary antery stenosis in anesthetized dogs. Anesthesia and Analgesia 82: $702-711$

22. Roekaerts PMHJ, Prinzen FW, de Lange S (1996) Beneficial effects of dexinedetomidine on ischaemic myocardium of anaesthetized dogs. British Journal of Anaesthesia 77:427-429

23. Rowe $\mathrm{GC}_{8}$ Afonso S, Gurtner HP, Chelius $\mathrm{CJ}$, Lowe WC, Castillo CA, Grumpton CW (1962) The systemic and coronary hemodynamic effects of adenosine triphosphate and adenosine. American Heart Journal 64: 228-234

24. Saeed M, Holtz J, Elsner D, Bassenge E (1985) Sympathetic control of myocardial oxygen balance in dogs mediated by activation of coronary vascular alpha 2 -adrenoreceptors. Jounnal of Cardiovascular Pharmacology 7: 167-173

25. Savola $J M$. Brennan KM, Maze M, Stalnaker CS, Budinger TJ (1990) No decrease in myocardial blood flow during infusion of dexmedetomidine as assessed using positron emission tomography in anaesthetized dogs. European Journal of Pharmacology 183: 360-361

26. Scheinin $H_{\text {, Virtanen }}$, Scheinin M (1986) Alpha2-adrenoreceptor agonists decrease free 3-methoxy. 4-hydroxyphenylglycol in rat cerebrospinal fluid. European Journal of Pharmacology 123:115-121

27. Scheinin M, Kallio A, Koulu M, Viikari J, Scheinin H (1987) Sedative and cardiowascular effects of medelomidine, a novel selective alpha 2 -adrenoreceptor agonist, in healthy volunteers. British Journal of Clinical Pharmacology 24: 443-451

28. Schmeling WT, Kampine $J P$, Roerig DL, Wartier DC (1991) The effects of the stereoisomers of the alpha 2 -adremergic agonist medetomidine on systemic and coronary hemodynamics in conscious dogs. Anesthesiology 75: 499-511

29. Talke P, Li J, Jain U, Leung ل, Drasner K, Hollenberg M, Mangano DT, The Study of Perioperative Ischemia Research Group (1995) Effects of perioperative dexmedetomidine infusion in patients undergoing vascular surgery. Anesthesiology 82: 620-633

30. The Merck Index. XI.Edt (1989) Budavari S, O' Neill MJ, Smith A, Heckelman PE, Edts. Rahway, NJ: Merck \& Co, 145

31. Unnerstall JA, Kopajtic TA, Kuhar MJ (1984) Distribution of alpha2 agonist binding sites in the rat

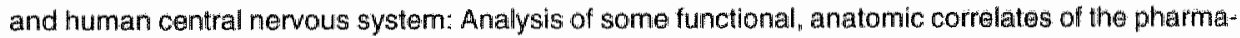
cologic effect of clonidine and related agemnts. Brain Research 319:69-101

32. Vickery $R G$, Sheridan $B C$, Segal IS, Maze M (1988) Anesthetic and hemodynamic effects of the stereoisomers of medetomidine, an alpha 2 -adrenergic agonist, in halotane-anesthetized dogs. Anesthesia and Analgesia 67: 611-615

33. Virtanen $R(1989)$ Pharmacological profiles of medetomidine and its antagonist, atipamezole. Acta Veterinaria Scandinavica $85: 29-37$

34. Virtanen $R$, Savola $J M$, Saano $V$ (1989) Highty selective and specific antagonism of central and peripheral alpha 2 -adrenoreceptors by atipamezole. Archives Internationales de Pharmacodynamie 297: 109-204 
CHAPTER 6

\title{
Coronary vascular effects of dexmedetomidine during reactive hyperemia in the anesthetized dog
}

\author{
P.M.H.J. Roekaerts \\ F.W. Prinzen \\ S. de Lange
}

Published in: Journall of Cardiothoracic and Vascular Anesthesia 10 (5):619-626, 1996 Reproduced with permission of the publisher (Presented in part at the Society of Cardiovascular Anesthesiologists Annual Meeting 1993. San Diego, California, USA and published in Abstract form in: FASEB J. 7. A 212, 1993) 


\section{Coronary vascular effects of dexmedetomidine during reactive hyperemia in the anesthetized dog}

\section{ABSTRACT}

Objective. The central sympatholytic effect of alpha 2 -adrenergic agonists is believed to be beneficial during myocardial ischemia, but the peripheral vasoconstrictive effect is controversial. The aim of this study was to investigate the coronary vascular effects of dexmedetomidine (DM) during reactive hyperemia.

Design: The study had a prospective, randomized, open comparative design.

Setting: University animal laboratory.

Participants: Nine mongrel dogs.

Interventions: Coronary artery acclusions lasting $2 \mathrm{~min}$ were induced 5 times at 40 min intervals. DM 0.1,1, and $10 \mu \mathrm{g} \cdot \mathrm{kg}^{-1}$ was administered $15 \mathrm{~min}$ before the 2nd, 3rd and 4 th coronary occlusion, respectively. The alpha 2 -antagonist atipamezole was administered before the 5 th coronary occlusion.

Measurements and Main Results: DM $1 \mu \mathrm{g} \cdot \mathrm{kg}^{-1}$ significantly decreased heart rate (from $128 \pm 13$ to $96 \pm 21$ beats $\cdot \mathrm{min}^{-1}$ ), $10 \mu \mathrm{g} \cdot \mathrm{kg}^{-1} \mathrm{DM}$ also significantly decreased cardiac output (from $3.4 \pm 1.1$ to $1.4 \pm 0.4 \mathrm{~L} \cdot \mathrm{min}^{-1}$ ). DM decreased myocardial blood flow in all layers of normally perfused myocardium. In hyperemic myocardium, DM significantly decreased epicardial blood flow from $3.30 \pm 1.43$ to $1.44 \pm 0.49$ $\mathrm{ml} \cdot \mathrm{min}^{-1} \mathrm{~g}^{-1}$ after DM $10 \mu \mathrm{g} \cdot \mathrm{kg}^{-1}$ ) while endocardial blood flow did not change, hereby significantly increasing the endo/epi blood flow ratio (from $0.99 \pm 0.54$ to $2.28 \pm 0.78$ ). Conclusions: In the post-ischemic hyperemic subendocardial layer, coronary blood flow was preserved after DM. DM reduced primary determinants of myocardial oxygen demand. These effects of DM may be beneficial in conditions of temporary coronary artery occlusion and subsequent reperfusion.

\section{INTRODUCTION}

Dexmedetomidine (DM) is a highly specific and selective alpha2-adrenoreceptor agonist. "Alpha 2 agonists are useful adjuncts to anesthesia because of their anxiolytic, sedative, sympatholytic analgesic, anesthetic-sparing and hemodynamic-stabilizing properties. 2 Previous studies have demonstrated the ability of these drugs to decrease sympathetic and increase parasympathetic central outflow, resulting in decreased blood pressure and heart rate. ${ }^{3.4}$ Probably due to these central effects, clonidine improved intraoperative hemodynamics, reduced intraoperative plasma catecholamines, improved myocardial ischemia and decreased post-coronary artery bypass graft hypertension. ${ }^{5}$ On the other hand, alpha 2 -adrenergic receptor agonists. have been found to directly stimulate postjunctional receptors on vascular smooth 
muscle, ${ }^{16}$ which causes vasoconstriction. This peripheral action could oppose the centrally mediated vasodilation. Coronary vasoconstriction by stimulation of the alpha $2_{2}$-adrenoreceptors on coronary vasculature has beendemonstrated in a number of studies in dogs. $7,8 \mathrm{DM}$ induced a pronounced decrease in coronary blood flow in the anesthetized $\operatorname{dog}_{9}{ }^{9}$ but not in awake dogs after slow intravenous or oral admini. stration. 10,11 During myocardial ischemia, the effects of alpha- or alphay-adrenergic stimulation are even more controversial. Heusch and cowworkers reported evidence for a detrimental role of alphaz-adrenergic receptor activation during sympathetic nerve stimulation and exercise in dogs with coronary stenosis. 12,13 In contrast, studies by Nathan \& Feigl and Chilian \& Ackell indicated that alphamadrenergic coronary constriction exerts a favorable effect on ischemic myocardium by preventing a transmural redistribution of blood flow away from the ischemic endocardium. 14,15 In addition, Kitakaze and colleagues demonstrated that intracoronary alphaz-adrenoreceptor administration may enhance the vasodilatory effects of adenosine released from the ischemic myocardium, thereby attenuating myocardial ischemia. 16

Previous studies do not allow to predict the effect of alpha like DM on myacardial blood flow during melabolic vasodilation. Accordingly, we studied the effects of intravenous dexmedetomidine on regional myocardial blood flow, oxygen and lactate extraction, and contractile function during reactive hyperemia following a short coronary artery occlusion in the anesthetized dog.

\section{MATERIAL AND METHODS}

\section{General preparation}

Healthy mongrel dogs of either sex and unknown age weighing 22-39 kg were studied after local animal ethical committee approval. After overnight fasting and approximately 1 hour after sedation with fentany $2 \mu \mathrm{g} \cdot \mathrm{kg}^{-1} \mathrm{im}$, the dogs were anesthetized with pentobarbital sodium $30 \mathrm{mg} \cdot \mathrm{kg}^{-1} \mathrm{iv}$. After intubation, they were ventilated with a mixture of oxygen/nitrous oxide $40 / 60 \%$ and halothane $1 \%$ using a Drager Pulmomat mechanical ventilator at an end-expiratory pressure of $5 \mathrm{~cm} \mathrm{H} 2 \mathrm{O}$. Tidal volume (initially $15 \mathrm{ml} / \mathrm{kg}$ ) and respiratory rate (12-18 per minute) were adjusted to maintain end-expired carbon dioxide concentration (Datex capnograph Oscar, Datex Instrumentation Corp. Helsinki, Finland) between 3.5 and $4.5 \mathrm{kPa}$. Oxygen saturation was monitored by pulse oximetry (Datex Oscar) and arterial blood gases were analysed every 30 min during the study. The temperature was recorded and maintained as close as possible to 37 degrees Celsius by means of a heating pad. A femoral artery was surgically exposed and a microtransducer-tipped catheter (Millar (PC 350), Houston, $\mathrm{TX}_{*}$ USA) for arterial blood sampling and measurement of arterial pressure introduced into the aorta. Another microtransducer-tipped catheter was inserted via a carotid artery into the left ventricle (LV) for measurement of left ventricular cavity pressure. A thermodilution pulmonary artery catheter (Edwards VIP) was introduced 
via the left internal jugular vein and floated into the pulmonary artery using the continuously displayed pressure tracing as a guide.

After acrninistration of suxamethonium $2 \mathrm{mg} \mathrm{kg}^{-1} \mathrm{i} . \mathrm{v}$. , the thorax was opened via the Sth left lateral intercostal space and the pericardium opened to expose the heart. The left anterior descending coronary artery ( $L A D)$ was prepared and an electromagnetic flow probe (Skalar, Delft, The Netherlands) placed around it near its origin. A small polyethylene catheter (PE 60, Clay Adams; $1 \mathrm{~mm}$ in diameter and $7 \mathrm{~cm}$ in length) was inserted into the coronary vein - accompanying the artery - in order to obtain regional venous blood samples

\section{Epicardial deformation}

Epicardial deformation in the area that was expected to become ischemic (the perfusion area of the LAD) was measured with three inductive coils, as described in detail before. ${ }^{17}$ These coils were attached to the epicardium in a right-angled triangle. Segment length changes in three different directions were measured. The area decrease of the epicardial region enclosed by the coills, as calculated from the length changes in the three different directions during the ejection phase, was used as an estimate of regional contractile function. Assuming that volume of a certain part of the ventricular wall is constant throughout the cardiac cycle, surface area decrease is related to wall thickening. Onset and end of the ejection phase were determined from the cross over of left ventricular pressure and ascending aortic pressure and from the dicrotic notch in the aortic pressure signal, respectively.

\section{Hemodynamic measurements}

Except for cardiac output, all hemodynamic variables measured [including heart rate, aortic pressure, LV end-diastolic pressure, LV dP/dt, LV pressure, coronary flow, mean coronary flow and ECG (lead II)] and the epicardial deformation variables were continuously displayed on an oscilloscope (Knott) and recorded on a multichannel Schwarzer recorder at $0.25 \mathrm{~cm} \cdot \mathrm{sec}^{-1}$ with the speed increased to $5 \mathrm{~cm} \cdot \mathrm{sec}^{-1}$ during data acquisition. Hemodynamic measurements were also digitized with 12 bits at 200 Hz using a DASH 16 G2 A/D convertor and stored on a Tulip Compact AT computer for further off-line analysis. Rate of change of LV pressure (dP/dt) was obtained by differentiation of the left ventricular pressure signal. The following formulae were used in order to calculate: stroke volume = cardiac output/heart rate; systemic vascular resistance $=$ mean arterial pressure/ cardiac output and coronary vascular resistance $=$ mean arterial pressure/myocardial blood flow. Cardiac output was measured in triplicate using cold injectate and the average taken (Edwards SAT-2 cardiac output computer).

\section{Myocardial blood flow measurements}

Radioactive microspheres (3M Company, USA) approximately $15 \mu \mathrm{m}$ in diameter and labeled with ${ }^{141} \mathrm{Ce},{ }^{113} \mathrm{Sn},{ }^{103} \mathrm{Ru}$ or ${ }^{95} \mathrm{Nb}$ were used to determine regional myocardial 
blood flow by the reference withdrawal method. ${ }^{18,19}$ Approximately $2.5 \cdot 10^{6}$ microspheres were injected into the left atrium for each measurement. A reference sample was taken from the brachial artery at a rate of $20.7 \mathrm{ml} \cdot \mathrm{min}^{-1}$ using a Harvard suction pump. Withdrawal of blood started $5 \mathrm{~s}$ before the injection of the microspheres and was continued during at least one minute. At the end of the study, the dogs were sacrificied with an overdose of pentobarbital. The heart was excised, rinsed and stored in formaldehyde $5 \%$. Before dissection, all other chambers, greal vessels, valves, and epicardial fat were removed from the left ventricle and interventricular septum. For blood flow determination, transmural samples were taken from the perfusion area of the LAD and from the posterior wall and interventricular system, perfused by the left circumflex or right coronary artery. Each sample was then divided into three layers: subendocardial, mid-wall and subepicardial. The myocardial pieces were weighed to the nearest milligram and counted in a gamma-counter (Packard Multichannel Analyzer or LKB Compugamma 1282), together with the reference blood samples. From these data myocardial blood flow in $\mathrm{ml} \cdot \mathrm{min}^{-1} \cdot \mathrm{g}^{-1}$ was calculated with the MIC II program. 20

\section{Metabolic measurements}

Blood gases and blood $\mathrm{pH}$ were assessed with a Radiometer ABL 3 blood gas analyser. Hemoglobin ( $\mathrm{Hb}$ ) content and oxygen saturation were determined with a Radiometer OSM-2 hemoximeter. The arteriall - local coronary venous (A-CV) oxygen saturation and lactate differences were assessed. Lactate concentration was determined spectrophotometrically (Cobas Bio System, Hoffman La Roche, Basel, Switzerland). Catecholamine concentrations in plasma were determined using high-performance liquid chromatography with coulometric electrochemical detection (HPL-EC). ${ }^{21}$ Concentrations of DM and atipamezole were determined in arterial blood (at the laboratory of Farmos, Turku, Finland).

\section{Study protocal}

Nine dogs were used in this protocol. In two dogs, multiple instrumentation failed before completion of all experiments; their metabolic data were not used for analysis. Halothane anesthesia was maintained at the same end-tidal halothane concentration of $1 \%$ throughout the entire experiment. Five min prior to the coronary occlusion, arterial and local venous blood samples were collected for measurement of blood gases, hemoglobin, oxygen saturation and plasma concentrations of lactate, DM and catecholamines. Cardiac output and all the continuously recorded hemodynamic and regiional contractile variables were also determined at this timepoint. After these control measurements had been performed the LAD was completely occluded just after the first diagonal branch during 2 minutes using a tantalium clamp. After 1 minute of occlusion, regional contractile variables were determined. After release of the acclusion, at reperfusion time $0.5 \mathrm{~min}, 1 \mathrm{~min}, 2 \mathrm{~min}$, and $5 \mathrm{~min}$, hemodynamic measurements were performed and blood samples were taken for determination of 
oxygen saturation and lactate concentration of the local coronary venous blood; regional contractile variables were also determined at these sample times. At each sample time, registration of the hemodynamic variables was made just before blood sampling. Local venous blood was continuously withdrawn from start reperfusion to reperfusion time $0.5 \mathrm{~min}$, from 0.5 to $1 \mathrm{~min}$, from 1 to $2 \mathrm{~min}$, and from 4 to $5 \mathrm{~min}$. Microspheres were injected over a $20 \mathrm{sec}$ period starting at reperfusion time $0.5 \mathrm{~min}$, coinciding with peak reactive hyperemia. Fifteen minutes after release of the occlusion, measurements were repeated, followed by the administration of DM $0.1 \mu \mathrm{g} \cdot \mathrm{kg}^{-1}$. Fifteen minutes after the DM administration, pre-occlusion measurements were repeated followed by another period of occlusion and reperfusion with similar measurements. This procedure was repeated another 3 times: after DM 1 and $10 \mu \mathrm{g} \cdot \mathrm{kg}^{-1}$ and after the alphaz-antagonist atipamezole $600 \mu \mathrm{g} \cdot \mathrm{kg}^{-1}$. No microspheres were injected during the last reperfusion phase.

\section{Statistical analysis}

Data were analysed for statistical significance using the General Linear Modelling Package, SuperANOVA (Abacus Concepts, Inc., Berkeley, California) on a Macintosh Apple computer. One factor Analysis of Variance (ANOVA) and Fisher's Least Significant Difference (LSD) tests were used. $P<0.05$ was considered significant. All results are expressed as mean $\pm \mathrm{SD}$.

\section{RESULTS}

Hemodynamic measurements and plasma concentrations of the catecholamines, dexmedetomidine and atipamezole

Table 1 shows the hemodynamic data and the plasma concentrations of the catecholamines, dexmedetomidine and atipamezole at control and 15 minutes following the administration of the study drugs, under normal conditions.

During peak reactive hyperemia, DM $0.1 \mu \mathrm{g} \cdot \mathrm{kg}^{-1}$ decreased heart rate from $136 \pm 12$ to $127 \pm 12$ beats $\mathrm{min}^{-1}$. DM 1 and $10 \mu \mathrm{g} \cdot \mathrm{kg}^{-1}$ significantly decreased heart rate to $101 \pm 16$ and $82 \pm 14$ beats $\mathrm{min}^{-1}$, respectively. DM 0.1 and $1 \mu \mathrm{g} \cdot \mathrm{kg}^{-1}$ increased mean arterial pressure during peak reactive hyperemia from $84 \pm 8$ to $87 \pm 9$ and $85 \pm 17$ $\mathrm{mmHg}$, respectively. $\mathrm{DM} 10 \mu \mathrm{g} \cdot \mathrm{kg}^{-1}$ significantly increased mean arterial pressure to $116 \pm 17 \mathrm{mmHg}$

After atipamezole, all hemodynamic variables returned to their baseline values.

Table 1 also shows that DM 1 and $10 \mu \mathrm{g} \cdot \mathrm{kg}^{-1}$ significantly decreased the plasma catecholamine concentrations.

No major arrhythmias were observed during this study and, consequently, anti-arrhythmogenic drugs or electrical defibrillation were never used. 
Table 1. The effects of dexmedetomidine and atipamezole on systemic hemodynamics and plasma concenirations of the catecholamines, dexmedetomidine and atipamezole in anesthetized dogs

\begin{tabular}{lccccc}
\hline & Control & DM 0.1 & DM 1 & DM 10 & ATI 600 \\
\hline Heart rate & $128 \pm 13$ & $120 \pm 15$ & $96 \pm 21^{*}$ & $81 \pm 21^{*}$ & $118 \pm 22$ \\
Mean arterial pressure & $78 \pm 11$ & $79 \pm 13$ & $90 \pm 12$ & $119 \pm 12^{*}$ & $84 \pm 17$ \\
LVEDP & $4.4 \pm 2.6$ & $5.8 \pm 4.4$ & $6.9 \pm 4.6$ & $11.5 \pm 5.8^{*}$ & $43 \pm 3.2$ \\
dPidttmax & $1647 \pm 557$ & $1350 \pm 372$ & $1347 \pm 1773$ & $1220 \pm 341$ & $1569 \pm 531$ \\
Cardiac output & $3.4 \pm 1.1$ & $3.0 \pm 1.0$ & $2.4 \pm 0.9$ & $1.4 \pm 0.4^{*}$ & $3.3 \pm 1.5$ \\
Stroke volwme & $27 \pm 8$ & $25 \pm 7$ & $25 \pm 5$ & $18 \pm 6^{*}$ & $27 \pm 9$ \\
Systemic vascular resistance & $25 \pm 8$ & $28 \pm 9$ & $40 \pm 11^{*}$ & $89 \pm 26^{*}$ & $30 \pm 13$ \\
Plasma epinephrine & $1.69 \pm 1.58$ & $1.43 \pm 1.01$ & $0.29 \pm 0.19^{*}$ & $0.3 \pm 0.1^{*}$ & $2.36 \pm 1.73$ \\
Plasma norepinephrine & $0.84 \pm 0.64$ & $0.70 \pm 0.45$ & $0.12 \pm 0.08^{*}$ & $0.43 \pm 0.18^{*}$ & $1.41 \pm 1.13$ \\
Piasma dexmedotomidine & & $0.04 \pm 0.07$ & $0.61 \pm 0.19^{*}$ & $11.8 \pm 6.0^{*}$ & $2.11 \pm 0.74^{*}$ \\
Plasma atipamezole & & & & & $194 \pm 73$ \\
\hline
\end{tabular}

Mean $\pm \mathrm{SD}$ data; $n=9 ;{ }^{*}=$ significantly different from control value $(P<0.05) ;$ Abbreviations: $D M=15$ minutes after the intravenous administration of dexmedetomidine in $\mu \mathrm{g} \cdot \mathrm{kg}^{*} ; \mathrm{ATI}=15$ minutes after the intravenous administration atipamezole in $\mu \mathrm{g} \cdot \mathrm{kg}^{-1 /} ; \mathrm{LVEDP}=$ left ventricular end-diastolic pressure; $\mathrm{dP} / \mathrm{dt}_{\max }=$ first derivative of left ventricular pressure; Units: heart rate in beats. min $^{*{ }^{*}}{ }_{i}$ mean arterial pressure and LVEDP in $\mathrm{mmHg}$; $\mathrm{dP} / \mathrm{dt}_{\max }$ in $\mathrm{mmHg} \cdot \mathrm{s}^{-1}$; cardiac output in $\mathrm{L} \cdot \mathrm{min}^{-1}$; stroke volume in $\mathrm{ml}$; systemic vascular resistance in $\mathrm{mmHg}$ min. $\mathrm{L}^{-1}$; epinephrine and norepinephrine in nmol. $\mathrm{L}^{-1}$; dexmedetonidine and atipamezole in $\mathrm{ng} \cdot \mathrm{ml}^{-1}$.

\section{Coronary blood flow}

Figure 1 depicts the values of coronary blood flow in $\mathrm{ml} \cdot \mathrm{min}^{-1}$, as measured with the electromagnetic flow probe around the left anterior descending coronary artery, under normal conditions and during reactive hyperemia. Peak reactive hyperemia resulted in blood flow values approximately 3 times the baseline values. DM and atipamezole did not significantly alter blood flow under normal conditions or during peak reactive hyperemia.

\section{Regional myocardial blood flow measurements}

Figure 2 presents the data on regional myocardial blood flow in the normally perfused region and figure 3 in the hyperemic region of the left ventricular wall, as measured with radioactive microspheres injected during peak reactive hyperemia.

In the normally perfused myocardium, DM $10 \mu \mathrm{g} \cdot \mathrm{kg}^{-1}$ significantly decreased blood flow in all layers: in the epicardial layer from $1.24 \pm 0.74$ to $0.62 \pm 0.31 \mathrm{ml} \cdot \mathrm{min}^{-1} \cdot \mathrm{g}^{-1}$ and in the endocardial layer from $1.27 \pm 0.66$ to $0.76 \pm 0.34 \mathrm{ml} \cdot \mathrm{min}^{-1} \cdot \mathrm{g}^{-1}$.

In the hyperemic region, DM $10 \mu \mathrm{g} \cdot \mathrm{kg}^{-1}$ significantly decreased blood flow in the epicardial layer (from $3.30 \pm 1.43$ to $1.44 \pm 0.49 \mathrm{ml} \cdot \mathrm{min}^{-1} \mathrm{~g}^{-1}$ ), but in the endocardial layer blood flow did not change after DM $1 \mu \mathrm{g} \mathrm{kg}^{-1}$ and even slightly increased after DM $10 \mu \mathrm{g} \cdot \mathrm{kg}^{-1}$ (from $2.78 \pm 1.23$ to $3.21 \pm 1.43 \mathrm{ml} \cdot \mathrm{min}^{-1} \cdot \mathrm{g}^{-1}$ ). 


\section{Coronary blood fllow}

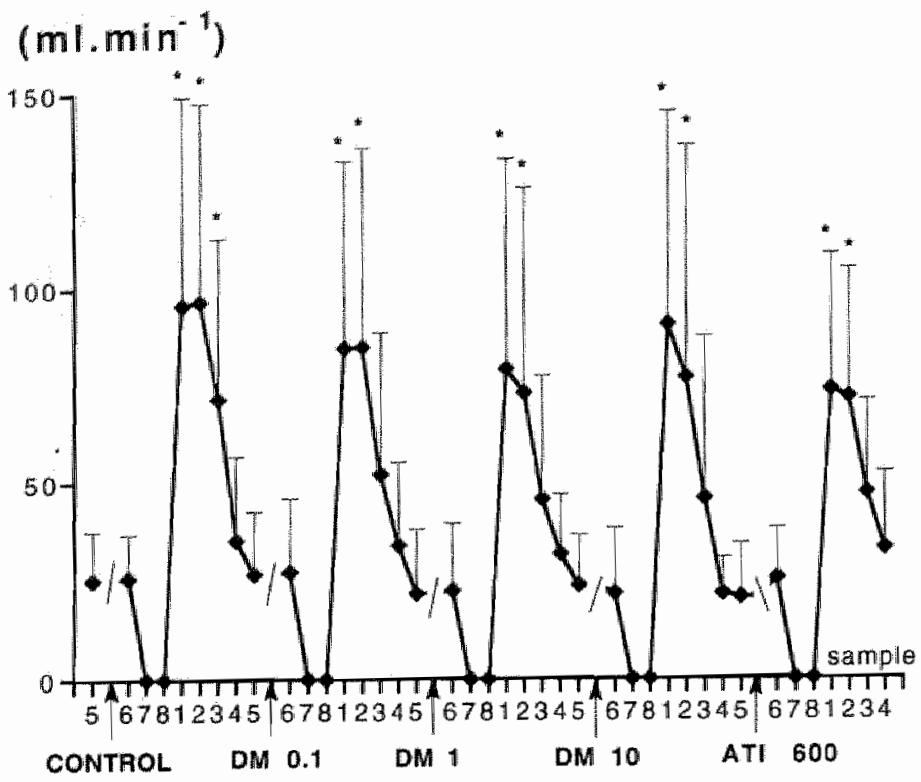

Figure 1. The effects of dexmedetomidine and atipamezale on coronary blood flow under normal conditions and during reactive hyperemia after coronary occhsion in anesthetized dogs

$1=$ after 30 sec of reperfusion; $5=$ baseline flow; $2=$ after 1 min of reperfusion; $6=$ control flow and flow after DM and Ati; $3=$ after $2 \min$ of reperfusion; $7 \&$ $8=$ coronary occlusion; $4=$ after 5 min of reperfusion; $D M=$ dexmedetomidine; Ati= atipamezole; Mean \pm SD data $(n=9)$ : * Significantly different from preceding value under normal conditions $(P<0,05)$

Figure 4 presents the endocardial/epicardial blood flow ratio. In the hyperemic region, this ratio significantly increased after DM 1 and $10 \mu \mathrm{g} \cdot \mathrm{kg}^{-1}$. In the normally perfused region, only after $\mathrm{DM}, 10 \mu \mathrm{g} \cdot \mathrm{kg}^{-1}$, a significant, although smaller, increase of this ratio was observed.

Table 2 shows the coronary vascular resistance in the normally perfused and hyperemic region in the epicardial-, mid-, and endocardial layer. In the normally perfused region, $D M 1 \mu \mathrm{g} \mathrm{kg}^{-1}$ did not alter coronary vascular resistance in any layer. After DM $10 \mu \mathrm{g} \cdot \mathrm{kg}^{-1}$ coronary vascular resistance significantly increased in all myocardial layers. In the hyperemic region, while DM 1 and $10 \mu \mathrm{g} \cdot \mathrm{kg}^{-1}$ significantly increased the coronary vascular resistance in the epicardial layer and midmyocardial layer, the resistance did not change in the endocardial layer. 


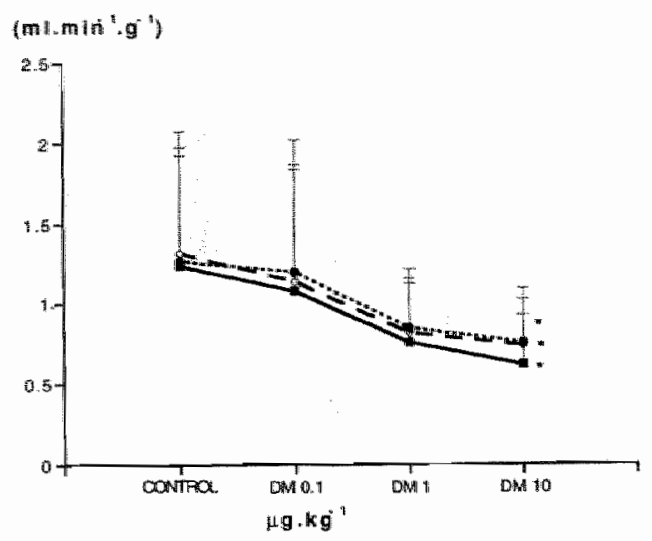

Figure 2. The effects of dexmedetomidine on the transmural distribution of myocardial blood flow in normally perfused myocardium in anesthetized dags

solid line = epicardial flow; striped line = midmyocardial flow; dashed line = endocardial flow; $\mathrm{DM}=$ dexmedetomidine; Mean \pm SD data $(n=9)$; " Significantly different from control value $(P<0.05)$

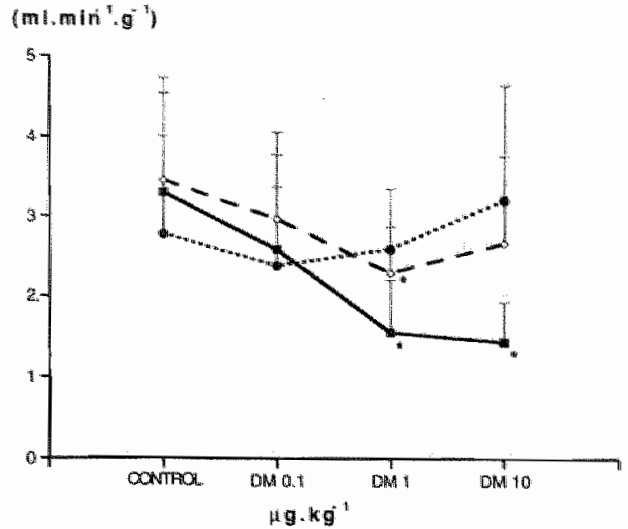

Figure 3. The effects of dexmedetomidine on the transmural distribution of myocardial blood flow in reactive hyperemic myocardium in anesthetized dogs

solid line = epicardial flow; striped line = midmyocarclial flow; dashed line $=$ endocardial How; $\mathrm{DM}=$ dexmedetomidine; mean \pm SD data $(n=9)$; * significantly different from control value $(P<0.05)$

Table 2. The effects of dexmedetomidine on the coronary vascular resistance in the different layers of the normally periused and reactive hyperemic myocardium in anesthetized dogs

\begin{tabular}{|c|c|c|c|c|}
\hline Coronary vascular resistance & $\begin{array}{c}\text { control } \\
\left(\mathrm{mmmHg} \cdot \min \cdot \mathrm{g} \cdot \mathrm{ml}^{-1}\right)\end{array}$ & $\begin{array}{l}\mathrm{DM} 0.1 \\
\mu \mathrm{g} \cdot \mathrm{kg}^{-1}\end{array}$ & $\begin{array}{l}\mathrm{DM} 1 \\
\mu \mathrm{g} \cdot \mathrm{kg}^{-1}\end{array}$ & $\begin{array}{l}\text { DM } 10 \\
\mu \mathrm{g} \cdot \mathrm{kg}^{-1}\end{array}$ \\
\hline \multicolumn{5}{|l|}{ Epicardial } \\
\hline - normally pertused & $90 \pm 47$ & $107+50$ & $146 \pm 75$ & $215 \pm 77^{*}$ \\
\hline - reactive hyperemic & $30 \pm 13$ & $39 \pm 16$ & $65 \pm 25^{*}$ & $87 \pm 31 *$ \\
\hline \multicolumn{5}{|l|}{ Midmyocardial } \\
\hline - normally perfused & $82 \pm 40$ & $93 \pm 37$ & $125 \pm 49$ & $168 * 48^{*}$ \\
\hline - reactive hyperemic & $26 \pm 8$ & $32 \pm 11$ & $40 \pm 8^{*}$ & $49 \pm 21 *$ \\
\hline \multicolumn{5}{|l|}{ Endocardial } \\
\hline -normally perfused & $85 \pm 45$ & $93 \pm 45$ & $121 \pm 49$ & $166 \pm 48^{*}$ \\
\hline - reactive hyperemic & $35 \pm 13$ & $42 \pm 22$ & $36 \pm 11$ & $41 \pm 18$ \\
\hline
\end{tabular}

Coronary vascular resistance $=$ mean arterial pressure $/$ blood flow (microspheres); $\mathrm{DM}=$ dexmedetomidine; Mean \pm SD data; $n=9_{i}$ " = significantly different from control value $(P<0.05)$ 


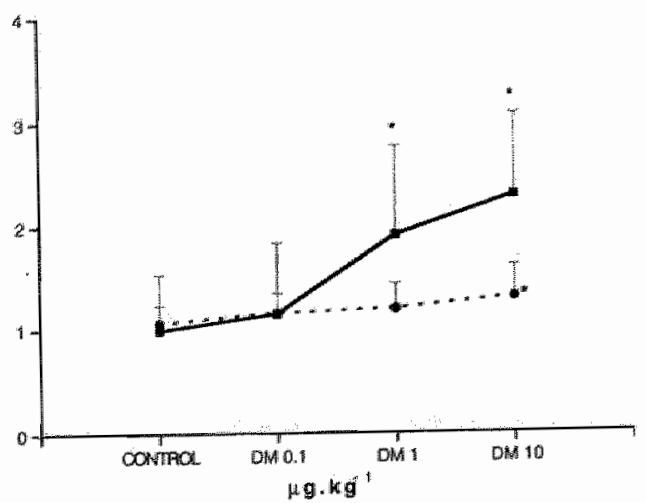

Figure 4. The effects of dexmedetomidine on the endocardialfepicardiaf blood tow ratio in anesthetized dogs

solid line = reactive hyperemic myocañdium; dashed line = normally pertused myocardium; $\mathrm{DM}=$ dexmedetomidine; mean is $\mathrm{SD}$ data $(n=9)$; " significantly different from controll value $(P<0,05)$

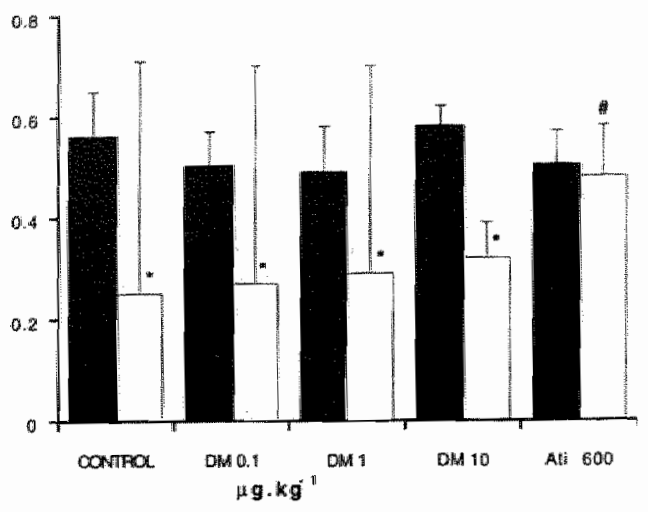

Fugure 5. The effects of dexmedetomidine and at: pamezole on the (arterial-coronary venous) oxygen saturation difference before coronay occlusion (black bars) and during peak reactive hyperemia (White bars) in anesthetized dogs

$D M=$ dexmedetomidine; ati = atipamezole; mean $S D$ data $(n=7)$; " significantly different from preceding value under normal conditions $(P<0.05)$; \# significantly different from corresponding control value

\section{Metabolic measurements}

Figure 5 shows the arterial - coronary venous (A-CV) oxygen saturation differences pre-occlusion and during the first half minute of reperfusion. During normal perfusion, the A-CV oxygen saturation differences were not significantly influenced by increasing doses of DM. During reactive hyperemia, the A-CV oxygen saturation differences significantly decreased compared to pre-occlusion values, except for atipamezole. These values during reactive hyperemia were not influenced by the administration of $\mathrm{DM}$; after atipamezole, the A-CV oxygen saturation difference during reactive hyperemia was significantly larger than during control reperfusion.

Figure 6 shows the A-CV lactate differences. During normal perfusion, the A-CV lactate difference was positive, indicating lactate uptake by the myocardium. This lactate uptake was not influenced by administration of DM or atipamezole. During reperfusion, lactate release did not change significantly with increasing doses of DM $\left(-1.6 \pm 1.3\right.$ to $-0.8 \pm 0.4 \mathrm{mmol} \cdot \mathrm{L}^{-1}$ after DM $\left.10 \mu \mathrm{g} \cdot \mathrm{kg}^{-1}\right)$. Following atipamezole, lactate release $\left(-2.1 \pm 0.4 \mathrm{mmol} \cdot L^{-1}\right)$, on the average, exceeded baseline values and was significantly larger than during the reperfusion phases after DM $0.1,1$ and $10 \mu \mathrm{g}^{-1}$.

\section{Regional contractile function measurements}

Figure 7 presents the effects of DM and atipamezole on epicardial surface area decrease. Under normal conditions, DM $10 \mu \mathrm{g} \cdot \mathrm{kg}^{-1}$ significantly reduced surface area 


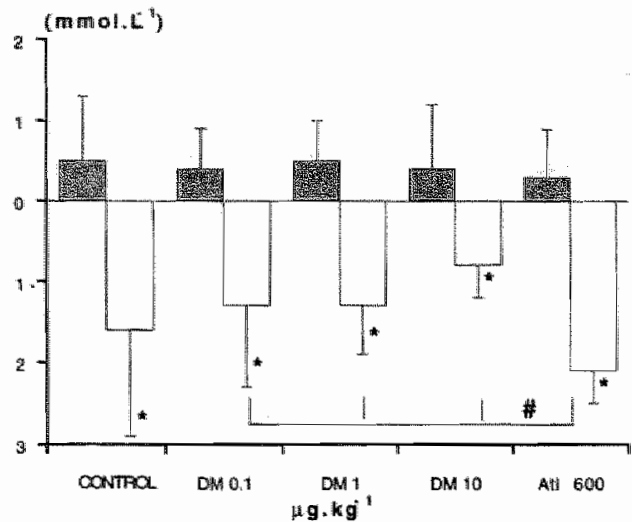

$(\%)$

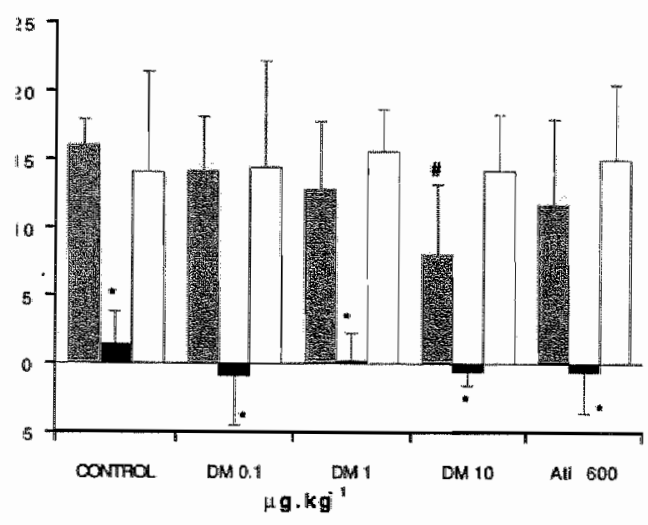

Figure 6. The effects of dexmedetomidine and atipamezole on the (arterial-coronary venous) lactate difference before coronany occlusion (shaded bars) and during peak reactive hyperemia (White bars) in anesthetized dogs

$D M=$ dexmedetomidine; At $=$ atipamezole; Mean \# SD data $(n=7)$; " significantly different from preceding value under normal conditions $(P<0.05)$; significantly different from lactate releases after DM $0.1,1$ and $10 \mu \mathrm{g} \cdot \mathrm{kg}-1 \quad(\mathrm{P}<0.05)$

Figure 7. The effects of dexmedetomidine and atipamezole on epicardial surface area decrease before (shaded bars) and during (black bars) coronary occlusion and during peak reactive hyperemia (white bars) in anesthetized" dogs

$D M=$ dexmedetomidine; Ati= atipamezole; Mean ISD data $(\mathrm{n}=9)^{\text {; }}$ " significantly different from pre* ceding value under normal conditions $(P<0.05)$; \# significantly different from corres-ponding timepoint at control state $(P<0.05)$

decrease as compared to control. During coronary stenosis, surface area decreases were severely disturbed and not significantly different from zero. DM and atipamezole had no effect on the reduction of surface area decrease during the stenoses. During reperfusion, DM and atipamezole had no effect on the recovery of regional contractile function.

\section{DISCUSSION}

The present study describes the effects of DM on blood flow in normally perfused and hyperemic myocardium. Under normal conditions, DM 1 and $10 \mu \mathrm{g} \mathrm{kg}^{-1}$ decreased coronary blood flow in all myocardial layers. The calculated coronary vascular resistance increased after DM, indicating vasoconstriction. However, the unchanged 
oxygen and lactate extraction indicate adequate adaptation of myocardial blood flow to metabolic requirements. This behaviour has also been reported when heart rate was varied by atrial pacing. ${ }^{22}$ In contrast, after a noradirenaline infusion oxygen extraction was found to increase. 23 Findings from the present study indicate that systemic DM in the doses administered does not interfere with local coronary flow regulation in normal coronary arteries of the anesthetized dog.

DM reduced primary determinants of oxygen demand, such as heart rate. Our data indicate that the reduction in coronary blood flow in the myocardium under normal conditions is probably primarily due to metabolic vasoregulation rather than to adrenerglic vasoconstriction.

This is the first report describing the transmural distribution of myocardial blood flow following DM during reactive hyperemia. In the hyperemic epicardial layer, DM decreased blood flow to a similar extent as in the normally perfused epicardial layer, but in the more vulnerable 24,25 hyperemic endocardial layer blood flow did not change. DM had no effect on the recovery of metabolic and functional parameters after the occlusions.

Our results are in contrast with findings that alpha $a_{2}$-adrenergic activation by exercise or nerve stimulation can induce myocardial ischemia. ${ }^{12,13}$ Our data neither substantiate the findings of Hori and co-workers. These authors described a beneficial effect of alpha ${ }_{2}$-adrenoreceptor stimulation in experimental myocardial ischemia: enhancement of the vasodilatory effect of adenosine released from ischemic myocardium and augmentation of the hyperemic response of coronary blood flow to adenosine.26,27 We cannot fully substantiate Hori's hypothesils as we found no decrease in coronary vascular resistance during reactive hyperemia after DM. However, the decrease of myocardial oxygen demand after DM in our experiment presumably resulted in a smaller build-up of adenosine during the occlusion periods. Subsequently, one would expect the reactive hyperemic flow to decrease after DIM. The unchanged reactive hyperemic flow in the endocardium therefore could indicate that DM potentiates adenosine released from the ischemic myocardium.

In the present study, changes in the distribution of blood flow during reactive hyperemia following DM indicate preservation of blood flow in the more vulnerable endocardial layer. This finding is similar to that reported by Nathan \& Feigl and Chilian \& Ackell in the ischemic myocardium following adrenergic stimulation. ${ }^{14,15}$ Our results are also in agreeement with the findings of Johannsen and coworkers who found that sympathetic nerve stimulation produced primarily subepicardial vasoconstriction in dogs with adenosine-induced maximal coronary vasodilation, even when heart rate and perfusion pressure were constant, ${ }^{28}$ showing that hemodynamic changes are not the only factors responsible for the redistribution of blood flow.

There are several possible explanations for this beneficial preservation of endocardial blood flow during reactive hyperemia. Feactive hyperemia has been attributed to the effect of the vasodilator nucleoside adenosine, 29 which accumulates during the period of obstructed coronary blood flow. However, as metabolic vasodilation is more pronounced in the endocardial layer as compared to the epicardial layer, ${ }^{30}$ it is possible that this vasodilation can overrule adrenergic vasoconstriction in the endo- 
cardial layer but not in the epicardial layer. There is also evidence that hypoxia and acidosis can impair adrenergic coronary vasoconstriction. ${ }^{31-33}$ As the degree of ischemia is most severe in the subendocardial layer during hypoperfusion with a greater build-up of ischemic metabolites or hypoxia, this may also explain the absence of vasoconstriction in the endocardial layer. A buildup of ischemic metabolites could also impair adrenergic neurotransmission via presynaptic mechanisms and limit endocardial adrenergic constriction. Other possibilities for non-uniform transmural coronary constriction could be related to a gradient in the density of coronary alpha-adrenergic receptors across the left ventricular wall, or in the density of the sympathetic nerves. However, these possibilities are not supported by findings in the literature. 28,34

\section{Experimental model considerations}

In the present study, serial coronary artery occlusions were used to test the effect of DM on metabolically vasodilated myocardium. In this way, each animal served as its own control. The set-up was such that short ( $2 \mathrm{~min}$ ) occlusions were followed by long (40 min) periods of recovery. This experimental design did not result in myocardial stunning or metabolic impairment: before each occlusion, there was complete recovery of regional contractile function and oxygen and lactate uptake. The recovery of the hemodynamic parameters and regional blood flow to baseline values after the alpha $_{2}$ antagonist atipamezole also demonstrates the stability of the experimental preparation.

It is not likely that ischemic preconditioning ${ }^{35}$ was effective in the present experiment, because 40 min reperfusion periods were allowed after each occlusion and it has been shown that the protective action of preconditioning is transient and wanes quite rapidly following reperfusion. ${ }^{36} 6_{y} 37$

Following the 2 min coronary artery occlusions the peak of reactive hyperemia occurred between 30 and 60 seconds after release of the occlusion. Using rapid (2 sec) microsphere injection, Downey and co-workers showed that after occlusions lasting 90 seconds, the peak of reactive hyperemia occurred earlier in the epicardial than in the endocardial layer. ${ }^{38}$ Because we were interested in time-averaged blood flow in metabolically dilated vaculature, the microspheres were injected relatively slow (over $20 \mathrm{sec}$ ), thus largely excluding that a possible effect of DM on the time course of reactive hyperemia in each of the myocardial layers would interfere with the measured distribution of blood flow. The results presented in figure 1 indicate that DM had no significant influence on the time course of reactive hyperemia.

\section{Extrapolation to man}

To our knowledge, there is only one report until now describing the effects of alphaz-adrenergic stimulation on the coronary vasculature in man. ${ }^{39}$ Indolfi and co-workers found that the intracoronary administration of an alpha 2 agonist produced a reduction in coronary blood flow in humans with angiographically normal coronary 
arteries, whereas in patients with coronary artery stenosis regional coronary blood flow decreased after alphar-receptor blockade. Indolfi's findings in humans seem compatible with our observations in dogs: while alpha 2 agonists increased coronary vascular resistance by $28 \%$ in humans with normal coronary arteries and more than $50 \%$ in dogs, no increase in coronary vascular resistance was found in patients with coronary stenosis or in dogs during reperfusion. This suggests that alpha $\mathrm{z}_{2}$-adrenergic agonists do not produce untoward coronary vasoconstriction in ischemic myocardium and may explain the positive experience with these drugs in patients with congestive heart failure, ${ }^{40}$ as well as in patients with coronary artery disease. ${ }^{5,41-43}$

The overall cardiovascular effect of alpha 2 agonists is determined by the relative preponderance of central versus peripheral effects. This overall effect in humans is a centrally mediated lowering of the blood pressure with a decrease in heart rate, but peripheral effects may dominate the central effects when the dose of these drugs is very high, initially following a rapidly given intravenous bolus and when the pre-existing tone is low and not much room is available for the central sympatholytic effects of these drugs to manifest themselves. ${ }^{10,11,44}$ There is evidence to suggest that in dog the peripheral vasoconstrictive effects of alpha adrenergic stimulation is more predominant as compared to humans. ${ }^{11,45-47}$

\section{Conclusions}

In the post-ischemic hyperemic subendocardial layer, coronary blood flow was preserved after dexmedetomidine.

Dexmedetomidine reduced primary determinants of myocardial oxygen demand. These effects of DM may be beneficial in conditions of temporary coronary artery occlusion and subsequent reperfusion.

More extensive investigations in humans are needed before the exact role of dexmedetomidine as an anesthetic adjuvant in patients with ischemic heart disease can be determined.

\section{Acknowledgements}

We thank Ruud Kruger, Theo van der Nagel and Jo Habets for their expert technical assistance and Cees van Leeuwen and Marie-Pauline Roukens for their help in data analysis.

We also thank Farmos Group Ltd., Turku, Finland, for generously supplying dexmedetomidine and atipamezole and for the determination of the plasma concentrations of dexmedetomidine and atipamezole.

We are grateful to Mika Scheinin, assistant professor of pharmacology, University of Turku, Finland, for the determination of the plasma concentrations of the catecholamines. 


\section{REFERENCES}

1. Vickery RG, Sheridan BC, Segal IS, Maze M: Anesthetic and hemodynamic effects of the stereoisomers of medetomidine, an alpha2-adrenergic agonist, in halothane-anesthetized dogs. Anesth Analg 67: 611-615, 1988

2. Maze $M$, Tranquilli $\mathrm{W}$ : Alphaz-Adrenoreceptor agonists: defining the role in clinical anesthesia. Anesthesiology $74: 581-605,1991$

3. Kobinger $W$ : Central alpha-adrenergic systems as targets for hypotensive drugs. Fev Physiol Biochem Pharmacol 81:39-100, 1978

4. Kallio A, Scheinin $M$, Koulu $M$ et al: Effects of dexmedetomidine, a selective alphaz-adrenoreceptor agonist, on hemodynamic control mechanisms. Clin Pharmacol Ther 46: 3342,1989

5. Dorman $\mathrm{BH}$, Zucker JR, Verrier ED et al: Clonidine improves perioperative myocardial ischemia, reduces anesthetic requirements, and alters hemodynamic parameters in patients undergoing coronary artery bypass surgery. J Cardiothorac Vasc Anesth 7: 386-395, 1993

6. Flacke JW, Flacke WE, Bloor BC, Molntee DF: Hemodynamic effects of dexmedetomidine, an alpha, adrenergic agonist, in autonomically denenvated dogs. J Cardiovasc Pharmacol 16: 616-623, 1990

7. Heusch G, Deussen A, Schipke HO, Thamer V: Alphay and alpha2-adrenoreceptor mediated vasoconstriction of large and small canine arterles in vivo. J Cardiovasc Pharmacol 6: 961-968, 1984

8. Chen $G$, Dai $X Z$, Zimmerman BG, Bache RJ: Postsynaptic aipha 1 and alpha2-mechanisms in coronary vasoconstriction. J Cardiovasc. Pharmacol 11: 61-67, 1988

9. Flacke WE, Flacke JW, Bloor BC et al: Effects of dexmedetomidine on systemic and coronary hemodynamics in the anesthetized dog. J Cardiothorac Vasc Anesth 7: 41-49, 1993

10. Schmeling WT, Kampine JP, Roerig DL, Warltier DC: The effects of the stereoisomers of the alpha2-adrenergic agonist medetomidine on systemic and coronary hemodynamics in conscious dogs. Anesthesiology 75: 499-511, 1991

11. Proctor LT, Schmeling WT, Roerig $D$ et al: Oral dexmedetomidine attenuates hemodynamioc responses during emergence from general anesthesia in chronically instrumented dogs. Anesthesiology $74: 108-114,1991$

12. Heusch $\mathrm{G}$, Deussen $\mathrm{A}$ : The effects of cardiac sympathetic nerve stimulation on perfusion of stenotic coronary arteries in the dog. Circ Res 53: 81-15, 1983

13. Seitelberger $R$, Guth $B D$, Heusch $G$ et al: Intracoronary alphaz-adrenergic receptor blockade attentuates ischemia in conscious dogs during exercise. Circ Res 62: 436-442, 1988

14. Nathan $H J$, Feigl $E O$ : Adrenergic vasoconstriction lessens transmural steal during coronary hypoperfusion. Am J Physiol (Heart Circ Physiol) 19: H645-H653, 1986

15. Chilian WM, Ackell PH: Transmural differences in sympathetic coronary constriction during exercise in the presence of coronary stenosis. Circ Res 62: 216-225, 1988

16. Kitakaze $M$, Hori $M$, Gotoh $K$ et al: Beneficial effects of alphaz-adrenoreceptor activity on ischemic myocardium during coronary hypoperfusion in dogs. Circ Res 65: 1632-1645, 1989

17. Prinzen FW, Arts T, van der Vusse GJ et al: Gradients in fiber shortening and metabolism across ischemic left ventricular wall. Am J Physiol (Heart Circ Physiol) 250: $\mathrm{H} 255-\mathrm{H} 264_{\text {" }} 1986$

18. Heymann MA, Payne BD, Hoffman JIE, Rudolph AM: Blood flow measurements with radionuclidelabeled particles. Progress Cardiovasc Dis 20: 55-79, 1977

19. Prinzen FW: Arts T, Hoeks APG, Reneman RS: Discrepancies between myocardial blood flow and fiber shortening in the ischemic border zone as assessed with video mapping of epicardial deforma* tion. Pflugers Arch 415: 220-229, 1989

20. Schosser $R$, Arfors KE, Messmer K: MIC Ill: a program for the determination of cardiac outpul, arterio-venous shunt and regional blood flow using the radioactive microsphere method. Comput Progr Biomed 9: 19-39, 1979 
21. Soheinin M, Koulu M, Laurikanen Ex Alonen H: Hypokalemia and other non-bronchial effects of inhaled fenoterol and salbutamol. A placebo-controlled dose-responise study in heathy volunteers. Br J Clin Pharmac 24: 645-653,1987

22. Weisis HR. Regional oxygen consumpution and supply in the heart: effect of atrilat pacing. Am $J$ Physiol (Heart Circ Physiol) 236: H231-H237, 1979

23. Mohman DE, Feigl EO Competition between sympathelic vasoconstriction and metabolic vasodila. tion in the canine coronary curculation. Circ Res $42,79-86,1978$

24. Hoffman JIE: Deteminants and prediction of transmural myocardial perfusion. Circulation 58 : $381-391,1978$

25. Griggs DM jr: Blood flow and metabolism in differemt layers of the lef ventricle. Physiologist $22: 36-40$. 1979

26. Hopi M, Kitakaze M. Tamai J el al: alpha2-Adrenoreceptor activity exerts dual controt of coronary blood flow un canine coronary artery. Am J Physiol (Heart Circ Physiol) 255: H250-H260, 1988

27. Hor M, Kitakaze M. Tamaî J et al: alphar-Adrenoreceptor stimulation can augment coronary vasodilation maximally induced by adenosine in dogs. Am J Physial (Heant Circ Physiol) 257: $\mathrm{H} 132 \mathrm{H} / \mathrm{HO}, 1989$

28. Johannsen UJ, Mark AL, Marcus ML: Responsiveness to cardiac sympathetic nerve stimulation duting maximal coronary dilation produced by adenosine. Circ Res 50: 510-517, 1982

29. Olsson RA, Snow JA, Gentry MK: Adenosine metabolism in canine myocardial reactive hyperemia. Circ Res 42: 358-362, 1978

30. Feigl EO: Coronary physiology. Physiological Reviews 63: 1-205, 1983

31. Heistad DD, Abboud FM, Mark AL, Schmid: Effect of hypoxemia on responses to norepinephrine and anglotensin in coronary and muscular vessels. I Pharmacol Exp Ther 193: 941-950, 1975

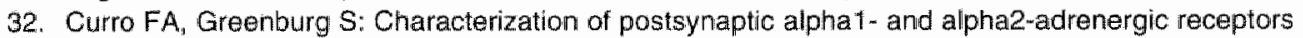
in canine vascular smooth muscle. Can J Physiol Pharmacol 61: 893-904, 1983

33. Anderson KM, Fabor JE: Differential semsitivity of arteriolar alpha1 and alpha 2 -adrenoreceptor constriction to metabolic inhibition during rat skeletal muscle contraction. Circ Res 69: 174-184, 1991.

34. Chilian WM, Harrison DG, Haws CW et al: Adrenergic coronary tone during submaximal exercise in the dog is produced by circulating catecholamines: Evidence for adrenergic denervation supersensitivity in the myocardiurm but not in coronany vessels. Circ Res 58: 68-82, 1986

35. Lawson CS, Downey JM: Preconditioning: state of the art myacardial protection. Cardiovasc Res 27 : $542-550,1993$

36. Murry CE, Richard $V_{\text {J }}$, Jennings RB, Reimer KA: Myocardial protection is lost before contractile function recowers from ischemic preconditioning. Am J Physiol (Heant Circ Physiol) 260: $\mathrm{H} 796-\mathrm{H} 804$. 1991

37. Miura T, Ogawa T, Iwamoto T of al: Infarct size limiting effect of preconditioning: its duration and "dose-iresponse" relationship. Circulation 82 (Suppl 1II) Ill:1078, 1990

38. Downey HF, Crystal GJ, Bashour FA: Asynchronous transmulal pertusion during coronary reactive myperaemia. Cardiovasc Res 17: 200-206, 1983

39. Indolfi $\mathrm{C}_{*}$ Piscione $\mathrm{F}$, Villari $\mathrm{B}$ et al: Role of alpha 2 -adrenoreceptors in nomal and alherosclerotic human cononary circulation. Circulation 86: 1116-1124, 1992

40. Giles TD, Iteld BJ, Mautner FK et al: Short-term effects of intrawenous clonidine in congestive heart failure. Clin Pharmacol Ther $30: 724=728,1981$

41. Ceremuzynski L. Zaleska T, Lada W. Zalewski A: Clonidine effect in angina pectoris. Double-blind, crossover trial on 60 patients. Eur J Cardial 10:415-427, 1979

42. Thomas MG, Quiroz AC, Fice JC et al: Antianginal effects of clonidine. J Cardiovasc Pharmacol B (Suppl 3):S69-S75, 1986

43. Quintin $L$, Cicala $\mathrm{A}$, Kent M, Thomsen $\mathrm{B}$ : Effect of ctonidine on myocardial ischaemia: a doublemblind pilot trial. Can J Anaesthesial 40: 85-86, 1993 (Letter)

44. Reid JL, Wing LMJ, Mathias CJ et al: The central hypotensive effects of clonidine -studies in tetraplegic subjects. Clin Pharmacol Ther 21: $375-381,1977$ 
45. Zornow MH, Fleisher JE, Scheller MS et al: Dexmedetomidine, an alphag-adrenergic agonist, decreases cerebral blood flow in the isoflurane-anesthetized dog. Anesth. Analg. 70: 624-630, 1990

46. Algeo $S$, Appleton CP, Martin GV et al: Effects of alphaz-adrenergic stimulation with UK 14,304-18 on the heart and peripheral circulation in intact dogs. J Cardiovase Pharmacol $7: 1055-1064,1985$

47. Bloor BC, Ward DS, Belleville JP, Maze M: Effects of intravenous dexmedetomidine in thumans. Anesthesiology $77: 1134-1142,1992$ 


\title{
CHAPTER 7
}

\section{Beneficial effects of dexmedetomidine on}

\section{ischaemic myocardium of anaesthetized dogs}

\author{
P.M.H.J. Roekaerts \\ F.W. Prinzen \\ S. de Lange
}




\section{Beneficial effects of dexmedetomidine on ischaemic myocardium of anaesthetized dogs}

\section{ABSTRACT}

We have studied the effect of dexmedetomidine during coronary artery stenosis (CAS) in dogs. Three periods of 15 min of CAS were induced at 40 -min intervals in 2 groups of dogs (dexmedetomidine compared with placebo). Dexmedetomidine was administered before the second and third periods of CAS in doses of 1 and $3 \mu \mathrm{g}^{-1}$, repectively.

Dexmedetomidine decreased plasma concentrations of noradrenaline by $71 \pm 9 \%$, heart rate by $8 \pm 4 \%$, cardiac output by $30 \pm 6 \%$, and increased mean arterial pressure by $23 \pm 10 \%$. Dexmedetomidine reduced blood flow in non-ischaemic myocardium and in the ischaemic epicardial layer by $16 \pm 8 \%$, but blood flow was preserved in the ischaemic midmyocardial and subendocardial layers. Consequently, dexmedetomidine increased the ischaemic/non-ischaemic blood flow ratio. Dexmedetomidine did not change myocardial oxygen consumption but decreased myocardial oxygen demand from $4.91 \pm 0.33$ to $3.76 \pm 0.25 \mu \mathrm{mol} \cdot \mathrm{min}^{-1} \cdot \mathrm{g}^{-1}$, thereby reducing the oxygen deficiency of the ischaemic myocardium from $1.47 \pm 0.37$ to $0.29 \pm 0.32 \mu \mathrm{mol} \cdot \mathrm{min}^{-}$ $1 \cdot g^{-1}$.

Key words: Sympathetic nervous system, adrenergic agonists. Heart, myocardial function. Sympathetic nervous system, dexmedetomidine. Heart, ischaemia. Heart, blood flow, myocardial. Dog.

\section{INTRODUCTION}

Preliminary studies suggest that the perioperative use of dexmedetomidine may result in a decreased risk of adverse cardiac events, including myocardial ischaemia. This probably depends on a centrally mediated sympatholytic effect which decreases catecholamine-mediated stress responses. In contrast with these beneficial central effects, alpha 2 agonists may also cause peripheral and coronary vasoconstriction by stimulation of postjunctional alpha ${ }_{2}$-adrenergic receptors. The effect of this vasoconstriction during myocardial ischaemia is controversial. Heusch and Deussen presented evidence that alpha ${ }_{2}$-adrenoreceptor activation can worsen ischaemia. ${ }^{2}$ In contrast, other investigators reported that alpha-adrenoreceptor stimulation can beneficially modulate coronary blood flow during myocardial ischaemia by preventing transmural redistribution of blood flow away from ischaemic endocardium. ${ }^{3}$ 
The aim of this study was to determine if systemic dexmedetomidine has beneficial effects on ischaemic myocardium in an animal model known to be highly sensitive to the direct, peripheral vasoconstrictor effect of alphan agonists.

\section{METHODS AND RESULTS}

After obtaining animal Ethics Committee approval, mongrel dogs were anaesthetized with pentobarbital and their lungs ventilated with $1 \%$ halothane and nitrous oxide in oxygen. The dogs were instrumented, as described previously, ${ }_{4}^{4}$ to measure aortic and left ventricular pressure and cardiac output. A cuff was placed on the left descending coronary artery (LAD). Coronary pressure was measured distal to the cuff. The degree of stenosis was controlled by keeping constant mean perfusion pressure distal to the stenosis using a Servo system feeding a motor-pump, which determined the degree of cuff inflation. Global myocardial oxygen demand was estimated using the pressure-work index. ${ }^{5}$ Regional oxygen consumption was measured from blood flow (radioactive microspheres) and local arterial-coronary venous oxygen content difference. Oxygen deficiency was calculated by substracting oxygen consumption from oxygen demand.

Five minutes before the first period of CAS, control blood samples were obtained and haemodynamic measurements were performed. Thereafter, CAS 1 was induced by reducing mean pressure in the LAD distal to the stenosis to $40 \%$ of mean arterial pressure. After 12 minutes of stenosis, microspheres were injected. Two minutes later, blood samples were obtained and haemodynamic measurements performed. Thereafter, the CAS was released. Twenty minutes after release of the stenosis, measurements were repeated, followed by administration of dexmedetomidine 1 $\mu \mathrm{g} \cdot \mathrm{kg}^{-1}$ in the active drug group $(n=11)$ and saline in the placebo group $(n=9)$. Twenty minutes after administration of dexmedetomidine, measurements were repeated followed by a second period of stenosis. Measurements during stenosis and the subsequent recovery period were the same as during the first episode of stenosis. This procedure was repeated a third time after administration of dexmedetomidine 3 $\mu \mathrm{g} \cdot \mathrm{kg}^{-1}$ in the drug group.

A two-way ANOVA for repeated measures was used for inter-group comparisons. Intragroup comparisons were evaluated using one-way ANOVA for repeated measures and Fisher's Protected LSD test as post-hoc test. Baseline values between the two groups were compared using Student's t test. $P<0.05$ was considered significant. Results are expressed as mean \pm SEM.

Dexmedetomidine decreased heart rate (from $126 \pm 6$ to $114 \pm 5$ beats. $\mathrm{min}^{-1}$ ), $\mathrm{dP} / \mathrm{dt}_{\max }$ (from $1371 \pm 128$ to $1177 \pm 62 \mathrm{mmHg} \cdot \mathrm{s}^{-1}$ ) and cardiac output (from $4.2 \pm$ 0.3 to $2.4 \pm 0.4 \mathrm{~L} \cdot \mathrm{min}^{-1}$ ) and increased mean arterial pressure (from $81 \pm 4$ to $98 \pm 4$ $\mathrm{mmHg}$ ) and systemic vascular resistance (from $1572 \pm 131$ to $3902 \pm 563$ dyne.s.cm ${ }^{5}$ ). In the placebo group, no haemodynamic changes were observed throughout the study. 


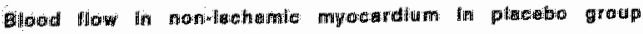

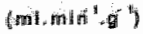
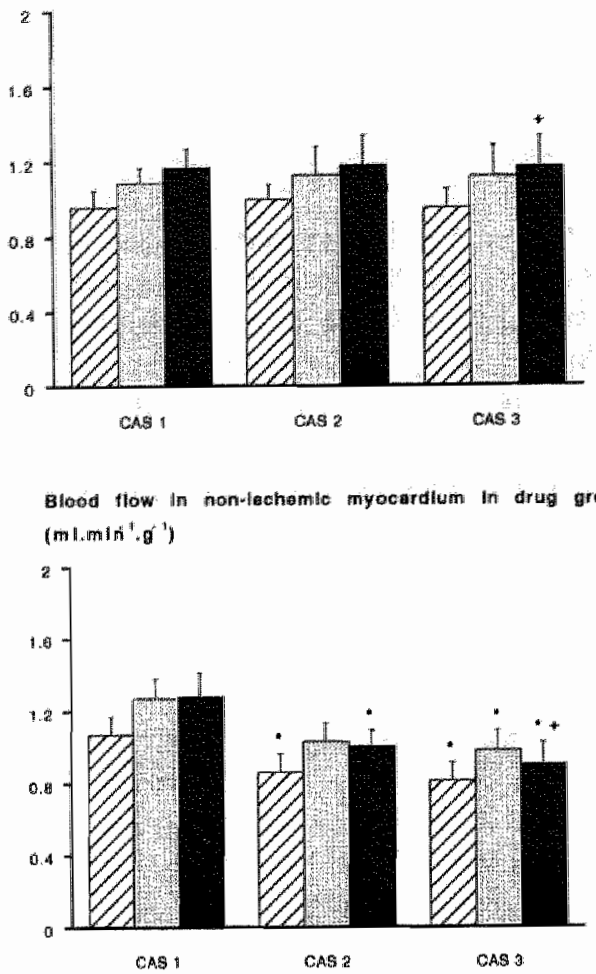

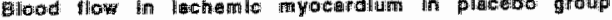
(m)

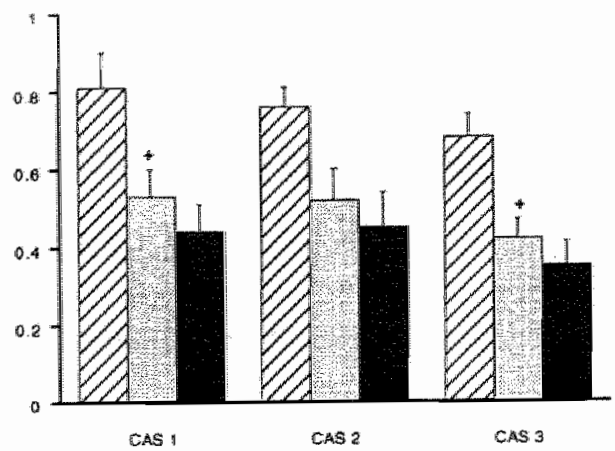

Ellood flow in lochemic myocardlum in drug group

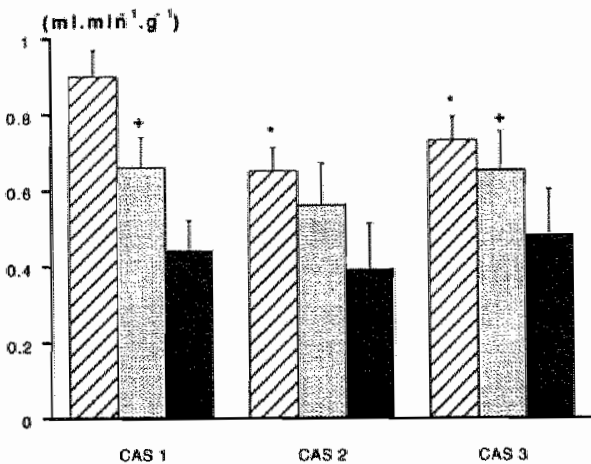

Fegional blood flow distribution in non-ischaemic (left) and ischaemic (right) myocardium in the placebo group (upper) and in the drug group (lower) as measured with radioactive microspheres.

Transmural samples were taken from the perfusion area of the LAD (ischaemic myocardium) and from the posterior wall and interventricular septum (non-ischaemic myocardium). Samples were divided into subendocardial, mid-wall and subepicardial layers. In this way, coronary blood flow could be measured simultaneously in non-ischaemic and ischaemic myocardium during the three stenoses. Striped bars = epicardial flow; grey bars $=$ midmyocardial flow; black bars $=$ endocardial flow; CAS $=$ coronary artery stenosis; mean \pm SEM data; $n=9$ in placebo group; $n=11$ in drug group; ${ }^{*}=$ significantly different from corresponding CAS 1 value; $+=$ significantly different from corresponding value in other group

Dexmedetomidine decreased plasma concentrations of norepinephrine from $121 \pm$ 17 to $25 \pm 12 \mathrm{pg} \cdot \mathrm{ml}^{-1}$.

After dexmedetomidine $3 \mu \mathrm{g} \cdot \mathrm{kg}^{-1}$, ischaemic/non-ischaemic blood flow ratios were significantly higher in the epicardial (from $0.81 \pm 0.07$ to $0.93 \pm 0.09$ ) and endocardial layers (from $0.33 \pm 0.06$ to $0.47 \pm 0.10$ ) compared to placebo (fig. 1).

Dexmedetomidine increased haemoglobin concentration from $7.2 \pm 0.2$ to $8.4 \pm 0.3$ mmol. $\mathrm{L}^{-1}$ and decreased myocardial oxygen demand from $4.91 \pm 0.33$ to $3.76 \pm 0.25$ $\mu \mathrm{mol} \cdot \mathrm{min}^{-1} \cdot \mathrm{g}^{-1}$. Regional myocardial oxygen consumption did not change after 
dexmedetomidine (from $3.08 \pm 0.39$ to $3.20 \pm 0.51 \mu \mathrm{mol}^{\prime} \cdot \mathrm{min}^{-1} \cdot \mathrm{g}^{-1}$ ). Dexmedetomidine decreased myocardial oxygen deficiency from $1.47 \pm 0.37$ to $0.29 \pm 0.32 \mu \mathrm{mol} \cdot \mathrm{min}^{-1} \cdot \mathrm{g}^{-1}$.

\section{DISCUSSION}

In this study, dexmedetomidine decreased myocardial oxygen demand and reduced blood flow in non-ischaemic myocardium. This was related to its haemodynamic effects: reduction in heart rate and $\mathrm{dP} / \mathrm{dt}_{\max }$. Blood flow in the ischaemic inner layers was preserved. In this way, the ischaemic/non-ischaemic blood flow ratio decreased and myocardial oxygen deficiency was reduced.

The effects of dexmedetomidine on regional blood flow in ischaemic myocardium are in accordance with studies on the effects of aspecific alpha-blockade or stimulation during ischaemia. ${ }^{3}$ Preservation of blood flow in ischaemic myocardium by alpha agonists is probably caused by the more powerful local metabolic stimuli during ischaemia, which overrule adrenergic vasoconstriction. As the degree of ischaemia is most severe in the inner layers during hypoperfusion, adrenergic vasoconstriction in this region is inhibited to a greater extent than in the outer layer.

Distal to a flow limiting stenosis, such specific epicardial vasoconstrictive effect may lead to improvement of endocardial perfusion, the "reverse steal" effect. ${ }^{3}$

The decrease in heart rate after dexmedetomidine could be an additional explanation for this beneficial effect on blood flow, because slowing of the heart rate favours endocardial relative to epicardial perfusion. The different findings of Heusch and Deussen ${ }^{2}$, who found that alpha ${ }_{2}$-adrenergic activation can worsen myocardial ischaemia, may be explained by differences in preparation, degree of ischaemia, anaesthesia and intensity and mode of alpha-adrenergic stimulation.

Our preparation was expected to be highly sensitive to the direct, peripheral vasoconstrictor effect of dexmedetomidine. ${ }^{4}$ Compared with humans, we therefore may have overestimated the coronary vasoconstrictive effects and underestimated the central sympatholytic effects of dexmedetomidine. This could also underestimate a possible anti-ischaemic effect of dexmedetomidine, because it was shown that systemic clonidine had anti-ischaemic properties, while intracoronary administration caused vasoconstriction. ${ }^{6}$ However, these results should be extrapolated with caution to potential clinical use in humans as the results relate only to halothane-anesthetized dogs. Halothane not only has marked haemodynamic effects, but could also have influenced the sympathetic responses.

\section{Acknowledgements}

This work was supported in part by Orion Corporation, Farmos, Turku, Finland. We thank Ruud Kruger, Theo Van Der Nagel and Jo Habets for expert technical assistance and Cees Van Leeuwen and Martin Luirink for help in data analysis. 


\section{REFERENCES}

1. Talke $P, L I J$, Jain $U$, Leung J, Drasner K, Hollenberg M, Mangano DT, The Study of Perioperative Ischemia Research Group: Effects of perioperative dexmedetomidine infusion in patients undergoing valscular surgery. Anesthesiology 1995; 82: 620-633

2. Heusch $G$, Deussen $A$. The effects of cardiac sympathetic nerve stimulation on perfusion of stenotic coronary arteries in the dog. Circ Res 1983; $53: 8-15$

3. Nathan Hd, Feigl EO. Adrenergic vasoconstriction lessens transmural steal during coronary hypoperfusion Am I Physiol 1986: 19: H645-H653

4. Roekaerts PMHJ, Prinzen FW, Willigers HMM, de Lange $S$ The effects of alphar-adrenergic stimulation with mivazerol on myocardial blood flow and function during coronary artery stenosis in anesthetized dogs. Anesth Analg 1996;82:702-711

5. Rooke GA, Feigl EO: Wark as a correlate of canine left ventricular oxygen consumption, and the problem of catecholamine oxygen wasting. Circ Res 1978; 42:79-86

6. Heusch $\mathrm{G}$, Schipke $\mathrm{J}$ and Thamer $\mathrm{V}$ : Clonidine prevents the sympathetic initiation and aggravation of poststenotic myocardial ischemia. J Cardiovasc Pharmacol 1985; 7: 1176-1182 
CHAPTER 8

The effects of alpha ${ }_{2}$-adrenergic stimulation with mivazerol on myocardial blood flow and function during coronary artery stenosis in anesthetized dogs

\author{
P.M.H.J. Roekaerts \\ F.W. Prinzen \\ H.M.M. Willigers \\ S. de Lange
}




\section{The effects of alpha $a_{2}$-adrenergic stimulation with mivazerol on myocardial blood flow and function during coronary artery stenosis in anesthetized dogs}

\section{ABSTRACT}

The central sympatholytic effect of alpha 2 agonists may be beneficial during myocardial ischemia, but could be opposed by their peripheral vasoconstrictive effect. We studied the effects of mivazerol during periods of moderate coronary artery stenosis in anesthetized dogs. Mivazerol decreased heart rate (from $125 \pm 6$ to $106 \pm 6$ beats. $\mathrm{min}^{-1}$ ) and cardiac output (from $4.4 \pm 0.6$ to $1.8 \pm 0.2 \mathrm{~L} \cdot \mathrm{min}^{-1}$ ) under normal conditions, while mean arterial pressure did not change. Mivazerol reduced blood flow in nonischemic myocardium and in the ischemic epicardial layer, but blood flow was preserved in the ischemic midmyocardial and subendocardial layer. Mivazerol had no effect on myocardial oxygen extraction during the stenoses, and regional myocardial oxygen consumption was unchanged. However, mivazerol decreased myocardial oxygen demand from $4.51 \pm 0.51$ to $3.17 \pm 0.24 \mu \mathrm{mol} \cdot \mathrm{min}^{-1} \cdot \mathrm{g}^{-1}$, thereby reducing oxygen deficiency of ischemic myocardium to values significantly lower than in the placebo group (from $1.07 \pm 0.32$ to $0.47 \pm 0.41 \mu \mathrm{mol} \cdot \mathrm{min}^{-1} \cdot \mathrm{g}^{-1}$ ). Mivazerol had no effect on myocardial lactate production during the stenoses. We conclude that mivazerol reduced myocardial oxygen demand while blood flow was preserved in the inner layers of ischemic myocardium.

Key words: alpha ${ }_{2}$-adrenergic agonists, cardiac function, mivazerol, myocardial ischemia, regional myocardial blood flow

\section{INTRODUCTION}

Alphag-adrenergic receptor agonists are useful adjuncts to anesthesia because of their anxiolytic, sedative, analgesic, anesthetic-sparing, sympatholytic, and hemodynamic stabilizing properties. ${ }^{1}$ There is evidence that the central effects of alpha 2 agonists may be beneficial in patients with ischemic heart disease. ${ }^{2}$

On the other hand, alpha 2 agonists can also cause peripheral and coronary vasoconstriction by stimulation of postjunctional alpha ${ }_{2}$-adrenergic receptors. ${ }^{3}$ The effect of peripheral alpha-adrenergic vasoconstriction during experimental myocardial ischemia is controversial. Heusch et al $1^{4,5}$ reported evidence for a detrimental role of alpha $a_{2}$-adrenoreceptor activation during sympathetic nerve stimulation and exer- 
cise in dogs with coronary stenosis. In contrast, other reports indicated that nonspecific alpha-adrenergic coronary constriction exerts a favorable effect on ischemic myocardium by preventing a transmural redistribution of blood flow away from the subendocardial layer. 6,7

Mivazerol is a new, highly specific and selective alpha ${ }_{2}$-adrenoreceptor agonist (UCB SA Pharma Sector, Braine l'Alleud, Belgium). ${ }^{8}$ Preliminary reports suggest that mivazerol has anti-ischemic effects both in animals and in humans. 9,10

The aim of the present study was to investigate whether mivazerol can protect the ischemic myocardium in an animal model known to be highly sensitive to the direct, peripheral vasoconstrictor effect of alpha 2 agonists. Therefore, the effects of mivazerol on regional myocardial blood flow, metabolic variables and regional contractile function were assessed during moderate coronary artery stenosis (CAS) in the anesthetized dog.

\section{MATERIAL AND METHODS}

\section{General preparation}

Mongrel dogs $(23-38 \mathrm{~kg})$ were studied after local animal ethical committee approval. After premedication with fentanyl $2 \mu \mathrm{g} \cdot \mathrm{kg}^{-1}$ intramuscularly, the dogs were anesthetized with pentobarbital $30 \mathrm{mg} \cdot \mathrm{kg}^{-1}$ intravenously and ventilated with oxygen/nitrous oxide $40 / 60 \%$ and halothane $1 \%$. Microtransducer-tipped catheters (Millar (PC 350), Houston, TX) were introduced into the aorta and into the left ventricle. A pulmonary artery catheter was introduced via an internal jugular vein. After suxamethonium 2 $\mathrm{mg} \cdot \mathrm{kg}^{-1}$ intravenously, the thorax was opened via the fifth left lateral intercostal space. An electromagnetic flow probe and an inflatable cuff were placed circumferentially distal to the first diagonal branch of the left descending coronary artery (LAD). Coronary artery pressure was measured via a catheter, inserted in the coronary artery distal to the cuff. The degree of stenosis was controlled by keeping constant the mean perfusion pressure distal to the site of the stenosis using a servosystem feeding a motor pump, which determined the degree of inflation of the cuff around the LAD. ${ }^{11}$ Another catheter was inserted into the coronary vein accompanying the artery to obtain regional venous blood samples.

\section{Epicardial deformation}

Epicardial deformation in the perfusion area of the LAD was measured with three inductive coils, as previously described. ${ }^{12}$ These coils were attached to the epicardium in a right-angled triangle. Segment length changes in three different directions were measured. The area decrease of the epicardial region enclosed by the coils, as calculated from the length changes in the three different directions during the ejection phase, was used as an estimate of regional contractile function. Assum- 
ing that volume of a certain part of the ventricular wall is constant throughout the cardiac cycle, surface area decrease is related to wall thickening.

\section{Hemodynamic measurements}

All the continuously measured parameters were displayed on an oscilloscope (Knott) and recorded on a multichannel Schwarzer recorder at $0.25 \mathrm{~cm} \mathrm{sec}{ }^{-1}$ with the speed increased to $5 \mathrm{~cm} \cdot \mathrm{sec}^{-1}$ during data acquisition. Hemodynamic measurements were also digitized with 12 bits at $200 \mathrm{~Hz}$ using a DASH $16 \mathrm{G} 2 \mathrm{~A} / \mathrm{D}$ convertor and stored on a Tulip Compact AT computer for further off-line analysis. Coronary vascular resistance was calculated as the quotient of distal LAD pressure and myocardial blood flow. The percentage coronary artery stenosis was calculated as [(mean arterial pressure -coronary artery pressure)/ mean arterial pressure] $100 \%$. Myocardial oxygen demand was estimated using the Pressure Work Index. ${ }^{13}$ Regional oxygen consumption was calculated using the data of blood flow and oxygen extraction. Oxygen deficiency was calculated by substracting oxygen consumption from oxygen demand. Cardiac output was measured in triplicate using cold injectate and the average taken (Edwards SAT-2 cardiac output computer).

\section{Myacardial blood flow measurements}

Radioactive microspheres, approximately 15 um in diameter, were used to determine regional myocardial blood flow, as previously described. ${ }^{11}$ Approximately $2.5 \cdot 10^{6}$ microspheres were injected into the left atrium for each measurement. A reference sample was taken from the brachial artery at a rate of $20.7 \mathrm{ml} \cdot \mathrm{min}^{-1}$ using a Harvard infusion/withdrawal pump. After the dogs were killed, transmural samples were taken from the perfusion area of the LAD (ischemic myocardium) and from the posterior wall and interventricular system (nonischemic myocardium). Samples were divided into subendocardial, midwall and subepicardial layers. In this way, coronary blood flow could be measured simultaneously in non-ischemic and ischemic myocardium during the three stenoses. All samples were weighed and counted in a gammacounter. From these data blood flow in $\mathrm{ml}_{\mathrm{min}}^{-1} \cdot \mathrm{g}^{-1}$ was calculated with the MIC II program.

\section{Metabolic measurements}

Blood gas tensions and blood $\mathrm{pH}$ were assessed with a Radiometer ABL 3 blood gas analyser. Hemoglobin $(\mathrm{Hb})$ content and oxygen saturation were determined with a Radiometer OSM-2 hemoximeter. Lactate concentration was determined spectrophotometrically (Cobas Bio System, Hoffman La Roche, Basel, Switzerland). Catecholamine concentrations in plasma were determined using high-performance liquid chromatography with coulometric electrochemical detection. Concentrations of mivazerol were determined at the Laboratory of Drug Metabolism and Pharmacokinetics of UCB SA Pharma Sector, Braine I" Alleud, Belgium. 


\section{Study protocol}

Twenty-one acutely instrumented dogs, in which three sequential CAS were applied, were studied. Decreases in cardiac output and $\mathrm{dP} / \mathrm{dt}$ max during the first stenosis were used as an estimate of the area at risk. To obtain a study group with a similar area at risk, five dogs were excluded from the study because changes in cardiac output and $\mathrm{dP} / \mathrm{dt}_{\max }$ during the first stenosis were minimal or very large. In this way, 16 dogs with similar hemodynamic changes during the first stenosis could be studied. In 8 dogs (drug group), mivazerol in two different doses was administered before the second and third CAS, while in the placebo group $(n=8)$ coronary stenoses were applied in a similar manner without drug administration. Reperfusion periods of 40 min were allowed after each ischemic episode. Halothane anesthesia was maintained at $1 \%$ throughout the experiment.

Five minutes prior to each CAS, control blood samples were taken, cardiac output was measured and all the continuously recorded hemodynamic variables were determined. Subsequently, mean pressure distal to the stenosis was decreased to about $40 \%$ of mean systemic arterial pressure. After 12 min of stenosis, microspheres were injected. After $14 \mathrm{~min}$ of stenosis, blood samples were taken and hemodynamic measurements were performed. Thereafter, the CAS was gradually released over a 3-min period. Recovery of coronary artery flow was checked using the traces of the flowprobe.

Twenty minutes after release of the first stenosis, recovery measurements of the hemodynamic and metabolic parameters were performed. Thereatter, mivazerol was administered in the drug group aiming at a target plasma concentration of $1 \mathrm{ng} \cdot \mathrm{ml}^{-1}$, using pharmacokinetic variables from beagle dogs. To this purpose, an initial infusion of mivazerol $50 \mu \mathrm{g} \cdot \mathrm{kg}^{-1} \cdot \mathrm{h}^{-1}$ was given over $5 \mathrm{~min}$ and a maintenance infusion of mivazerol started at the rate of $0.8 \mu \mathrm{g} \cdot \mathrm{kg}^{-1} \cdot \mathrm{h}^{-1}$ using infusion pumps. Twenty minutes after the start of the mivazerol infusion, control measurements were repeated followed by the second stenosis. After the second recovery measurements, the dose of mivazerol was increased in the drug group aiming at a target plasma concentration of $2 \mathrm{ng} \cdot \mathrm{ml}^{-1}$ by using an initial dose of mivazerol of $35 \mu \mathrm{g} \cdot \mathrm{kg}^{-1} \cdot \mathrm{h}^{-1}$ over $5 \mathrm{~min}$ and by increasing the maintenance infusion of mivazerol to $1.1 \mu \mathrm{g} \cdot \mathrm{kg}^{-1} \cdot \mathrm{h}^{-1}$.

\section{Statistical analysis}

A two-way analysis of variance for repeated measures was used for intergroup comparisons. Intragroup comparisons were evaluated using one-way analysis of variance for repeated measures and Fisher's protected least significant difference test as post-hoc test. Baseline values between the two groups were compared using Student's t-test. $P<0.05$ was considered significant. All results are expressed as mean \pm SEM. 
Table 1. Hemodynamic measurements and plasma concentrations of the catecholamines in the placebo group of anesthetized dogs

\begin{tabular}{|c|c|c|c|c|}
\hline & & CAS 1 & CAS 2 & CAS 3 \\
\hline $\begin{array}{l}\text { Heart rate } \\
\text { (beats-min }\end{array}$ & $\begin{array}{l}\text { control } \\
\text { stencisis }\end{array}$ & $\begin{array}{l}123 \pm 6 \\
116 \pm 8\end{array}$ & $\begin{array}{l}115 \pm 6 \\
123 \pm 7^{+}\end{array}$ & $\begin{array}{l}108 \pm 6 \\
121 \pm 9^{4}\end{array}$ \\
\hline $\begin{array}{l}\text { Mean arterial pressure } \\
(\mathrm{mmH})\end{array}$ & $\begin{array}{l}\text { control } \\
\text { stenasis }\end{array}$ & $\begin{array}{l}86 \pm 3 \\
88 \pm 5\end{array}$ & $\begin{array}{l}87 \pm 6 \\
86 \pm 6\end{array}$ & $\begin{array}{l}80 \pm 4 \\
89 \pm 8\end{array}$ \\
\hline $\begin{array}{l}\text { Left ventricular end-diastolic } \\
\text { pressure (mmHg) }\end{array}$ & $\begin{array}{l}\text { control } \\
\text { stenosis }\end{array}$ & $\begin{array}{r}9 \pm 1 \\
10 \pm 1\end{array}$ & $\begin{array}{l}11 \pm 1 \\
12 \pm 2\end{array}$ & $\begin{array}{r}9 \pm 1 \\
11 \pm 2\end{array}$ \\
\hline $\begin{array}{l}\mathrm{dP} / \mathrm{d} \mathrm{t}_{\text {max }} \text { (tirst derivative of } \\
\mathrm{LV} \text { pressure) }\left(\mathrm{mm} \mathrm{Hg} \cdot \mathrm{s}^{-1}\right)\end{array}$ & $\begin{array}{l}\text { Control } \\
\text { stenosis }\end{array}$ & $\begin{array}{l}1513 \pm 66 \\
1397 \pm 61\end{array}$ & $\begin{array}{l}1383 \pm 73 \\
1439 \pm 73^{+}\end{array}$ & $\begin{array}{l}1362 \pm 94^{+} \\
1384 \pm 104^{+}\end{array}$ \\
\hline $\begin{array}{l}\text { Cardiac output } \\
\left(\mathrm{L} \cdot \mathrm{min}^{-1}\right)\end{array}$ & $\begin{array}{l}\text { control } \\
\text { stenosis }\end{array}$ & $\begin{array}{l}4.1 \pm 0.4 \\
3.4 \pm 0.3^{3}\end{array}$ & $\begin{array}{l}3.5 \pm 0.3^{+} \\
3.9 \pm 0.5^{+}\end{array}$ & $\begin{array}{l}3.8 \pm 0.4^{+} \\
3.4 \pm 0.4^{+}\end{array}$ \\
\hline $\begin{array}{l}\text { Systemic vascular resistance } \\
(\text { dyne.s.cm } \\
\end{array}$ & $\begin{array}{l}\text { control } \\
\text { stenosis }\end{array}$ & $\begin{array}{l}1750 \pm 116 \\
2159 \pm 219\end{array}$ & $\begin{array}{l}2120 \pm 294^{+} \\
2007 \pm 331^{+}\end{array}$ & $\begin{array}{l}1781 \pm 179^{*} \\
2250 \pm 281^{*}\end{array}$ \\
\hline $\begin{array}{l}\text { Distal coronary pressure } \\
(\mathrm{mmilg})\end{array}$ & $\begin{array}{l}\text { control } \\
\text { stenosis }\end{array}$ & $\begin{array}{l}82 \pm 5 \\
34 \pm 2^{87}\end{array}$ & $\begin{array}{l}80 \pm 5^{+} \\
32 \pm 2^{4}\end{array}$ & $\begin{array}{l}73 \pm 3^{*} \\
32 \pm 3^{*}\end{array}$ \\
\hline $\begin{array}{l}\text { Percent coronary stenosis } \\
\text { Myocardial oxygen demand } \\
\left.\text { (umol } \min ^{-1} \cdot \mathrm{g}^{-1}\right)\end{array}$ & $\begin{array}{l}\text { stenosis } \\
\text { control } \\
\text { stenosis }\end{array}$ & $\begin{array}{c}61 \pm 2 \\
4.48 \pm 0.35 \\
4.111 \pm 0.34\end{array}$ & $\begin{array}{c}63 \pm 1 \\
4.01 \pm 0.29 \\
4.37 \pm 0.42^{+}\end{array}$ & $\begin{array}{l}64 \pm 2 \\
3.94 \pm 0.33^{*} \\
4.14 \pm 0.40^{*}\end{array}$ \\
\hline $\begin{array}{l}\text { Myocardial oxygen consumption } \\
\left(\mu \mathrm{mol} \cdot \mathrm{min}^{-1} \cdot \mathrm{g}^{-1}\right)\end{array}$ & stenosis & $2.66 \pm 0.27$ & $2.88 \pm 0.58$ & $2.62 \pm 0.36$ \\
\hline $\begin{array}{l}\text { Hemoglobin in arterial blood } \\
\left(\text { mmol. } L^{-1}\right)\end{array}$ & control & $7.3 \pm 0.3$ & $7.5 \pm 0.2^{*}$ & $7.4 \pm 0.3^{+}$ \\
\hline $\begin{array}{l}\text { Arterial-coronary venous oxygen } \\
\text { saturation }(\%)\end{array}$ & $\begin{array}{l}\text { control } \\
\text { stenosis. }\end{array}$ & $\begin{array}{l}0.58 \pm 0.06 \\
0.65 \pm 0.05\end{array}$ & $\begin{array}{l}0.60 \pm 0.06 \\
0.71 \pm 0.06\end{array}$ & $\begin{array}{l}0.53 \pm 0.09 \\
0.51 \pm 0.15\end{array}$ \\
\hline $\begin{array}{l}\text { Arterilal-coronary venous oxygen } \\
\text { content }(\text { mmol } L-1-1)\end{array}$ & $\begin{array}{l}\text { control } \\
\text { stenosis }\end{array}$ & $\begin{array}{l}3.93 \pm 0.25 \\
4.68 \pm 0.35^{*}\end{array}$ & $\begin{array}{l}4.22 \pm 0.32 \\
5.25 \pm 0.24\end{array}$ & $\begin{array}{l}4.28 \pm 0.37 \\
4.98 \pm 0.45\end{array}$ \\
\hline $\begin{array}{l}\text { Norepinephrine } \\
\left(\mathrm{pg} \cdot \mathrm{m}^{-1}\right)\end{array}$ & $\begin{array}{l}\text { contral } \\
\text { stenosis }\end{array}$ & $\begin{array}{l}121 \pm 36 \\
107 \pm 21\end{array}$ & $108 \pm 35$ & $166 \pm 45^{+}$ \\
\hline $\begin{array}{l}\text { Epinephrine } \\
\left(\text { pgl.m| }\left.\right|^{* 1}\right)\end{array}$ & $\begin{array}{l}\text { Gontrol } \\
\text { stenosis }\end{array}$ & $\begin{array}{l}164 \pm 59 \\
221 \pm 79\end{array}$ & $145 \pm 57$ & $220 \pm 66$ \\
\hline $\begin{array}{l}\text { Mivazero } \\
\left(\text { (ng } \mathrm{ml}^{-1}\right)\end{array}$ & control & $a \pm 0$ & $0 \pm 0^{+}$ & $0 \pm 0^{+}$ \\
\hline
\end{tabular}

Mean $\pm S E M$ data; $n=8 ; C A S=$ coronary artery stenosis; $L V=$ left ventricular; control $=5$ min before $C A S$; stenosis = after $12-14 \mathrm{~min}$ of CAS; " = significantly different from corresponding CAS 1 value; \#= significantly different from preceding control value; $+=$ significantly different from corresponding value in the drug group. 


\section{RESULTS}

Hemodynamic measurements and plasma concentrations of the catecholamines and mivazerol.

In the placebo group (Table 1), control values (before each CAS) of these variables were not significantly different from each other, apart from the distal coronary pressure before CAS 3 .

In the drug group (Table 2), mivazerol dose-dependently decreased heart rate, $\mathrm{dP} / \mathrm{dt}_{\text {max }}$ and cardiac output and increased left ventricular end-diastolic pressure and systemic vascular resistance.

In both groups, cardiac output significantly decreased during the first stenosis compared to the pre-stenosis control values.

In the drug group, $\mathrm{dP} / \mathrm{dt}_{\max }$ was significantly lower during than before the first stenosis, but not significantly different from the corresponding value in the placebo group.

The norepinephrine plasma concentration was significantly lower in the drug group compared to the placebo group after the higher dose of mivazerol.

In the placebo group, oxygen extraction significantly increased during CAS 1 and CAS 2 compared to pre-stenosis control values.

Mivazerol significantly increased oxygen extraction in the absence of CAS, but did not influence oxygen extraction during CAS. No significant differences were found between the two study groups.

\section{Myocardial blood flow}

In nonischemic and ischemic myocardium of the placebo group, no significant changes in subepicardial, midmyocardial or subendocardial blood flow were observed between the three periods of CAS (Figure 1).

Mivazerol decreased blood flow in all three layers of the non-ischemic myocardium. In contrast, in the ischemic myocardium of the drug group, blood flow decreased only in the epicardial layer. The difference between the 2 groups was only significant for the ischemic subepicardial layer during CAS 3.

\section{Coronary vascular resistance}

In the placebo group, no significant changes were observed in the coronary vascular resistance (Figure 2).

Mivazerol increased coronary vascular resistance in all layers of the nonischemic myacardium. In the ischemic myocardium, mivazerol increased only coronary vascular resistance in the subepicardial layer. No significant differences were found in the ischemic myocardium between the two groups. 
Table 2. Hemodynamic measurements and plasma concentrations of the catecholamines and mivazerol in the drug group of anesthetized dogs

\begin{tabular}{|c|c|c|c|c|}
\hline & & CAS 1 & CAS 2 & CAS 3 \\
\hline $\begin{array}{l}\text { Heart rate } \\
\text { (beats } \min ^{-1} \text { ) }\end{array}$ & $\begin{array}{l}\text { control } \\
\text { stenosis }\end{array}$ & $\begin{array}{l}125 \pm 6 \\
126 \pm 3\end{array}$ & $\begin{array}{l}109 \pm 5 \\
106 \pm 3^{+}\end{array}$ & $\begin{aligned} 106 & \pm 6^{*} \\
99 & \pm 4^{*}\end{aligned}$ \\
\hline $\begin{array}{l}\text { Mean arterial pressure } \\
(\mathrm{mmH}-\mathrm{H})\end{array}$ & $\begin{array}{l}\text { control } \\
\text { stenosis }\end{array}$ & $\begin{array}{l}87 \pm 8 \\
85 \pm 7\end{array}$ & $\begin{array}{l}98 \pm 9 \\
94 \pm 4\end{array}$ & $\begin{array}{l}91 \pm 5 \\
90 \pm 5\end{array}$ \\
\hline $\begin{array}{l}\text { Left ventricular end-ciastolic } \\
\text { pressure (mmHg) }\end{array}$ & $\begin{array}{l}\text { control } \\
\text { stenosis }\end{array}$ & $\begin{array}{l}8 \pm 1 \\
7 \pm 1\end{array}$ & $\begin{array}{l}14 \pm 1^{\circ} \\
12 \pm 2^{*}\end{array}$ & $\begin{array}{l}12 \pm 2^{*} \\
13 \pm 2^{2}\end{array}$ \\
\hline $\begin{array}{l}\mathrm{dP} / \mathrm{dt}_{\text {max }} \text { (first derivative of } \\
\mathrm{LV} \text { pressure) }\left(\mathrm{mmHg} \cdot \mathrm{s}^{-1}\right)\end{array}$ & $\begin{array}{l}\text { control } \\
\text { stenosis }\end{array}$ & $\begin{array}{l}1551 \pm 131 \\
1412 \pm 91\end{array}$ & $\begin{array}{l}1280 \pm 115^{\circ} \\
1208 \pm 85^{\circ}\end{array}$ & $\begin{array}{l}1134 \pm 61^{2}+ \\
1049 \pm 65^{2+}\end{array}$ \\
\hline $\begin{array}{l}\text { Cardiac output } \\
\left(L \cdot \min ^{-1}\right)\end{array}$ & $\begin{array}{l}\text { control } \\
\text { stenosis }\end{array}$ & $\begin{array}{l}4.4 \pm 0.6 \\
3.8 \pm 0.5^{\text {f }}\end{array}$ & $\begin{array}{l}2.5 \pm 0.3^{*} * \\
2.3 \pm 0.3^{*}\end{array}$ & $\begin{array}{l}1.8 \pm 0.2^{2}+ \\
1.7 \pm 0.2^{*}+\end{array}$ \\
\hline $\begin{array}{l}\text { Systemic vascular resistance } \\
\left(\text { dyne } 5 \mathrm{~cm}^{-5}\right)\end{array}$ & $\begin{array}{l}\text { contral } \\
\text { stenosis }\end{array}$ & $\begin{array}{l}1560 \pm 176 \\
1851 \pm 283\end{array}$ & $\begin{array}{l}3972 \pm 1086^{11+} \\
4158 \pm 1052^{x+}\end{array}$ & $\begin{array}{l}4311 \pm 541^{*}+ \\
4741 \pm 914^{\prime \prime}\end{array}$ \\
\hline $\begin{array}{l}\text { Distal coronary pressure } \\
(\mathrm{mm} H \mathrm{Hg})\end{array}$ & $\begin{array}{l}\text { control } \\
\text { stenosis }\end{array}$ & $\begin{array}{l}75 \pm 3 \\
34 \pm 2^{\text {Hi }}\end{array}$ & $\begin{array}{l}96 \pm 9^{*+} \\
39 \pm 2^{\#}\end{array}$ & $\begin{array}{l}86 \pm 5^{*} \\
38 \pm 2^{*}\end{array}$ \\
\hline Percent coronary stenosis & stenosis & $59 \pm 3$ & $58 \pm 1$ & $58 \pm 2$ \\
\hline $\begin{array}{l}\text { Myocardial oxygen demand } \\
\left(\mu \mathrm{mol} \cdot \mathrm{min}^{-1} \cdot \mathrm{g}^{-1}\right)\end{array}$ & $\begin{array}{l}\text { control } \\
\text { stenosis }\end{array}$ & $\begin{array}{l}4.51 \pm 0.51 \\
4.05 \pm 0.30\end{array}$ & $\begin{array}{l}3.82 \pm 0.42^{\prime \prime} \\
3.45 \pm 0.24^{* *}\end{array}$ & $\begin{array}{l}3.17 \pm 0.24^{*+} \\
2.97 \pm 0.23^{\circ+}\end{array}$ \\
\hline $\begin{array}{l}\text { Myocardial oxygen consumption } \\
\left(\text { umol } \min ^{-1} \cdot g^{-1}\right)\end{array}$ & stenasis & $2.83 \pm 0.13$ & $2.87 \pm 0.21$ & $2.50 \pm 0.41$ \\
\hline $\begin{array}{l}\text { Hemoglobin in arterial blood } \\
\left(\text { mmoll } \mathrm{L}^{-1}\right)\end{array}$ & control & $7.1 \pm 0.2$ & $8.7 \pm 0.5^{\mathrm{m}+\phi}$ & $8.7 \pm 0.4^{*+}$ \\
\hline $\begin{array}{l}\text { Arteriall-coronaly venous oxygen } \\
\text { saturation }(\%)\end{array}$ & $\begin{array}{l}\text { control } \\
\text { stenosis: }\end{array}$ & $\begin{array}{l}0.51 \pm 0.03 \\
0.68 \pm 0.02^{11}\end{array}$ & $\begin{array}{l}0.57 \pm 0.03 \\
0.62 \pm 0.03\end{array}$ & $\begin{array}{l}0.58 \pm 0.02 \\
0.62 \pm 0.05\end{array}$ \\
\hline $\begin{array}{l}\text { Arterial-coronary venous oxygen } \\
\left.\text { content (mmol. } \mathrm{L}^{* 1}\right)\end{array}$ & $\begin{array}{l}\text { control } \\
\text { stenosis }\end{array}$ & $\begin{array}{l}3.66 \pm 0.22 \\
4.81 \pm 0.18^{4}\end{array}$ & $\begin{array}{l}5.11 \pm 0.18^{*} \\
5.35 \pm 0.25\end{array}$ & $\begin{array}{l}5.04 \pm 0.33^{*} \\
5.15 \pm 0.44\end{array}$ \\
\hline $\begin{array}{l}\text { Norepinephrine } \\
\left(\operatorname{pg} \mathrm{m}^{-1}\right)\end{array}$ & $\begin{array}{l}\text { control } \\
\text { stenosis }\end{array}$ & $\begin{array}{l}82 \pm 12 \\
89 \pm 13\end{array}$ & $57 \pm 18$ & $51 \pm 14^{*}$ \\
\hline $\begin{array}{c}\text { Epinephrine } \\
\left(\text { pg } \mathrm{ml}^{-1}\right)\end{array}$ & $\begin{array}{l}\text { control } \\
\text { stenosis }\end{array}$ & $\begin{array}{l}257 \pm 95 \\
191 \pm 58\end{array}$ & $385 \pm 304$ & $257 \pm 190$ \\
\hline $\begin{array}{l}\text { Mivazerol } \\
\left(\text { ng } \mathrm{ml}^{-1}\right)^{\mathrm{j}}\end{array}$ & control & $0 \pm 0$ & $1.39=0.29^{*}+$ & $1.82 \pm 0.13^{*+\infty}$ \\
\hline
\end{tabular}

Mean $\pm S E M$ data; $n=8 ; C A S=$ coronary artery stenosis; $L V=$ left ventricular control $=5 \mathrm{~min}$ before $C A S$; stenosis = after 12-14 min of CAS; * = significantly different from corresponding CAS 1 value; \# = significantly different from preceding control value; $+=$ significantly different from corresponding value in the placebo group $; ~=$ significantly different from corresponding CAS 2 value. 
Blood flow in non-lechemlc myociardium in placebo glrowp $\left(\mathrm{m} \min \min ^{2}+g^{3}\right)$

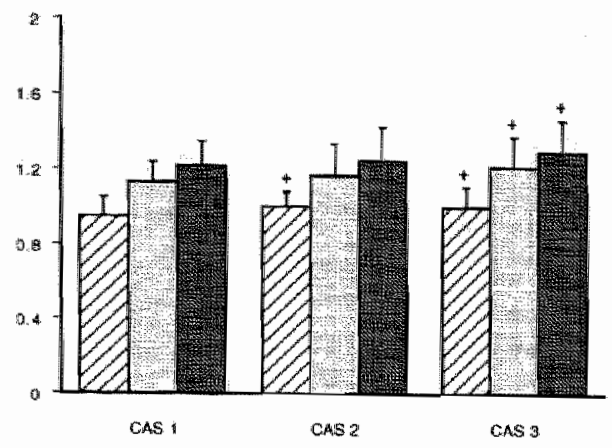

Blood flow in nom-lisehamile myosardium lo drug group $\left(m \ln m i i^{3} \cdot a^{i}\right)$

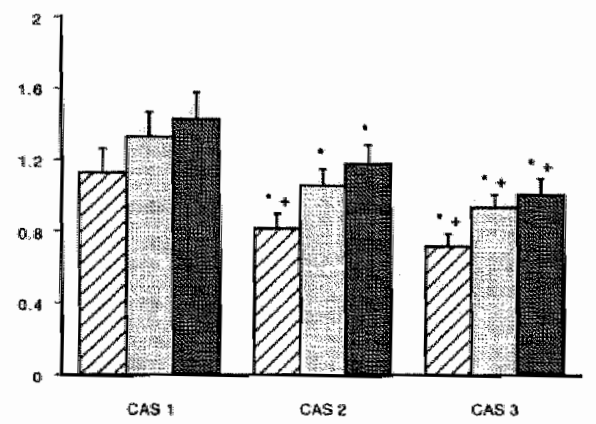

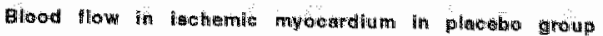
(

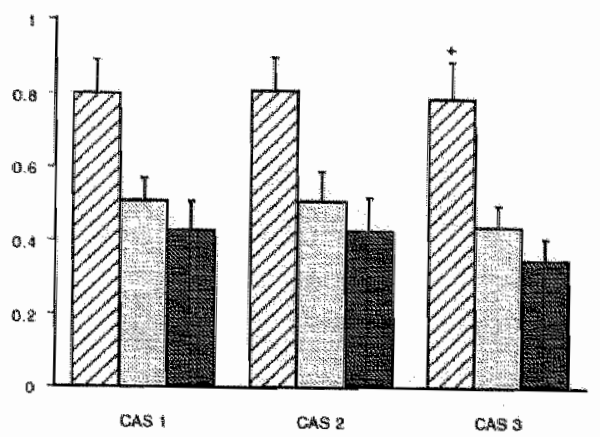

Blood tlow in lachentle myocarelium in drug group

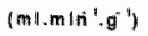

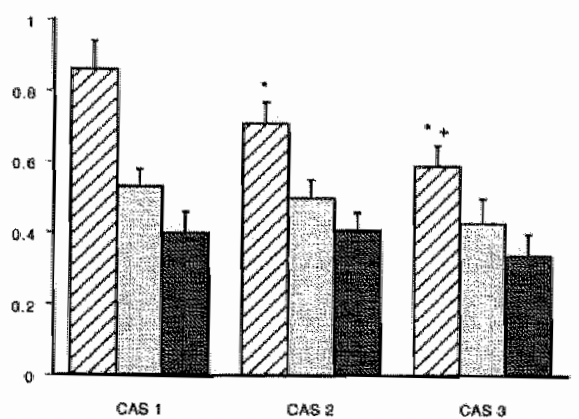

Figure 1. Regional blood flow distribution in non-ischemic (left) and ischemic (right) myocardium in the placebo group (upper) and in the drug group (lower)

Striped bars = epicardial flow; light grey bars = midmyocardial flow; dark grey bars = endocardial flow; CAS = coronary artery stenosis; Mean \pm SEM data; $n=8$ in both groups; * $=$ Significantly different from corresponding CAS 1 value; * = Significantly different from corresponding value in other group (Note the doubling of the flow scale in the nonischemic myocardium as compared to the ischemic myocardiumy.

\section{Myocardial metabolism and regional contractile function}

All three consecutive episodes of CAS decreased the arterial-cronary venous lactate difference in both groups to the same extent. No significant differences were found between the two study groups (Figure 3).

In the placebo group, no significant differences were observed between the three control and recovery values of surface area decrease (Figure 3). Stenosis reduced surface area decrease to a similar extent during the three stenoses. 

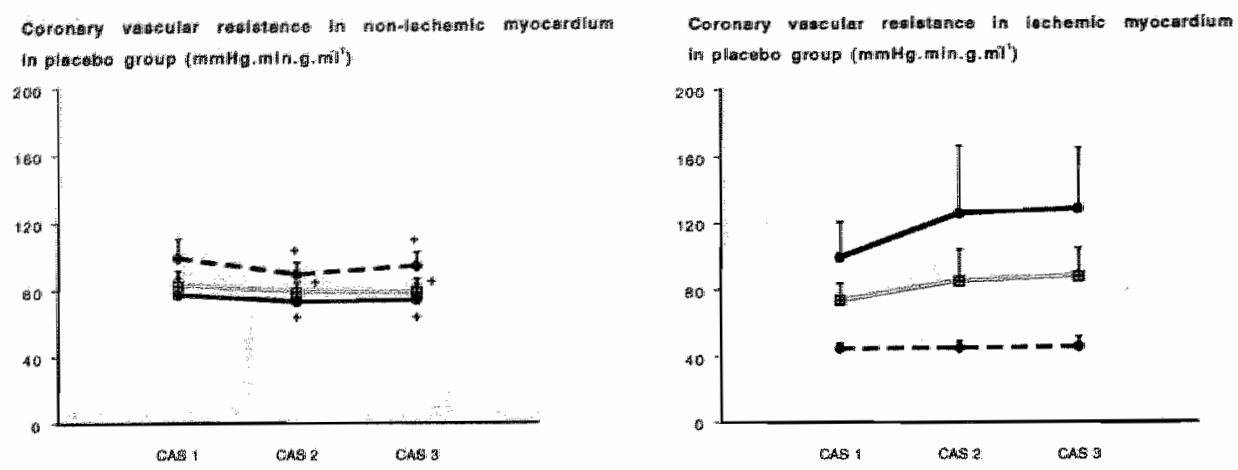

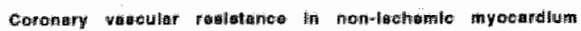

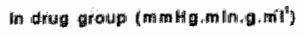

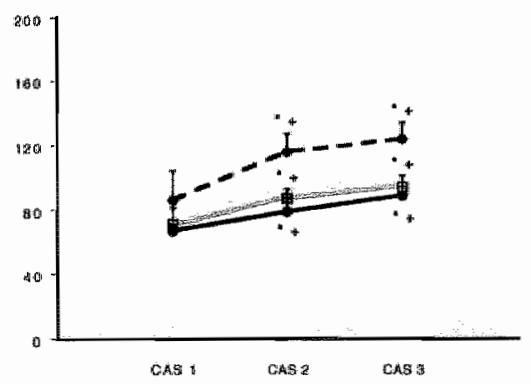

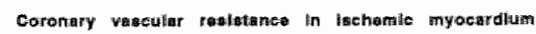

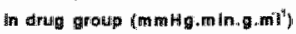

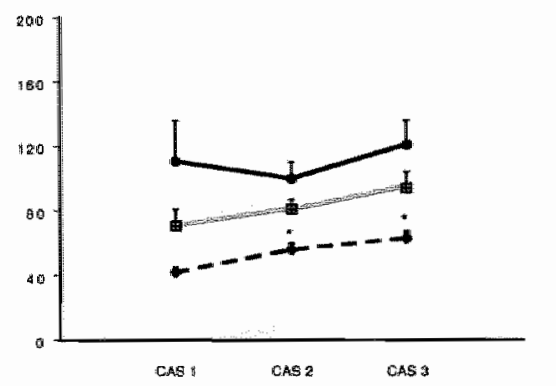

Figure 2. Coronary vascular resistance in non-ischemic (left) and ischemic (right) myocardium in the placebo group (upper) and in the drug group (lower)

Striped line = epicardial flow; grey line = midmyocardial flow; solid line = endocardial flow; CAS = coronary artery stenosis; Mean \pm SEM; $n=8$ in both groups: ${ }^{*}=$ significantly different from corresponding CAS 1 value; $+=$ significantly different from corresponding value in other group.

In the drug group, mivazerol dose-dependently reduced surface area decrease before onset of the stenoses. Surface area decrease during the third stenosis was significantly lower than during the first stenosis.

No significant differences were found between the two study groups.

\section{Myacardial axygen deficiency}

As shown in Figure 4, myocardial oxygen deficiency during the second and third CAS was significantly lower in the mivazerol group than in the placebo group. 
Arterial a coromary venous lactate difference in pliatebo group (man all. $\mathrm{L}^{\mathrm{y}}$ )

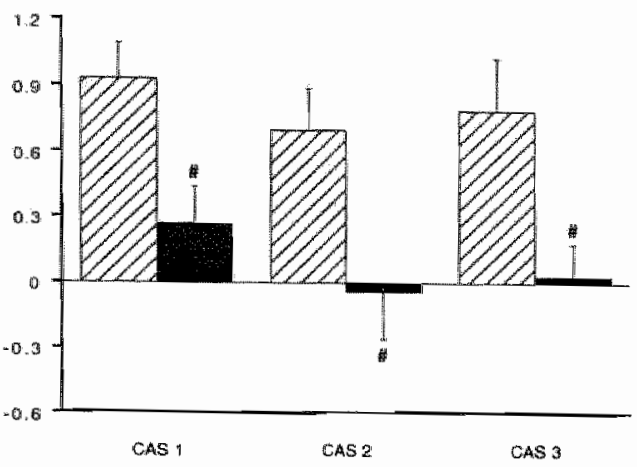

Arterial - coranary wanous vactate difference in erug groujp (mmoi. [1)

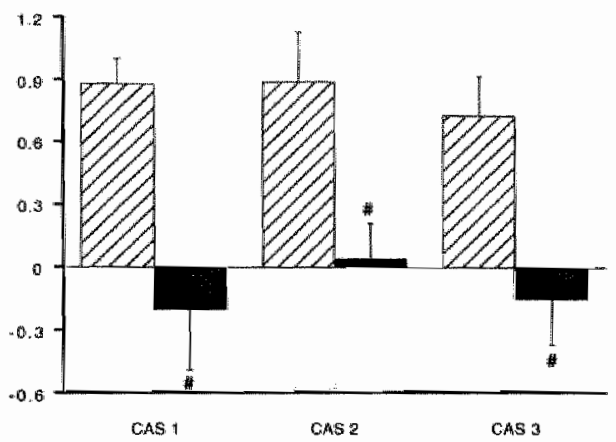

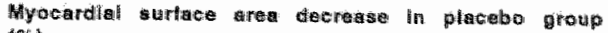
(\%)

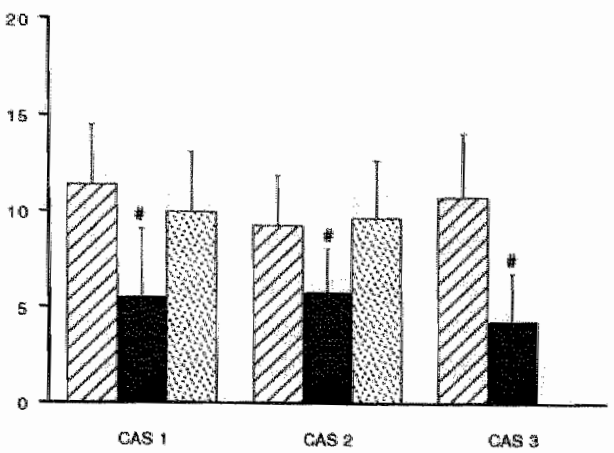

Ayyacardal aurfaco araia decreaso In drug group (4)

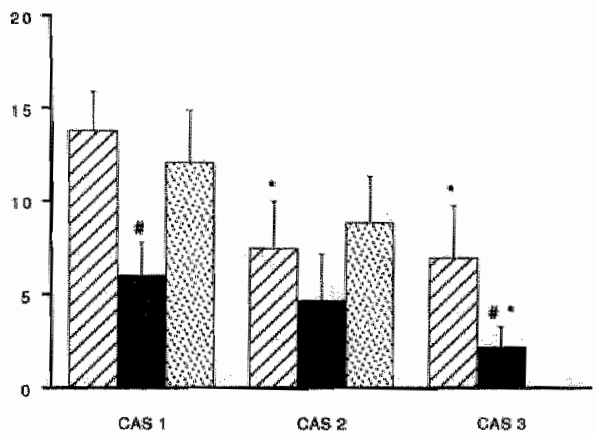

Figure 3. Arterial - coronary wenous lactate differences (left) and myocardial surface area decreases in the placebo group (upper) and in the drug group (lower)

Striped bars = before coronary stenosis; dark grey bars = during stenosis; light grey bars $=10$ min after release of stenosis; CAS $=$ coronary artery stenasis; Mean \pm SEM data; $n=8$ in both groups; * $=$ significantly different from corresponding CAS 1 value;

H mall, $\left.\mathbf{m} \| \mathrm{n}^{1} \cdot \mathrm{g}^{-1}\right)$

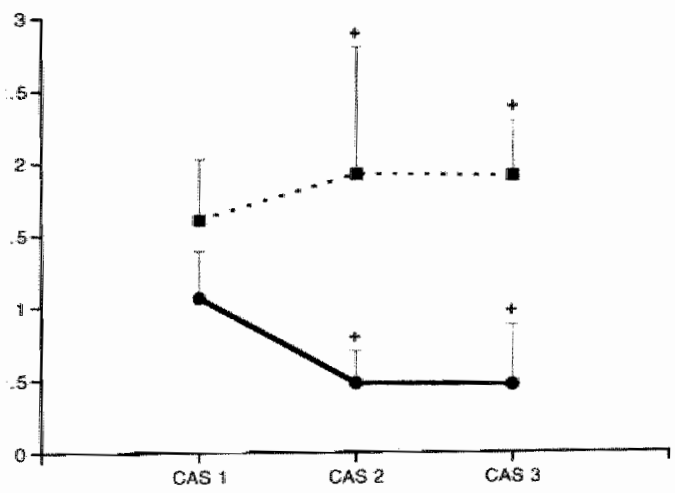

Figure 4. Myocardial oxygen deficiency in the placebo group and in the drug group Striped tine = placebo group; sollid line = drug group; $C A S$ = coronary antery stenosis; mean \pm SEM data; $n=B$ in both groups; + = significantly different from colresponding value in other group. 


\section{DISCUSSION}

The hemodynamic effects of mivazerol (increases in systemic vascular resistance and left ventricular end-diastolic pressure and reductions in heart rate, cardiac output, and $\mathrm{dP} / \mathrm{dt}_{\max }$ ) are similar to those of other alpha 2 agonists, both in animal and in humans. ${ }^{14.15}$

In the present study, mivazerol reduced myocardial oxygen demand and blood flow in non-ischemic myocardium. However, blood flow and oxygen consumption of ischemic myocardium did not decrease, thereby reducing oxygen deficiency of the ischemic myocardium to values significantly lower than in the placebo group. These changes did not result in altered metabolism or contractile function of ischemic myocardium.

Mivazerol decreased myocardial oxygen demand due to its hemodynamic effects and increased arterial hemoglobin content. These effects decrease myocardial perfusion requirements. Other investigators have shown that alpha-adrenergic vasoconstriction can compete with this metabolic vasoregulation. ${ }^{16}$ In the present experiment, although there was a significant increase in oxygen extraction after mivazerol, no change in lactate production was observed. This suggests that the reduction of coronary blood flow in non-ischemic myocardium was probably primarily due to metabolic vasoregulation rather than to adrenergic vasoconstriction.

There are several possible explanations for the beneficial preservation of blood flow in the ischemic endocardial layer by mivazerol. Mivazerol decreased heart rate and slowing of heart rate is known to favor endocardial relative to epicardial perfusion since endocardial flow occurs mainly in diastole. ${ }^{17}$ Alsa, metabolic vasodilation could overrule adrenergic vasoconstriction in these layers. This possibility is supported by evidence that hypoxia and acidosis can impair adrenergic coronary vasoconstriction. ${ }^{17}$ As the degree of ischemia is most severe in the inner layers during hypoperfusion, ${ }^{17}$ inhibition of adrenergic vasoconstriction may be larger in these layers. Other possibilities for non-uniform coronary vasoconstriction, like a gradient in the density of coronary alpha-adrenergic receptors or sympathetic nerves, are not supported by other experimental findings. ${ }^{18}$

Our results are in contrast with findings that alpha $a_{2}$-adrenergic actvation by exercise or nerve stimulation can induce myocardial ischemia. ${ }^{4,5}$ The different findings may be explained by differences in the preparation, degree of ischemia, anesthesia and intensity and mode of alpha-adrenergic stimulation. Our results also do not substantiate the findings of Kitakaze and co-workers ${ }^{19}$ who reported a vasodilatory effect of intracoronary clonidine in ischemic myocardium of beta-blocked anesthetized dogs. In our experiments, mivazerol did not decrease vascular resistance in the ischemic myocardium.

Regional contractile function decreased with increasing doses of mivazerol, probably related to the decreased overall myocardial contractility. Therefore, the decreased regional contractile function during the third stenosis as compared to the first stenosis appears to be primarily related to this decreased contractility rather than to aggravated ischemia. This idea is supported by the finding that changes in surface 
area decrease from control to stenosis were not significantly different between CAS 1 and CAS 3.

\section{Canine versus human alphaz-adrenergic stimulation}

Our preparation was expected to be highly sensitive to the direct, peripheral vasoconstrictor effect of mivazerol. Firstly, sympathetic outflow was low in these anesthetized, unstressed animals. This would limit the central sympatholytic effect of the drug and emphasize the peripheral effect. Secondly, Bloor et al ${ }^{15}$ suggested that the peripheral vasoconstrictive effects of alpha adrenergic stimulation are more pronounced in dogs than in humans. ${ }^{15}$ The dose-response relationship, however, is so steep that only a full exploration of different doses would clarify that postulate. Nevertheless, administration of dexmedetomidine $2 \mu \mathrm{g} \cdot \mathrm{kg}^{-1}$ in humans resulted in a $100 \%$ increase in systemic vascular resistance ${ }^{15}$ and a $28 \%$ increase in coronary vascular resistance. ${ }^{20}$ In contrast we found a $160 \%$ increase in systemic vascular resistance and a $50 \%$ increase in coronary vascular resistance in anesthetized dogs. Similarly, Schmeling et al ${ }^{21}$ reported a $180 \%$ increase in systemic vascular resistance in awake dogs after dexmedetomidine $1.25 \mu \mathrm{g} \cdot \mathrm{kg}^{-1}$. We may have overestimated the coronary vasoconstrictive effects and uderestimated the central sympatholytic effects of mivazerol compared to humans. This could also underestimate a possible anti-ischemic effect of mivazerol, because Heusch et al ${ }^{22}$ showed that the central effects of systemic clonidine had anti-ischemic properties, while the intracoronary administration caused coronary vasoconstriction.

There is only one report describing the effects of alphaz-adrenergic stimulation on the coronary vasculature in humans. ${ }^{20}$ Intracoronary administration of an alpha. agonist produced a reduction in coronary blood flow in humans with angiographically normal coronary arteries. In patients with CAS, regional coronary blood flow decreased after alpha 2 -receptor blockade, probably related to prejunctional release of norepinephrine. This suggests that alpha $a_{2}$-adrenergic agonists do not produce untoward coronary vasoconstriction in ischemic myocardium.

\section{Experimental model considerations}

In the present study, an experimental model of three repetitive moderate coronary artery stenoses of short duration followed by myocardial reperfusion periods was used, allowing to use each dog as its own control.

We used distal coronary artery pressure rather than percent reduction of flow or percent narrowing of coronary artery to control the degree of stenosis. One of the advantages of this method is that during coronary stenosis distal pressure can still be measured accurately. Moreover, in ischemic myocardium, autoregulation is almost exhausted and coronary blood flow highly depends on perfusion pressure. Another advantage of this technique is that the post-stenotic coronary artery pressure takes into account the pressure transmitted through the stenosis and through the collaterals, which may be considerable in the dog. 23 In validation studies of this method, it 
was shown that within and between individuals reproducible stenoses could be induced. ${ }^{24}$ Using this technique, if arterial blood pressure would be different between the various episodes of CAS, this would also affect coronary perfusion pressure. The same would be the case if a fixed stenosis was applied. In this study, the pharmacological intervention did not lead to significant differences in perfusion pressure during any of the stenoses. Moreover, by calculation of the coronary vascular resistance, influences of perfusion pressure on residual blood flow were taken into account.

It is not likely that ischemic preconditioning was effective in our experiment, because 40-minute reperfusion periods were allowed after each ischemic episode and the protective action of preconditioning is transient and wanes quite rapidly following reperfusion. 25 The moderate degree of ischemia also did not induce myocardial stunning. This is evidenced by the recovery of surface area decrease after each stenosis in the placebo group. Also, no hemodynamic changes were seen under nonischemic conditions prior to the second and third period of CAS, indicating the stability of the model. Hemodynamic changes caused by the first CAS in the placebo group were not significantly different from hemodynamic changes caused by the first CAS in the drug group (prior to the drug administration). We therefore assumed that the area at risk was similar in both groups.

\section{Conclusions}

We conclude that mivazerol decreased myocardial oxygen demand and reduced blood flow in non-ischemic myocardium. Because mivazerol did not change blood flow in underperfused midmyocardial and subendocardial layers, oxygen deficiency of ischemic myocardium was less than in the placebo group. These effects were not accompanied by changes in metabolism and function of ischemic myocardium.

\section{Acknowledgements}

The authors thank Ruud Kruger and Theo Van Der Nagel for their expert technical assistance. The authors also thank UCB SA Pharma Sector, Braine l'Alleud, Belgium, for generously supplying mivazerol and for the determination of the plasma concentrations of the catecholamines and mivazerol. 


\section{REFERENCES}

1. Maze $\mathrm{M}_{3}$ Tranquilli $\mathrm{W}$ : Alpha2-Adrenoreceptor agonists: defining the role in clinical anesthesia. Anesthesiology 1991; 74: 581-605

2. Dorman $\mathrm{BH}$, Zucker JR, Verrier ED: Clonidine improves perioperative myocardial ischemia, reduces anesthetic requirements, and alters hemodynamic parameters in patients undergoing coronary artery bypass surgery. J Cardiothorac Vasc Anesth 1993; 7: 386-395

3. Coughlan MG, Lee JG, Bosnjak ZJ, Schmeling WT, Kampine JP, Warltier DC: Direct coronary and cerebral vascular responses to dexmedetomidine. Anesthesiology 77: 998-1006, 1992

4. Heusch $G$, Deussen $A$ : The effects of cardiac sympathetic nerve stimulation on perfusion of stenotic coronary arteries in the dog. Circ Res 1983; 53: $8-15$

5. Seitelberger $\mathrm{R}$, Guth $\mathrm{BD}$, Heusch $\mathrm{G}$ : Intracoronary alpha 2 -adrenergic receptor blockade attenuates ischemia in conscious dogs during exercise. Circ Res 1988; 62: 436-442

6. Nathan HJ, Feigl EO: Adrenergic vasoconstriction lessens transmural steal during coronary hypoperfusion. Am J Physiol (Heart Circ Physiol) 1986", 19: H645-H653

7. Chilian WM, Ackell PH: Transmural differences in sympathetic coronary constriction during exercise in the presence of coronary stenosis. Circ Res $1988 ; 62: 216-225$

8. Noyer $M$, De Laveleye $F$, Vauquelin $G$ : Mivazerol a novel compound with high specificity for alphaz adrenergic receptors: binding studies on different human and rat membrane preparations. Neurochem. Int. 1994; 24: 221-229

9. Kharkevitch T, Noyer M, Guyaux M: Mivazerol, a new alphaz-adrenergic agonist with anti-ischaemic effects in animal models of myocardial ischaemia. J Cardiothorac Vasc Anesth 1994: 8(3), suppl 2, 86

10. Wright RA, Decroly $P$, Kharkevitch $T$, Oliver MF: Exercise tolerance in angina is improved by mivazerol-an alpha 2 -adrenoreceptor agonist. Cardiovasc Drugs Ther 1993; 7; 929-934

11. Prinzen FW, Alewilinse R, Van der Vusse GJ: Coronary artery stenosis controlled by distal perfusion pressure: description of the senvo-system and time-dependent changes in regional myocardial blood flow. Basic Res Cardiol 1987; 82: 375-387

12. Prinzen FW, Arts T, van der Vusse GJ: Gradients in fiber shortening and metabolism across ischemic left ventricular wall. Am I Physial (Heart Circ Physiol) 1986; 250: H255-H264

13. Rooke GA, Feigl EO: Work as a correlate of canine left ventricular oxygen consumption, and the problem of catecholamine oxygen wasting. Circ Res 1978; 42:79-86

14. Flacke WE, Flacke JW, Bloor BC: Effects of dexmedetomidine on systemic and coronary hemodynamics in the anesthetized dog. J Cardiothorac Vasc Anesth 1993; 7:41-49

15. Bloor $B C$, Ward DS, Belleville JP, Maze M: Effects of intravenous dexmedetomidine in humans. Anesthesiology $1992 ; 77: 1134-1142$

16. Mohtman DE, Feigl EO: Competition between sympathetic vasoconstriction and metabolic vascodila tion in the canine coronary circulation. Circ Res 1978; 42: 79-86

17. Feigl EO: Coronary physiology. Physiological Reviews 1983; 63: 1-205

18. Chillan WM, Harrison $\mathrm{DG}_{\text {, }}$ Haws $C W$ : Adrenergic coronary tone during subrnaximal exercise in the dog is produced by circulating catecholamines: Evidence for adrenergic denervation supersensitivity in the myocardium but not in coronary vessels. Circ Res 1966; $58: 68-82$

19. Kitakaze $M_{*}$ Hori $M$, Gotoh $K$ : Beneficial effects of alphaz-adrenoreceptor activity on ischemic myocardium during coronary hypoperfusion in dogs. Circ Res 1989; $65 ; 1632-1645$

20. Indolfi $C$, Piscione F, Villari B: Role of alpha2-adrenoreceptors in normal and atherosclerotic human coronary circulation. Circulation 1992; 86: 1116-1124

21. Schmeling WT, Kampine JP, Roerig DL, Warltier DC: The effects of the stereoisomers of the alpha2-adrenergic agonist medetomidine on systemic and coronary hemodynamics in conscious dogs, Anesthesiology 1991; $75: 499-511$ 
22. Heusch $\mathrm{G}$, Schipike $\mathrm{J}$ and Thamer $\mathrm{W}$ : Clonidine prevents the sympathetic initiation and aggravation of poststenotic myocardial ischemia. \& Cardiovasc Phamacol 1985; 7: 1176-1182

23. Messina LM, Hanley FL, Uhlig PN et al: Eftects of pressure gradients between branches of the left coronary artery on the pressure axis intercept and the shape of steady state circumflex pressure-flow relations in clogs. Circ Res 1985:56:11-19

24. VanderVusse $G J$, Coumans WA, Kruger $R$ et al: Effect of fentanyl on myocardial fatty acid and carbohydrate metabolism and oxygen utilization during experimental ischemia. Anesth Analg 1980; 59: $644-654$

25. Murry $\mathrm{CE}$, Fichard VJ, Jennings $\mathrm{RB}$, Reimer KA: Myocardial protection is lost before contractile function recovers from ischemic preconditioning. Am J Physiol (Heart Circ Physiol) 1991: 260: $\mathrm{H} 796-\mathrm{H} 804$ 


\section{CHAPTER 9}

\section{The effect of mivazerol on perioperative hemodynamic stability and myocardial ischemia}

The European Multicenter Study of Perioperative Ischemia Group (McSPI)

The San Francisco Analysis Group (Chairman: Dennis $T$. Mangano, PhD, MD, Director of the Ischemia Research and Education Foundation)

The Maastricht McSPI Investigators:

P.M.H.J. Roekaerts

H.M.M. Willigers

S. de Lange 


\section{The effect of mivazerol on perioperative hemodynamic stability and myocardial ischemia}

\section{ABSTRACT}

Background: In vitro and animal studies have demonstrated anti-ischemic properties of mivazerol related to sympathetic modulation. To evaluate the safety and efficacy of mivazerol in patients subjected to profound stress, a multicenter phase II clinical trial was performed to assess effects on hemodynamic stability and myocardial ischemia in patients at risk for coronary artery disease undergoing vascular surgery. Methods: Following institutional approval, 300 patients from 23 European Medical Centers participated in this study. The allocated patient cohort for the Maastricht Center was 14 patients. Patients received either high-dose mivazerol (HDM: 1.5 $\mu \mathrm{g} \cdot \mathrm{kg}^{-1} \cdot \mathrm{h}^{-1}, \mathrm{n}=98$ ), low dose mivazerol (LDM: $0.75 \mu \mathrm{g} \cdot \mathrm{kg}^{-1} \cdot \mathrm{h}^{-1}, \mathrm{n}=99$ ), or placebo ( $\mathrm{PL}$, $n=103$ ), for 72 hours continuously, commencing prior to anesthesia, continuing throughout surgery, and ending on the third postoperative day.

Results: Compared with placebo, HDM significantly decreased the incidence of tachycardia during the intraoperative ( $\mathrm{HDM}=30 \%, \mathrm{LDM}=38 \%, \mathrm{PL}=51 \% ; \mathrm{P}=0.002)$, early (0-24 hrs) postoperative ( $\mathrm{HDM}=29 \%, \mathrm{LDM}=51 \%, \mathrm{PL}=50 \% ; \mathrm{P}=0.002)$, and late $(24-72 \mathrm{hrs}$ ) postoperative ( $\mathrm{HDM}=46 \%, \mathrm{LDM}=54 \%, \mathrm{PL}=70 \% ; \mathrm{P}=0.001)$ periods. The incidence of hypertension was significantly decreased during the intraoperative period ( $\mathrm{HDM}=46 \%, \mathrm{LDM}=43 \%, \mathrm{PL}=63 \%, ; \mathrm{P}=0.021$ ). There was no difference in treatment for bradycardia or in the incidence of hypotension between the groups.

Intraoperative myocardial ischemia was significantly lower in the high-dose group ( $\mathrm{HDM}=20 \%, \mathrm{LDM}=23 \%, \mathrm{PL}=34 \% ; \mathrm{P}=0.026$, HDM vs PL). When the intraoperative period was divided was divided into non-emergence and emergence period, the incidence of myocardial ischemia was significantly decreased in the high-dose group during emergence (HDM $=11 \%, L D M=19 \%, P L=30 \% ; P=0.003$ ). Conclusions: Mivazerol decreased the incidence of tachycardia, hypertension, and measures of myocardial ischemia, particularly during high stress periods.

\section{INTRODUCTION}

The stress during and after surgery is associated with increased sympathetic activity which may be manifested as hemodynamic instability. Tachycardia and hypertension may result in increased myocardial oxygen demand and reduced supply (at higher heart rates). In the presence of a compromized circulation, the imbalance between supply and demand could lead to myocardial ischemia and, possibly, serious adverse outcome.1,2 
Alpha 2 -adrenoreceptor agonists have centrally-mediated sympatholytic, sedative, analgesic and anxiolytic effects, thereby enabling stabilization of the sympathetic nervous system and attenuation of catecholamine response to perioperative stress. Thus, alpha 2 agonists may prevent the occurence of perioperative hyperdynamic changes, mitigating imbalances in myocardial oxygen supply-demand, and possibly the incidence of myocardial ischemia ${ }^{3,4}$

The new alpha - -adrenoreceptor agonist mivazerol was shown to blunt the surge of plasma catecholamines induced by surgical stress, to decrease the basal norepinephrine concentrations and appears to demonstrate anti-ischemic properties in animal modeis of myocardial ischemia. ${ }^{5-7}$ In clinical pharmacology studies, mivazerol produced a decrease in basal plasma norepinephrine levels, an early and transient increase in afterload, mild bradycardia, and negative inotropic effects at higher doses. In patients with stable angina undergoing a treadmill exercise tolerance test, mivazerol exhibited anti-ischemic and anti-anginal activity. ${ }^{8}$

The aim of the present study was to investigate whether mivazerol could afford hemodynamic stability in patients at high risk for coronary artery disease undergoing vascular surgery and general anesthesia. Mivazerol's effect on the incidence and severity of perioperative myocardial ischemia and adverse clinical outcome was also determined.

\section{METHODS}

Following institutional approval and informed consent, three hundred patients from 23 European medical centers participated in this placebo-controlled, double-blind, randomized "parallel-group trial. Eligible study patients were those scheduled for vascular surgery (excluding aortic surgery) under general anesthesia lasting for at least one hour. The patient group was comprised of patients with coronary artery disease or in the population group at risk for coronary artery disease.

Coronary artery disease was confirmed by one or more of the following: 1) history of typical angina pectoris or atypical angina with an ischemic response to exercise or scintigraphic evidence of myocardial perfusion defect; 2) history of myocardial infarction; 3) Q wave on ECG typical of infarction without a history; 4) coronary artery disease by angiography; 5 ) two or more of the following risk factors: age 65 years, current smoking, plasma cholesterol $240 \mathrm{mg} / \mathrm{dl}$, treated diabetes, and treated hypertension. Patients received either high-dose mivazeral (HDM: $1.5 \mu \mathrm{g} \cdot \mathrm{kg}^{-1} \cdot \mathrm{h}^{-1}, \mathrm{n}=98$ ), low dose mivazerol (LDM: $0.75 \mu \mathrm{g} \cdot \mathrm{kg}^{-1} \cdot \mathrm{h}^{-1}, \mathrm{n}=99$ ), or placebo ( $\mathrm{PL}, \mathrm{n}=103$ ), for 72 hours continuously, commencing prior to anesthesia, continuing throughout surgery, and ending on the third postoperative day (POD). The perioperative anesthetic management was standardized and systolic blood pressure and heart rate were prescribed to be maintained within $20 \%$ of preoperative baseline values by using prespecified anesthetic changes and cardiovascular drugs. Prophylactic use of ischemia therapy was specifically prohibited. Hemodynamics (blood pressure and heart rate) were monitored continuously for 96 hours, and myocardial ischemia was 
assessed using Holter electrocardiography for at least 8 hours prior to induction of anesthesia and continuing until 96 hours postoperatively. Twelve-lead electrocardiograms (ECG) and creatine phosphokinase isoenzymes (CK-MB) were obtained preoperatively and over multiple prespecified periods postoperatively.

Hemodynamic episodes were defined for the intraoperative period as: HR $>20 \%$ increase from baseline or HR $<40 \mathrm{bpm}$, and SBP $>20 \%$ increase or SBP $<20 \%$ decrease from baseline, with episodes lasting for at least $5 \mathrm{~min}$; for the postoperative period, episodes were defined as: $\mathrm{HR}<40$ or $\mathrm{HR}>100 \mathrm{bpm}$, and SBP $<90$ or SBP $>180 \mathrm{mmHg}$. In addition, cardiovascular treatment for correction of hemodynamic changes (tachycardia, bradycardia, hypertension, hypotension) were recorded and characterized.

An electrocardiographic ischemic episode was defined as a reversible ST segment change, lasting at least one minute, and involving a shift from baseline of either: 0.1 mV ST segment depression at $J+40 \mathrm{msec}$, or $0.2 \mathrm{mV}$ ST segment elevation at the $J$ point. The baseline ST segment was defined as the average ST segment over a period of 15-60 minutes preceding each episode. Reversibility was defined as a return to baseline of the ST segment for at least one minute. Each episode was assessed for duration, magnitude, severity (area-under-the-curve/AUC) as well as for ischemic burden (minute of ischemia/hours monitored).

Myocardial infarction was diagnosed if any of three criteria were met: 1) new $\mathrm{Q}$ wave on a postoperative 12-lead ECG using Minnesota Code quantitation (1-1 to 1-3) and investigator panel validation, or 2) $\mathrm{CK}-\mathrm{MB}$ elevation-either elevation of $\mathrm{CK}-\mathrm{MB}$ concentration to $100 \mathrm{ng}^{-1}$ at any time post surgery or elevation of CK-MB concentration to $70 \mathrm{ng} \cdot \mathrm{ml}^{-1}$ at any time after 12 hours post surgery, or 3) acute MI diagnosed via autopsy.

The primary measures of efficacy were hemodynamic instability (tachycardia, hypertension) and the use of cardiovascular medications to treat instability. The secondary measures were myocardial ischemia (incidence and severity) and the use of ischemia medications. Safety was assessed via adverse clinical events, hemodynamic abnormalities (bradycardia, hypotension), and the use of cardiovascular medications to treat hemodynamic abnormalities.

\section{Data and Statistical Analysis}

All research data (Holter ECG, hemodynamic, 12-lead ECG data) were analysed at the coordinating center (IREF, San Francisco, CA, USA) in a blinded fashion to ensure that uniform data analysis criteria were employed. Block randomization was performed within each of the 23 centers; thus, the analyses presented here include an adjustment for center effect.

For the analysis of the incidence of hemodynamic or ischemic episodes, when the outcome variable was binary and the explanatory variable was treatment, the two-by-three contingency table analysis was controlled for center effect using the Cochran-Maentel-Hanszel general association Chi-square statistic. For the highdose versus placebo comparison, the same technique was performed using data for 
the high-dose and placebo groups. These analyses were performed using PROC FREQ of the Statistical Analysis System (SAS, SAS Institute, Cary, SC). For a continuousresponse variable, a general linear model was used and included center and treatment-by-center effects in order to derive the adjusted treatment effect.

The treatment-by-center effect was included in all models, regardless of whether the efffect was statistically significant or not (at the $5 \%$ level), because the sample size per center was not sufficiently large to assess adequately whether there was treatment-by-center effect, and because randomization was carried out within each center. Furthermore, in most of the models, the center effect was significant, suggesting a high level of heterogeneity in the least-square estimated means of the response variable across the 23 centers. PROC GLM (General Linear Model) was used to fit these models and to obtain the adjusted estimated treatment efffect. The comparison between high-dose and placebo was carried out using data from the high-dose and placebo groups, and the same technique as described was used.

The secondary efficacy variables included myocardial ischemia, anesthetic and analgesic requirements, and adverse clinical outcomes. For these endpoints, incidence was compared using either Chi-square or Fisher's Exact Test. ANOVA or Kruskal-Wallis methods were used to analyze characteristics of hemodynamic and ischemic abnormalities. For analysis of area-under-the-CK-MB-curve and the maximum CK-MB, the data window was taken to be four hours post surgery to 96 hours post surgery, which encompassed fourteen measurements of CK-MB. Area-underthe-CK-MB-curves and maximum CK-MB values were compared across treatment groups using ANOVA techniques. Missing data were considered unevaluable; therefore, they were not included in the analysis. However, since the values were missing at random across study groups, the statistical inferences were still generalizable for the whole sample size.

\section{RESULTS}

Compared with placebo, high-dose mivazerol significantly decreased the incidence of tachycardia during the intraoperative, early postoperative (0-24 hrs) and late postoperative (24-72 hrs) periods. The number of patients receiving treatment for tachycardia was significantly less in the high-dose mivazerol group (vs placebo) during the early and late postoperative period. 


\begin{tabular}{lllll}
\hline & & Intraoperative & Early postop & Late postop \\
\hline Tachycardia & HDM & $30 \%$ & $29 \%$ & $46 \%$ \\
& LDM & $38 \%$ & $51 \%$ & $54 \%$ \\
& PL & $51 \%$ & $50 \%$ & $70 \%$ \\
& P & 0.002 & 0.002 & 0.001 \\
Treatment for tachycardia & HDM & & & \\
& LDM & $10 \%$ & $6 \%$ \\
& PL & $20 \%$ & $13 \%$ \\
& P & $20 \%$ & $15 \%$ \\
& & 0.043 & 0.024 \\
\hline
\end{tabular}

The incidence of hypertension was significantly decreased during the intraoperative period $(\mathrm{HDM}=46 \%, \mathrm{LDM}=43 \%, \mathrm{PL}=63 \% ; \mathrm{P}=0.021)$, and treatment for hypertension exhibited a trend $(\mathrm{HDM}=33 \%, \mathrm{LDM}=34 \%, \mathrm{PL}=46 \% ; \mathrm{P}=0.062, \mathrm{HDM}$ vs PL).

The incidence of bradycardia was increased in the low-dose and high-dose mivazerol groups during drug administration (intraoperative, early and late postoperative period) and after drug discontinuation. However, there was no difference in treatment for bradycardia during and after drug administration.

\begin{tabular}{llllll}
\hline & & Intraoperative & Early postop & Late postop & Drug disconti \\
\hline Bradycardia & HDM & $9 \%$ & $6 \%$ & $6 \%$ & $6 \%$ \\
& LDM & $7 \%$ & $5 \%$ & $4 \%$ & $6 \%$ \\
& PL & $3 \%$ & $0 \%$ & $0 \%$ & $0 \%$ \\
& P & 0.091 & 0.043 & 0.659 & 0.088 \\
Treatment for bradycardla & HDM & $32 \%$ & $4 \%$ & $1 \%$ & $2 \%$ \\
& LDM & $32 \%$ & $3 \%$ & $2 \%$ & $0 \%$ \\
& PL & $36 \%$ & $1 \%$ & $4 \%$ & $1 \%$ \\
& P & 0.978 & 0.395 & 0.422 & 0.322 \\
\hline
\end{tabular}

The incidence of hypotension was similar between the three groups during the monitoring periods, and there was no difference in the treatment for hypotension.

Intraoperative myocardial ischemia was significantly lower in the high-dose group ( $\mathrm{HDM}=20 \%, \mathrm{LDM}=23 \%, \mathrm{PL}=34 \% ; \mathrm{P}=0.026, \mathrm{HDM}$ vs $\mathrm{PL}$ ). When the intraoperative period was divided into non-emergence and emergence period, the incidence of myocardial ischemia was significantly decreased in the high-dose group during emergence $\left(\mathrm{HDM}=11 \%, \mathrm{LDM}=19 \%, \mathrm{PL}=30 \% \%^{\prime} \mathrm{P}=0.003\right)$.

Adverse cardiac outcomes occurred in $3 \%$ of HDM, $2 \%$ of LDM, and $8 \%$ of PL patients, and myocardial infarction was diagnosed in $2 \%$ of HDM patients, $1 \%$ of LDM patients and $6 \%$ of $P L$ patients $(P=0.118)$. 


\section{Conclusions}

Mivazerol, when administered to high-risk patients for 72 hours continuousty perioperatively "appears to be safe, without significant hypotension or adverse events, but with evidence of bradycardia which was not associated with clinical adverse events. Regarding efficacy, mivazerol appears to mitigate the incidence of ${ }_{1}$ and treatment for, tachycardia, hypertension, and measures of myocardial ischemia, particularly during high-stress periods. Thus, these salutary effects of mivazerol on efficacy surrogates indicate further study in large-scale trials assessing mivazerol" effect on adverse cardiac outcome. 


\section{REFERENCES}

1. Mangano DT: Perioperative cardiac morbidity. Anesthesiology 72: 153-184, 1990

2. Mangano DT, Browner WS, Hollenberg $M$, London MU, Tubau JF, Tateo IM, SPI Research group: Association of perioperative myocardial ischemia with cardiac morbidity and mortaility in men undergoing noncardiac surgery. N Engl I Med 323: 1781-1788, 1990

3. Maze $M_{i}$ Tranquilly $W$ : Alphaz-adrenoreceptor agonists: Defining the role in clinical anesthesia. Anesthesiology $74: 581-605,1991$

4. Flacke JW: Alphag-adrenergic agonists in cardiovascular anesthesia. J Cardiothorac Vasc Anesth 6: 344-359, 1992

5. Kharkevitch T, Guyaux $M_{*}$ Gobert $J_{3}$ Wulfert $E$ : Mivazerol, a new alphaz-receptor agonist reduces ischemia produced by coronary occlusion in raifs and dogs. Cardiovasc Drugs Ther 5: 407, 1991

6. Hoet $B_{i}$ Kharkevitch $T$, Debeer $L$ : Mivazerol, a new alpha2 adrenoreceptor agonist, increases the ventricular fibrillation treshold in anesthetized dogs. J Mol Cell Cardial 23:A 96, 1991

7. Roekaerts PMHJ, Prinzen FW, Willigers HMM, de Lange S: The effects of alpha2 adrenergic stimulation with mivazerol on myocardial blood flow and function during coronary artery stenosis in anesthetized dogs. Anesth Analg 82: 702-711, 1996

8. Wright $R A$, Decroly $P$, Kharkevitch $T$, Oliver MF: Exercise tolerance in angina is improved by mivazerol-an alphazadrenoreceptor agonist. Cardiovasc Drugs Ther 7: 929-934, 1993 


\section{CHAPTER 10}

\section{Summary and conclusions}

Alphaz-adrenergic receptors are widely distributed in various animal and human tissues. These receptors mediate a variety of physiological functions, depending on the adrenoceptor type and the tissue. Therefore, the activation of adrenoceptors represent the net effect of sometimes conflicting actions at different sites.

Alpha $_{2}$-adrenergic receptor agonists are drugs that activate these receptors. In 1964 , the prototypical alpha 2 agonist clonidine was tested for possible use as a nasal decongestant. Volunteers receiving intranasal clonidine became very sleepy and their heart rate and blood pressure decreased. It was decided therefore by the pharmaceutical company to further study clonidine for it's anti-hypertensive properties. In 1966, clonidine was introduced into clinical practice for the treatment of hypertension. The sedative and antisialic effects of clonidine certainly must have limited the popularity of the drug when used as chronic anti-hypertensive medication.

In recent years, interest has been focused on the application of clonidine in the perioperative period. In addition to decreased sympathoadrenal activity to provide more cardiovascular stability, clonidine has been shown to cause sedation, anxiolysis, analgesia, decreased salivation and to reduce anesthetic requirements. These effects of clonidine might be especially beneficial in patients with severe systemic diseases. Data from preliminary studies in small patient groups suggest that clonidine may decrease the incidence of myocardial ischemia in high-risk cardiovascular patients.

In this thesis, we studied whether the new, specific and selective alpha ${ }_{2}$-adrenoreceptor agonists like dexmedetomidine and mivazerol could be beneficial anesthetic adjuvants in the perioperative period in patients at risk for coronary artery disease. To this purpose, a series of laboratory investigations was designed to study potential anti-ischemic mechanisms of action of dexmedetomidine and mivazerol. Special attention was paid to their central sympatholytic effect, their systemic cardiovascular effects, and to their effects on perfusion and function of normal and ischemic myocardium. In addition, we studied - together with investigators from The Multicenter Study of Perioperative Ischemia Group (McSPI) from other European Medical Centers -the effect of mivazerol on perioperative hemodynamic stability and myocardial ischemia in 300 patients at risk for coronary artery disease.

Dexmedetomidine and mivazerol consistently caused profound sympatholysis with decreases in circulating catecholamines. The clinical dose of $1 \mu \mathrm{g} \cdot \mathrm{kg}-1$ dexmedetomidine decreased heart rate by $20 \%$, increased mean arterial pressure by $25 \%$ and decreased cardiac output by $32 \%$ (chapters 4,6 and 7 ). Mivazerol decreased heart rate by $13 \%$, increased mean arterial pressure by $13 \%$ and decreased cardiac output by $43 \%$ (chapter 8 ). In 8 dogs we measured left ventricular pressure-volume relations with the conductance catheter technique, before and after the administration of 1 
$\mu \mathrm{g} \cdot \mathrm{kg}^{-1}$ dexmedetomidine. $\mathrm{dP} / \mathrm{dt}_{\max }$, which is a pre-and afterload dependent index of contractility, decreased approximately $10-20 \%$, but not always significantly. End-systolic elastance and preload-recruitable stroke work, pre- and afterload independent variables of contractility, decreased $45 \%$ and $40 \%$, respectively. Left ventricular ejection fraction decreased $35 \%$. (R. Frietman, J.J. Schreuder, F.W. Prinzen, P.M.H.J. Roekaerts and S. de Lange: Pressure-volume relationships in the left ventricle during use of dexmedetomidine. Ned Tijdschr Geneeskd 139 (30): 1575 1995). Thus, alpha 2 agonists significantly decrease cardiac contractility. However, it is most important to note that long and extensive clinical experience with clonidine has not produced any evidence of adverse effects on cardiac and coronary function. On the contrary, clonidine has been used successfully in patients with coronary artery disease, as well as in patients with congestive heart failure. It is becoming increasingly apparent that the optimum way of anesthetizing patients with ischemic heart disease is to "reduce the determinants of myocardial oxygen demand". (WK Hamilton: Do let the blood pressure drop and do use myocardial depressants! Anesthesiology 45(3): 273-274, 1976).

The reductions in heart rate and contractility after dexmedetomidine and mivazerol decrease myocardial oxygen demand and are therefore important mechanisms for the anti-ischemic potential of alpha ${ }_{2}$-adrenergic agonists.

In the present experiments, dexmedetomidine and mivazerol caused coronary vasoconstriction under normal, non-ischemic, conditions (chapters 4,6 and 8). This vasoconstriction however was not associated with changes in arterial-coronary venous oxygen saturation or lactate differences, indicating adequate adaptation of myocardial blood flow to metabolic requirements (chapter 6 ).

In chapter 4, we showed that the systemic and coronary vasoconstriction after alpha 2 agonists could be alleviated by the calcium channel blocker Isradipine. If peripheral, potentially undesirable, vasoconstrictive effects of alpha 2 agonists would occur initially after their administration in humans, the present study indicates that the short-lasting administration of a short-acting calcium antagonist like Isradipine could be used to rapidly antagonize these vasoconstrictive effects, while having no effect on the central sympatholytic and anesthetic qualities of the alpha $a_{2}$ agonist.

In chapter 5, in order to find out whether the decrease in cardiac function after dexmedetomidine was secondary to its peripheral vasoconstrictive effect, we administered the purinoceptor vasodilating agent adenosine triphosphate (ATP) to reverse the vasoconstrictive effects of dexmedetomidine. As the reversal of the vasoconstrictive effect of dexmedetomidine was associated with only partial restoration of cardiac function, we concluded that the decrease in cardiac function after dexmedetomidine is mainly due to a decrease in sympathetic outflow. This study also showed that alpha ${ }_{2}$-adrenergic vasoconstriction could be completely antagonized by ATP. Extracellular ATP is converted rapidly by ecto-5'-nucleotidases into ADP, AMP and adenosine, which are important mediators of metabolic coronary vasodilation during myocardial hypoperfusion. This encouraged us to further study the interaction between alpha-adrenergic coronary vasoconstriction and metabolic coronary vasodilation. 
In chapter 6 , we investigated the effect of dexmedetomidine during reactive hyperemia after 2 minutes coronary artery occlusions. This hyperemia is known to be mainly caused by the metabolic vasodilation by adenosine. Although dexmedetomidine reduced myocardial oxygen demand and decreased blood flow in nomally perfused myocardium, the supranormal blood flow levels in the endocardial and midmyocardial layers during reactive hyperemia were not influenced by dexmedetomidine. Lactate release during the reperfusion phases after dexmedetomidine were significantly less than after the alphaz-antagonist atipamezole.

From our findings in chapters 5 and 6 , it appeared that the vasoconstriction of alpha agonists could be overruled by metabolic vasodilation. These findings encouraged us to further study the new alpha, agonists during experimental myocardial ischemia.

In chapters 7 and 8 , we found that dexmedetomidine and mivazerol reduced myocardial oxygen demand and, in parallel, decreased blood flow in nonischemic myocardium. In ischemic endocardium however, blood flow was preserved. Dexmedetomidine was found to increase the ischemic/non-ischemic blood flow ratio. Both dexmedetomidine and mivazerol reduced oxygen deficiency of ischemic myocardium. The peripheral vasoconstrictive effect of dexmedetomidine and mivazerol is thus restricted to the epicardial layer during myocardial ischemia, with preservation of blood flow in the more vulnerable endocardial and midmyocardial layers. Preservation of blood flow in ischemic myocardium by alpha 2 agonists is probably caused by local metabolic stimuli during ischemia, which overrule adrenergic vasoconstriction. As the degree of ischemia is most severe in the inner layers during hypoperfusion, adrenergic vasoconstriction in this region is inhibited to a greater extent than in the outer layer. Specific epicardial vasoconstriction distal to a flow limiting stenosis which leads to improvement of endocardial perfusion is called the "reverse steal" effect.

The findings of these studies are now being applied to patient care. (chapter 9). A preliminary study on the effects of mivazerol on perioperative hemodynamic stability and myocardial ischemia was carried out in 23 centers in 300 patients and published in abstract form; the allocated patient cohort for each center was $12-13$ patients. This study showed that mivazerol, when administered for 72 hours continuously perioperatively in patients at risk for coronary artery disease, decreased the incidence of tachycardia and hypertension. The incidence of bradycardia was increased in the treatment group, but there was no difference in the treatment for bradycardia. There was no increase in the incidence of hypotension in the drug group. Intraoperative myocardial ischemia was significantly lower in the alpha agonist group, especially during the emergence period.

\section{CONCLUSIONS}

Our experimental studies reveal several mechanisms by which alphan agonists may have beneficial actions during myocardial ischemia: 
- the central sympatholytic effect of dexmedetomidine and mivazerol causes a reduction in heart rate and contractility, thereby reducing myocardial oxygen demand. - during myocardial ischemia the peripheral vasoconstrictive effect of these alphas agonists is restricted to the epicardial layer, with a preservation of blood flow in the ischemic midmyocardial and endocardial layer. The decrease in heart rate also favours endocardial relative to epicardial perfusion.

The clinical study showed that the administration of mivazerol is safe in high-risk patients and decreases measures of myocardial ischemia, particularly during highstress periods.

Evidence is thus mounting that alpha 2 -adrenoreceptor agonists may decrease perioperative myocardial ischemia. However, although postoperative ischemia is a predictor of adverse cardiac outcome, there are no definitive data demonstrating that prevention of the postoperative ischemia will reduce adverse outcome. Therefore, further study is indicated in large-scale trials assessing the effects of the alphar-adrenoreceptor agonists on cardiac outcome. 


\section{CHAPTER 11}

\section{Samenvatting en conclusies}

Adrenerge receptoren bevinden zich verspreid over het gehele lichaam. Activatie van deze receptoren brengt diverse reacties teweeg. Alpha $a_{2}$-adrenerge receptor agonisten zijn middelen die deze receptoren activeren. In 1964 werd de eerste alpha agonist, clonidine, ontwikkeld als een ontzwellend middel van het neusslijmvlies. Patiënten die dit middel namen werden echter slaperig en kregen een lagere bloeddruk en hartslag. Daarom werd in 1966 door de farmaceutische industrie besloten om clonidine verder te ontwikkelen als een middel tegen hoge bloeddruk. De slaperigheid die dit middel teweeg brengt heeft echter het sukses van clonidine als anti-hypertensie middel sterk belemmert. De laatste jaren wordt clonidine meer en meer gebruikt in de perioperatieve periode. Clonidine blijkt immers niet alleen sederende, angstverminderende en pijnstillende effecten te hebben, maar ook kan men de dosering van anesthesiemiddelen drastisch verminderen wanneer tijdens een operatie ook clonidline wordt toegediend. Bovendien vertoont de patiënt tijdens en ook na de operatie een stabielere bloeddruk en hartfrekwentie wanneer hij clonidine heeft ontvangen tijdens de anesthesie. Recent werd in een aantal kleinere onderzoeken gesuggereerd dat, wanneer clonidine tijdens een operatie gegeven wordt aan patiënten met coronaire vernauwingen, bij deze patiënten de kans kleiner zou worden dat er myocardischemie optreedt.

In deze thesis hebben wij onderzocht of de nieuwe, specifieke en selectieve alpha $a_{2}$-adrenerge receptor agonisten zoals dexmedetomidine en mivazerol gunstige effecten hebben wanneer zij toegediend worden in de perioperatieve periode aan patiënten met coronaire vernauwingen. Hiertoe hebben wij een aantal laboratoriumonderzoeken uitgevoerd om de potentiële anti-ischemische werkingsmechanismen van dexmedetomidine en mivazerol te onderzoeken. Speciale aandacht werd besteed aan hun sympatholytisch effect, aan hun effecten op hart en bloedvaten, en op hun effect op de doorbloeding en werking van normaal en ischemisch hartspierweefsel. Daarnaast hebben we, samen met onderzoekers van de "Multicenter Study of Perioperative Ischemia Group" van een aantal andere Europese Medische Centra, de effecten onderzocht van mivazerol op de perioperatieve stabiliteit van de hemodynamiek en op het optreden van ischemie van het hart bij 300 patiënten die een verhoogd risico hadden om aan coronaire vernauwingen te lijden.

Dexmedetomidine en mivazerol veroorzaakten beide een sympatholytische effect met een vermindering van de hoeveelheid adrenaline en noradrenaline in de bloedsomloop. De klinische dosering van $1 \mu \mathrm{g} \cdot \mathrm{kg}^{-1}$ dexmedetomidine vertraagde de hartslag met $20 \%$, deed de gemiddelde bloeddruk toenemen met $25 \%$ en verminderde het hartminutenvolume met $32 \%$ (hoofdstukken 4,6 en 7 ). Mivazerol vertraagde de hartslag met $13 \%$, deed de gemiddelde bloeddruk toenemen met $13 \%$ en verminderde het hartminutenvolume met $43 \%$ (hoofdstuk 8 ). 
In 8 honden hebben we ook linker kamer druk-volume relaties onderoch met behulp van de conductantiekatheter, voor en na de toediening van $1 \mu \mathrm{g} . \mathrm{kg}^{-1}$ dexmedetomidine. dP/dtmax, die een maat is voor de contractiliteit van het hart, verminderde ongeveer $10-20 \%$, doch niet altijd significant. Deze contractiliteitsindex is afhankelijk van de preload van het hart alsook van de afterload.

De gemeten indexen van contractiliteit die niet afhankelijk zijn van pre-en afterload (end-systolic elastance en preload-recruitable stroke work), verminderden met $45 \%$ en $40 \%$, respectievelijk. De linker kamer ejectie fractie verminderde met $35 \%$. $(R$. Frietman, J.d. Schreuder, F.W. Prinzen, P.M.H.J. Roekaerts and S. de Lange: Pressure-wolume relationships in the left ventricle during use of dexmedetomidine. Ned Tijdschr Geneeskd 139 (30): 1575, 1995).

Alphaz agonisten verminderen dus significant de contractiliteit van het hart. Het is hier echter belangrijk om op te merken dat er een zeer lange en uitgebreide klinische ervaring bestalat met clonidine en dat van dit middel nooit beschreven werd dat het nadelige gevolgen had voor het hart of voor de coronairen. Integendeel zelfs, clonidine werd met sukses gebruikt bij patiënten met coronaire vernauwingen en bij patiënten met hartfalen.

Het is de laatste jaren ook duidelijk geworden dat de correcte manier om patiënten met coronaire vernauwingen anesthesie te geven eruit bestaat om die factoren te verminderen die de zuurstofbehoefte van het hart doen toenemen. (WK Hamilton: Do let the blood pressure drop and do use myocardial depressants! Anesthesiology 45(3): 273-274, 1976).

De vertraging van de hartslag en de vermindering van de contractiliteit van het hart na toediening van dexmedetomidine of mivazerol veminderen de zuurstofbehoefte van het myocard en zijn daarom belangrijke mechanismen woor het anti-ischemische potentieel van alpha ${ }_{2}$-adrenerge agonisten.

In de huidige experimenten veroorzaakten dexmedetomidine en mivazerol coronaire vasoconstrictie onder normale, niet-ischemische, condities. (hoofdstukken 4,6 en 8). Deze vasoconstrictie echter ging niet gepaard met veranderingen in de arterieel-coronair veneuze zuurstofsaturatie of melkzuur verschillen. Dit wijst erop dat er een adequate aanpassing is van de bloeddoorstroming van het hart aan de metabole behoeftes.

In hoofdstuk 4 toonden wij aan dat de vasoconstrictie in de lichaamsbloedvaten en in de coronairen kan afgezwakt worden door de calcium-antagonist Isradipine. Indien perifere, potentieel ongewenste, vaatvernauwende effecten van alpha. agonisten zouden optreden initieel na hun toediening bij de mens, dan toont deze studie aan dat een kortdurenede toediening van hel kortwerkende Isradipine snel cleze vasoconstrictie zou kunnen opheffen zonder de centrale sympatholytische en anesthesie-effectem van de alpha 2 agonist aan te tasten.

In hoofdstuk 5 onderzochten wij of de vermindering van de harffunctie na dexmedetomidine secundair was aan zijn periphere effecten. Daartoe dienden wij de purinoceptor vaatverwijder adenosine triphosphate (ATP) toe om de vasoconstrictieve effecten van dexmedetomidine om te keren. Omdat het opheffen van het vasoconstrictief effect van dexmedetomidine geassocieerd was met slechts een 
gedeeltelijk herstel van de hartfunctie, concludeerden wij dat de vermindering in hartfunctie na dexmedetomidine vooral te wijten is aan een verminderde sympathische outflow. Deze studie toonde ook aan dat alphag-adrenerge vasoconstrictie compleet kan geantagoneerd worden door ATP. Extracellulair ATP wordt door ecto-5'-nucleotidases snel omgezet in ADP, AMP en adenosine. Dit zijn belangrijke mediatoren van de metabole coronaire vasodilatatie die optreedt wanneer er myocardiale hypoperfusie ontstaat. Deze gegevens stimuleerden ons om verder de interactie tussen alpha-adrenerge vasoconstrictie en metabole coronaire vasodilatatie te bestuderen.

In hoofdstuk 6 onderzochten we de effecten van dexmedetomidine tijdens reactieve hyperemie na 2 minuten durende totale coronaire afsluitingen. Deze hyperemie wordt vooral veroorzaakt door de metabole vasodilatatie door adenosine. Alhoewel dexmedetomidine zowel de myocardiale zuurstofvraag alsook de coronaire bloedstroom verminderde in normaal doorbloed myocardium, beinvloedde dexmedetomidine niet de supranormale bloedstroom hoeveelheden in de endocardiale en midmyocardiale lagen tijdens reactieve hyperemie. Het vrijkomen van melkzuur tijdens de reperfusie phasen na het geven van dexmedetomidine was significant minder dan tijdens de reperfusie phase na het geven van de alpha $a_{2}$-antagonist atipamezole. Deze bevindingen in hoofdstukken 5 en 6 toonden aan dat de vasoconstrictieve effecten van alpha $a_{2}$ agonisten volledig teniet gedaan kunnen worden door metabole vasodilatatie. Deze gegevens stimuleerden ons om deze nieuwe alphaz-agonisten te bestuderen tijdens experimentele myocardiale ischemie.

In hoofdstukken 7 en 8 toonden we aan dat dexmedetomidine en mivazerol de myocardiale zuurstofvraag reduceren en, in parallel, de bloedstroom in het niet-ischemische myocard verminderen. In thet ischemisch endocard echter bleef de bloedstroom behouden. Dexmedetomidine bleek zelfs de ischemische/niet-ischemische bloedstroom ratio te vergroten. Zowel dexmedetomidine als mivazerol verminderden het zuurstoftekort van ischemisch myocardium. Het periphere vasoconstrictieve effect van dexmedetomidine en mivazerol blijft dus beperkt tot de epicardiale laag tijdens myocardischemie, met behoud van bloedstroom in de meer kwetsbare endocardiale en midmyocardiale lagen. Behoud van bloedstroom in ischemisch myocardium na alpha agonisten wordt vermoedelijk veroorzaakt door locale metabole prikkels tijdens ischemie, die vasodilatatie veroorzaken die de adrenerge vasoconstrictie kan overheersen. Omdat de ernst van ischemie het ergst is in de binnenste myocard lagen tijdens hypoperfusie, zal de adrenerge vasoconstrictie in deze lagen meer geinhibeerd worden dan in de buitenste laag. Specifieke epicardiale vasoconstrictie distaal van een coronaire stenose die de bloedstroom beperkt en die leidt tot verbeterde endocardiale bloeddoorstroming noemt men het "reverse steal" effect.

In hoofdstuk 9 hebben we, samen met de "Multicenter Study of Perioerative Ischemia Group" en de San Francisco Analyzis Group, aangetoond dat mivazerol, wanneer het 72 uur continu perioperatief werd toegediend aan 300 patiënten met een verhoogd risiko voor coronairafwijkingen, de incidentie van tachycardie en hypertensie deed afnemen. De incidentie van bradycardie was toegenomen in de mivazerol 
groep, maar er was geen verschil in het aantal behandelingen voor bradycardie tussen de mivazerol groep en de placebo groep. Er was geen toename in de incidentie van typotensie in de mivazerol groep. Intraoperatieve myocard ischemie was significant lager in the alphaz agonist groep, vooral tijdens de emergence periode.

\section{CONCLUSIES}

Onze experimentele studies onthullen diverse mechanismen waardoor alpha agonisten gunstige effecten kunnen hebben tijdens myocard ischemie:

- het centrale sympatholytische effect van dexmedetomidine en mivazerol veroorzaakt een vertraging van de hartfrekwentie en een afname van de contractiliteit, met als gevolg een vermindering van de myocardiale zuurstof vraag.

- het periphere vasoconstrictieve effect van deze alphan agonisten blijft beperkt tot de epicardiale laag tijdens myocard ischemie, met een behoud van bloedstroom in het ischemische midmyocardiale en endocardiale gebied. De vertraging van de hartfrekwentie bevoordeelt ook de endocardiale doorbloeding relatief ten opzichte van de epicardiale doorbloeding.

De klinische studie toont aan dat de toediening van mivazerol bij hoog-risiko patiënten veilig is en dat mivazerol de incidentie van myocardischemie vermindert, vooral tijdens de meest stressvolle periodes.

Er komen nu steeds meer aanwijzingen dat alpha 2 -adrenerge receptor agonisten perioperatieve myocardischemie kunnen verminderen. Echter, allhoewel postoperatieve ischemie een predictor is voor 'adverse cardiac outcome', zijn er nog geen definitieve gegevens die aantonen dat het voorkomen van postoperatieve ischemie de 'adverse cardiac outcome' zal verminderen. Daarom moeten er grootschalige onderzoeksprojecten opgestart worden die de effecten van het perioperatief toedienen van alphaz-adrenerge receptor agonisten op 'cardiac outcome' onderzoeken. 


\section{Acknowledgements}

The present series of studies was carried out at the Cardiovascular Research Institute Maastricht (CARIM), Department of Physiology and at the Department of Anesthesiology, University Hospital of Maastricht, during the years 1992-1996.

I am most grateful to Professor Simon de Lange, head of the Department of Anesthesiology, for creating an inspiring atmosphere for scientific work at our department and for his support and encouragement throughout these studies.

I owe my sincere gratitude to Dr Frits Prinzen for his guidance, advice and never-failing enthusiasm during the course of these studies.

My interest for alpha $_{2}$ adrenoceptor research was stimulated during the sabbatical visit (1989-1990) to our department of Joan Flacke, Professor of Anesthesiology at UCLA, USA, and Werner Flacke, Professor of Pharmacology at UCLA, USA. I wish to express my sincere gratitude for their interest and help with my studies.

I owe sincere thanks to the evaluation committee for their constructive remarks.

I owe my warmest thanks to my co-worker Henriette Willigers. I have enjoyed her friendship and never-failing endurance during these years.

I am very much indebted to my colleague Chris Lawrence for his valuable contributions toward the completion of these studies.

I am grateful to Professor Mika Scheinin, Department of Pharmacology, University of Turku, Finland, for the determination of the plasma concentrations of the catecholamines in the dexmedetomidine studies.

I am grateful to Dr Jan Schreuder and Ron Friedman for the analysis of left-ventricular pressure-volume relation by conductance catheter in the experimental studies.

I am grateful to Ruud Kruger, Theo Van Der Nagel and Jo Habets for expert technical assistance during the experimental studies and to Anita Rousseau for analysing of the blood samples.

I am thankful to Marie-Pauline Roukens, Cees van Leeuwen and Martin Luirink for their help in data analysis.

I am greatly indebted to the operation-room assistants anesthesia, the recovery nurses, the nurses from the cardiac surgical care unit and the nurses of the departments A4 and B4 of the University Hospital of Maastricht, for their help in the continuous monitoring of the clinical study patients for 72 hours postoperatively.

The medical staff of the Division of Vascular Surgery, Department of Surgery, is acknowledged for patience and patients.

I would like to thank all my colleagues sincerely for taking over many of my professional duties during the preparation of this thesis.

I should also like to thank the secretarial staff of the Department of Anesthesiology for their unfailing assistance.

I am also very grateful to all those who I have failed to mention by name, who helped with this thesis. 
l owe my deepest respect and gratitude to my late father and mother, who did their utmost to give me full educational support throughout my life.

Words can hardly express the warmth and gratitude that I feel towards my dear wife Monika and my three daughters Anouk, Esmee and Nona, for their loving support and understanding at all times. To them, I dedicate this work. 


\section{List of Publications}

Roekaerts PMHJ, Huygen FJPM, De Lange S:

Use of Propofol Infusion for Sedation following Coronary Artery Surgery Journal of Cardiothoracic and Vascular Anesthesia

Vol 3, No 5, suppl 1: 27, 1989

Roekaerts PMHJ, Huygen FJPM, De Lange S:

Hemodynamic Effects of a Propofol-Sufentanil Infusion for Sedation in the ICU following Coronary Artery Surgery

Journal of Cardiothoracic and Vascular Anesthesia

Vol 3, No 5, suppl 1: 47, 1989

Huygen FJPM, Roekaerts PMHJ, De Lange S:

Propofol Infusion for Sedation following Coronary Artery Surgery

SEOHS Abstract Book, 1989

Roekaerts PMHJ, Huygen FJPM, De Lange S:

Propofol Plus Sufentanil Provides Easily Titrated Sedation

Convention Reporter 12, june 1989

Roekaerts PMHJ, Huygen FJPM, De Lange S:

infusion of Propofol versus Infusion of Midazolam for Sedation in the ICU following Coronary Artery Surgery

Anesthesiology $73: 3 A, 227,1990$

Huygen FJPM, Roekaerts PMHJ, De Lange S:

Het gebruik en de hemodynamische effecten van propofol en midazolam in continue infusie voor sedatie op de intensive care-afdeling na coronaire-bypasschirurgie

Nederllands Tijdschrift voor Geneeskunde 136, ni 3, 156, 1992

Roekaerts PMHJ, Huygen FJPM, De Lange S:

Infusion of Propofol Versus Midazolam for Sedation in the Intensive Care Unit Following Coronary Artery Surgery

Journal of Cardiothoracic and Vascular Anesthesia

Voll 7, No 2,142-147, 1993

Roekaerts PMHJ, Huygen FJPM, De Lange S:

Con: Midazolam is Not the Sedative of Choice to Supplement Narcotic Anesthesia Journal of Cardiothoracic and Vascular Anesthesia

Vol 7, No 5, 620-623, 1993 
Gerrits $H$, Roekaerts $P$, Timmerman $B$, de Lange S:

Continue infusies van alfertanil en propofol tijdens coronairchirurgie

Nederlands Tijdschrift woor Geneeskunde 137 (38), 1951, 1993

Roekaerts PMHJ, Prinzen FW, De Lange S:

The Effect of the alpha 2 -Adrenergic Agonist Dexmedetomidine on the Recovery from Transient Myocardial Ischemia

Society of Cardiovascular Anesthesiologists 15th Annuall Meeting Abstract Book 241, April 24-28, 1993. San Diego, CAL - USA

Prinzen FW, Roekaerts PMHJ, De Lange S:

The Effect of the alphas-Adrenergic Agonist Dexmedetomidine on Myocardial Blood Flow and Lactate Release during Reactive Hyperemia

FASEB J, 7, A 212, 1993

Paul Roekaerts, Fríts Prinzen, Henriette Willigers, Simon de Lange:

The effect of dexmedetomidine on systemic haemodynamics, regional myocardial function and blood flow during coronary artery stenosis in acute anaesthetized dogs Journal of Cardiothoracic and Vascular Anesthesia

8 (5) (supp| 3): 58, 1994

Roekaerts PMHJ, Smets MJW, Pelzer JMG, Penn OCKM, De Lange S:

Continuous Measurement of Mixed Venous Oxygen Saturation in Infants and Children During and After Open Heart Surgery

Journal of Cardiothoracic and Vascular Anesthesia

Vol 8, No 3, Suppl 2, 53,1994

Roekaerts PMHJ, Gerrits HJ, Timmerman BE, De Lange S:

Continuous Infusions of Alfentanil and Propofol for Coronary Artery Surgery

Journal of Cardiothoracic and Vascular Anesthesia

Vol 8, No 3, Suppl 2, 150,1994

Roekaerts PMHJ, Prinzen FW, Willigers HWW, De Lange S:

Effect of the new alphaz-adrenergic agonist mivazerol on metabolism and blood flow of ischemic myocardium in anesthetized dogs

Anesthesiology 81, 3A, 757, 1994

Roekaerts PMHJ, Gerrits HJ, Timmerman BE, De Lange S:

Continuous Infusions of Alfentanil and Propofol for Coronary Artery Surgery

Journal of Cardiothoracic and Vascular Anesthesia

Vol 9, No 4 (August), 362-367, 1995 
Frietman RC, Schreuder JJ, Prinzen FW, Roekaerts PMHJ, De Lange S: Druk-volume relaties van de linker ventrikel tijdens het gebruik van dexmedetomidine Nederlands Tijdschrift voor Geneeskunde 139 (30): 1575, 1995

Roekaerts PMHJ, Prinzen FW, De Lange S:

Coronary vascular effects of dexmedetomidine during reactive hyperemia in the anesthetized dog

Journal of Cardiothoracic and Vascular Anesthesia 10(5): 619-626, 1996

Roekaerts PMHJ, Prinzen FW, Willigers HMM, de Lange S:

The effects of alpha 2 -adrenergic stimulation with mivazerol on myocardial blood flow and function during coronary artery stenosis in anesthetized dogs

Anesthesia and Analgesia 82:702-711, 1996

Roekaerts PMHJ, Prinzen FW, de Lange S: Beneficial effects of dexmedetomidine on ischaemic myocardium of anaesthetized dogs

British Journal of Anaesthesia 77: 427-429,1996

Roekaerts PMHJ: Clinical use of alphaz-adrenergic receptor agonists SMART 1996, 92-94. Springer-Verlag ISBN 3-540-75026-6

Roekaerts PMHJ, Lawrence CJ, Prinzen FW, de Lange S:

Alleviation of the peripheral hemodynamic effects of dexmedetomidine by the calcium-channel blocker isradipine

Acta Anaesthesiologica Scandinavica (in press) 



\section{Curriculum Vitae}

The author of this thesis was born on March 25th, 1953 in Opglabbeek (Belgium). He attended the secondary school (Oude Humaniora) at the Sint Jan Berchmanscollege in Genk from 1965 to 1971.

He went to medical school at the Catholic University of Leuven (Belgium), where he graduaded in 1978 .

He commenced his training in anesthesiology in 1978 at the University Hospital of Leiden (Head: Prof. dr. Joh. Spierdijk) and was registered as an anesthesiologist on the 1 st of February 1982.

Since 1983 he has been a staff member in the Department of Anesthesiology at the University Hospital of Maastricht (Head: Prof. Dr. S. de Lange). 